\title{
Development Of Oxide-Dispersion-Strengthened Nickel-Based Super Alloy Powders For Additive Manufacturing
}

\author{
Sizhe Huang \\ West Virginia University, sh0037@mix.wvu.edu
}

Follow this and additional works at: https://researchrepository.wvu.edu/etd

Part of the Metallurgy Commons, and the Other Materials Science and Engineering Commons

\section{Recommended Citation}

Huang, Sizhe, "Development Of Oxide-Dispersion-Strengthened Nickel-Based Super Alloy Powders For Additive Manufacturing" (2018). Graduate Theses, Dissertations, and Problem Reports. 3699.

https://researchrepository.wvu.edu/etd/3699

This Thesis is protected by copyright and/or related rights. It has been brought to you by the The Research Repository @ WVU with permission from the rights-holder(s). You are free to use this Thesis in any way that is permitted by the copyright and related rights legislation that applies to your use. For other uses you must obtain permission from the rights-holder(s) directly, unless additional rights are indicated by a Creative Commons license in the record and/ or on the work itself. This Thesis has been accepted for inclusion in WVU Graduate Theses, Dissertations, and Problem Reports collection by an authorized administrator of The Research Repository @ WVU. For more information, please contact researchrepository@mail.wvu.edu. 


\title{
DEVELOPMENT OF OXIDE-DISPERSION- STRENGTHENED NICKEL-BASED SUPER ALLOY POWDERS FOR ADDITIVE MANUFACTURING
}

\author{
Sizhe Huang
}

Thesis submitted to the

College of Engineering and Mineral Resources at West Virginia University, in partial fulfillment of the requirements for the degree of

\author{
Master of Science \\ in \\ Material Science and Engineering
}

\author{
Bruce S. Kang, Ph. D., Chair \\ Xueyan Song, Ph. D. \\ Terence Musho, Ph. D.
}

Department of Mechanical and Aerospace Engineering

\section{Morgantown, West Virginia \\ 2018}

Keywords: Nickel, Oxide-Dispersion-Strengthened (ODS), Additive Manufacturing (AM), Scanning Electron Microscope (SEM), X-ray diffraction (XRD)

Copyright 2018 Sizhe Huang 


\title{
ABSTRACT
}

\section{DEVELOPMENT OF OXIDE-DISPERSION-STRENGTHENED NICKEL-BASED SUPER ALLOY POWDERS FOR ADDITIVE MANUFACTURING}

\author{
Sizhe Huang
}

\begin{abstract}
Oxide-Dispersion-Strengthened (ODS) Nickel-Based superalloy has been drawn a huge attention and developed with good oxidation resistance, corrosion resistance and high creep strength. It has been considered as critical materials for Additive Manufacturing (AM). The quality and the efficiency of fabrication methods of ODS limits the performance of itself on AM. The development of new type of ODS, new methodologies and evaluation techniques are required if the enhanced quality of ODS and enhanced efficiency of fabrication are to be achieved. Of the current fabrication techniques for AM, Gas Atomization (GA) is widely used since they can generate spherical powders with high qualities. However, GA is incapable of producing Ni-based ODS powders with uniform dispersion oxide contents since it requires the melting on constituent powders, and oxide contents have higher melting point than other major contents. Ball-milling (BM), is a prevailing and wellknown technique for ODS and has been proven with the capability of producing particles with nanocrystalline structures. Mechano-Chemical-Bonding (MCB) is another new type of technique by using mechanical alloying effect without adding any binders to produce ODS.
\end{abstract}

In this research, MCB (MCB-only process) and its combined technique (MCB+BM process) were carried out to produce ODS powders with composition of Ni-20Cr-5Al-3W-1.5 $\mathrm{Y}_{2} \mathrm{O}_{3}$ in wt\%. The MCB is different with previous published techniques, raw element particles are subjected to breakdown, mixing, diffusion bonding, fracturing, shearing, and re-welding under different rotating speeds and different running durations. $X$-ray Diffraction $(X R D)$ was adopted to prove that $\mathrm{Y}_{2} \mathrm{O}_{3}$ has been evenly distributed onto major particles. Also, the morphology, shape and size of particles are analyzed Scanning Electron Microscope (SEM). More spherical in shape and smoother particle surface produced by the MCB than the $\mathrm{BM}$ that benefits powder feeding during AM. Also, X-ray diffraction (XRD) was utilized to examine the lattice spacing of crystal structure. Three different batches of powders fabricated by the MCB process and its combined techniques were used in two different AM system. Results shows the powders were successfully deposited onto flat substrates and densified microstructures were obtained. In order to investigate the as-printed microstructure, X-ray diffraction (XRD) and Scanning Electron Microscope (SEM) were employed.

In conclusion, $\mathrm{MCB}$-only technique can manufacture desirable Nickel-base alloy for AM by determining the particle shape, surface and size characteristics, as well as, reasonable alloy status and profound microstructure. 


\section{ACKNOWLEDGMENTS}

To my academic advisor, Bruce.S.Kang, I feel so grateful for his guidance, mentorship, and support toward my Master's graduation.

I would like to show my gratitude to my committee members, Dr. Terence Musho and Dr. Xueyan Song for their suggestions, guidance and impartial supports for my Master's research.

Besides, I want to thank Dr. Edward Sabolsky for accepting me into the Materials Science and Engineering program from Aerospace Engineering. I would like to also express my gratitude to Dr. Victor Mucino for his inspiration and support throughout my whole study in WVU.

With a special mention to the MAE department. It was fantastic to have the opportunity to work as a Teaching Assistant and a Research Assistant in the department.

Also, I would like to thank my group members in WVU: Eric Chia and Markova Macpherson. I could not finish my Master's study without their help, motivation, discussion and precious time.

Furthermore, I am willing to thank all my friends and family members for their unselfish support and encouragements. Especially Ruixi Niu, Minying Kong, Jiayi Sun and my parents for helping me overcome my hardship during my study.

Last but not least, I must show my profound gratitude to my partner for providing continuous motivation and unfailing support. Thank you all who have devoted their encouragements and support to my life. 


\section{TABLE OF CONTENTS}

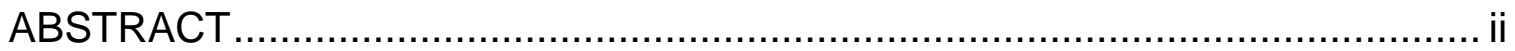

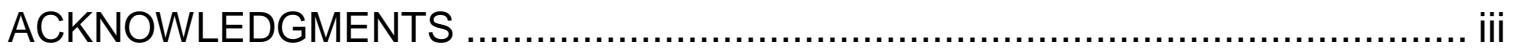

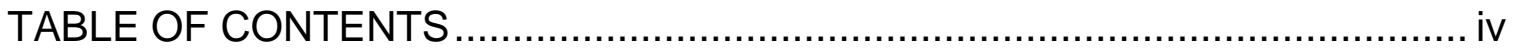

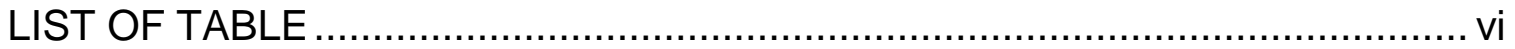

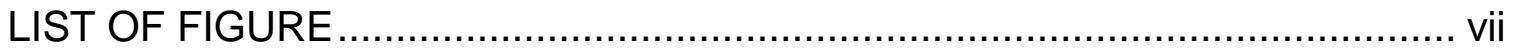

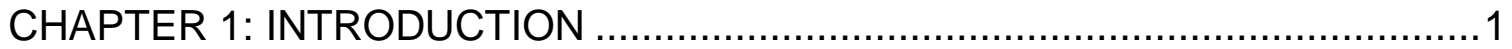

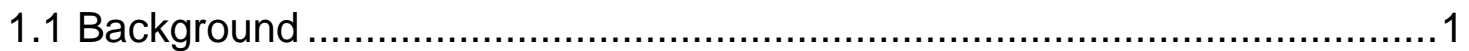

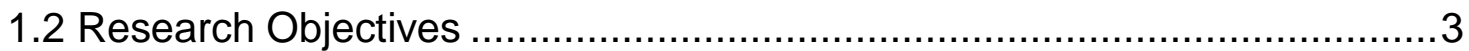

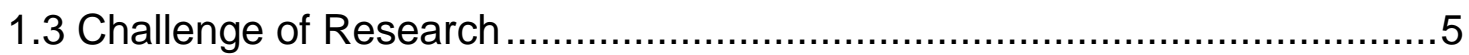

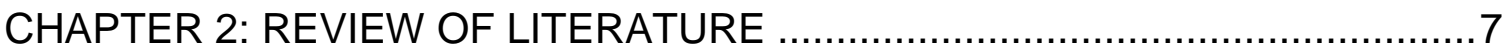

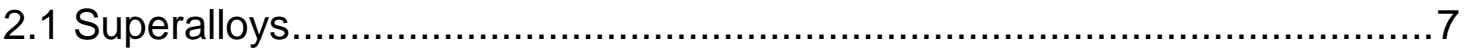

2.2 Oxide -Dispersion-Strengthened (ODS) Superalloys .............................. 7

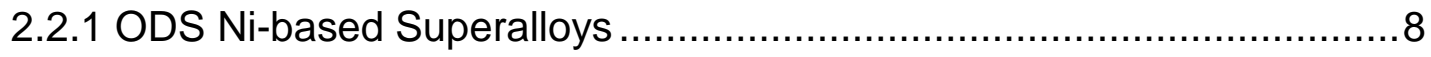

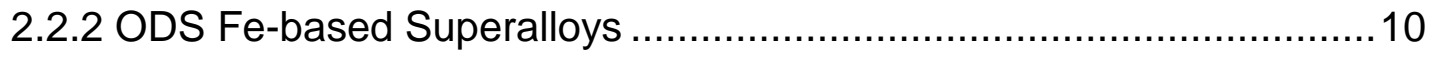

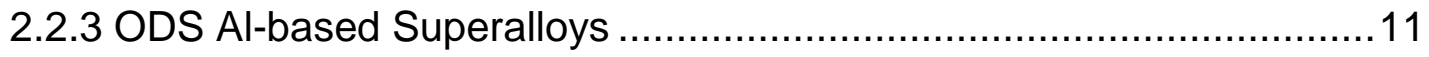

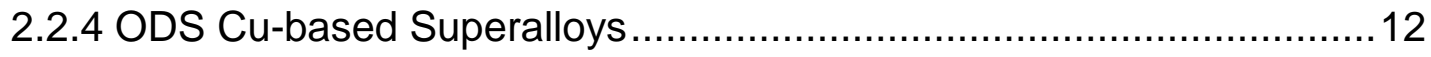

2.2.5 ODS Co-based Superalloys ....................................................... 12

2.3 Fabrication Techniques of ODS Superalloys Powder.............................12

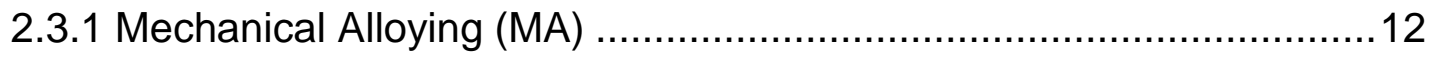

2.3.2 Mechano-Chemical Bonding (MCB) …....................................... 15

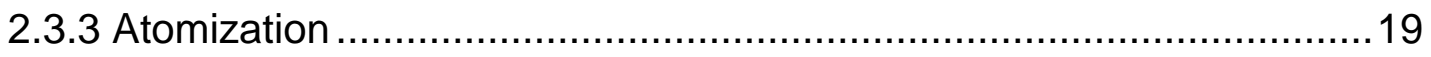

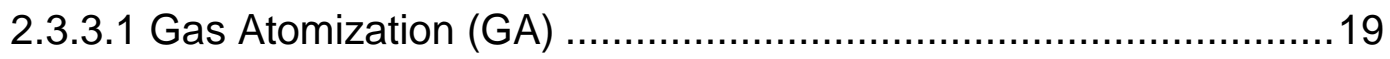

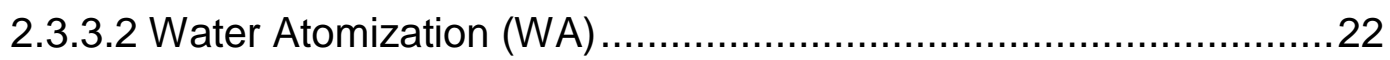

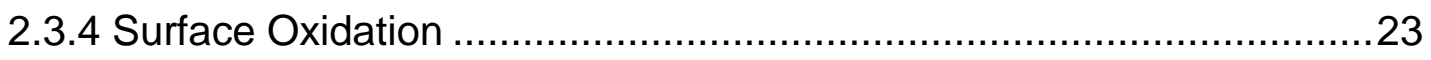

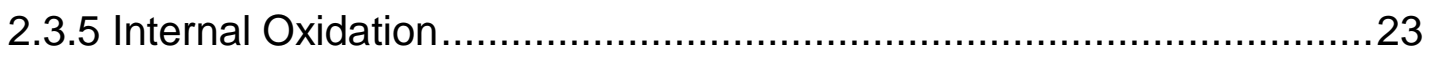

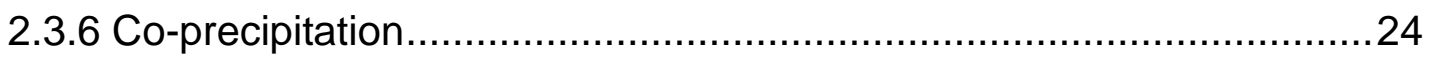

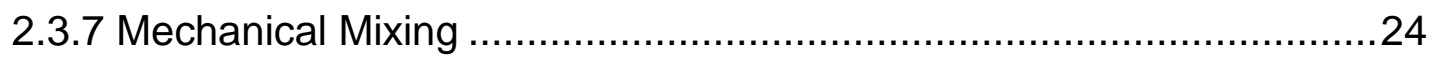

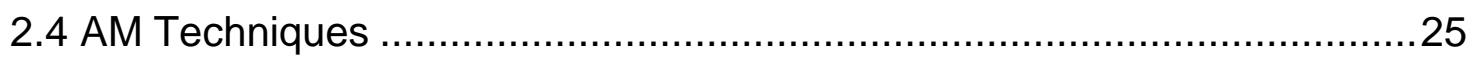

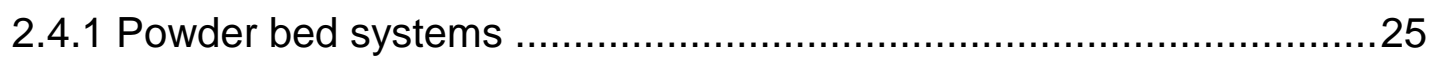

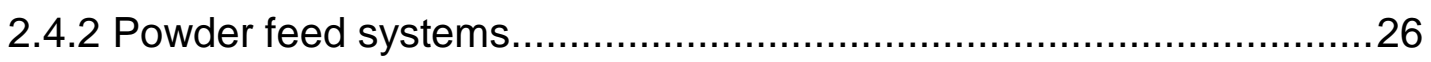




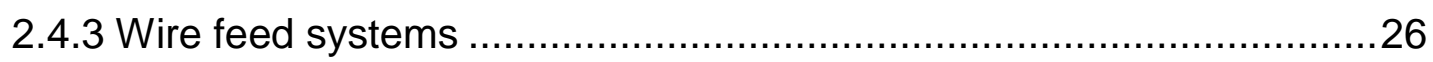

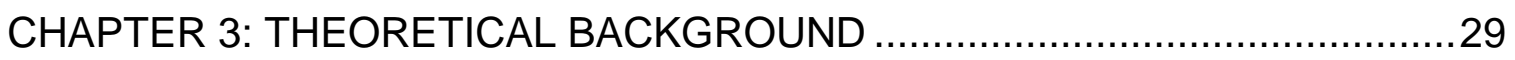

3.1 Strengthening Mechanisms of ODS Ni-Based Superalloys ......................29

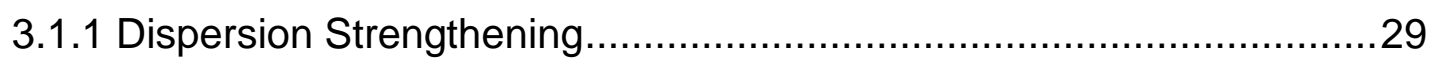

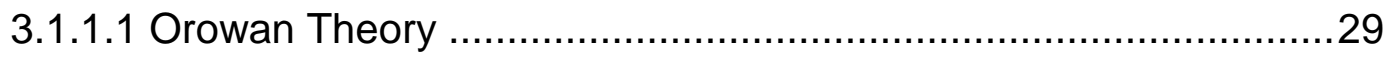

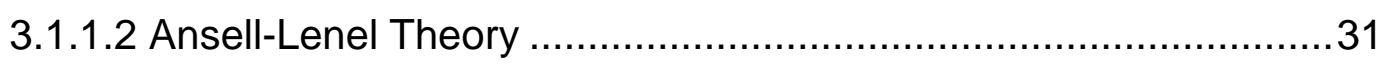

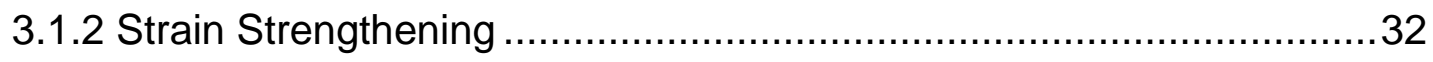

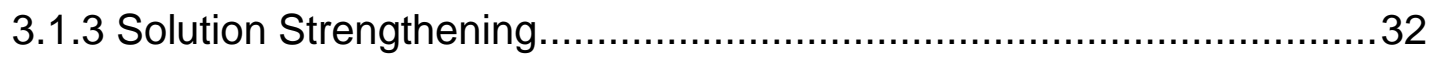

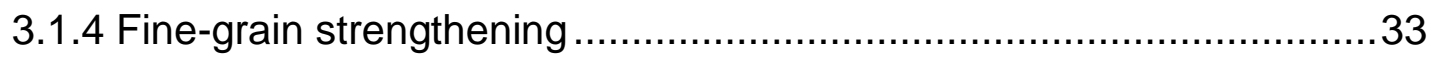

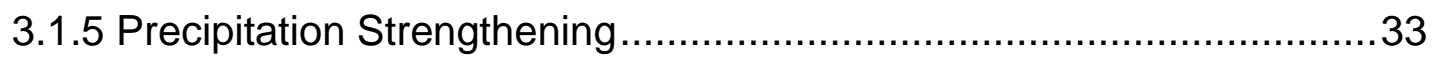

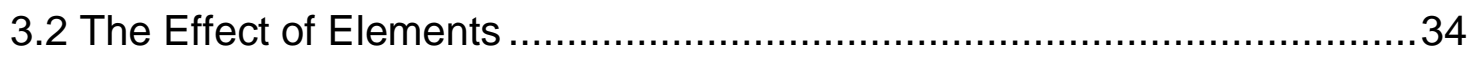

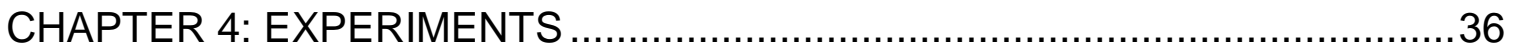

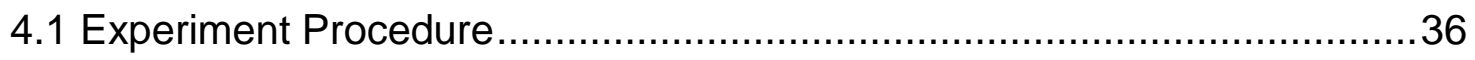

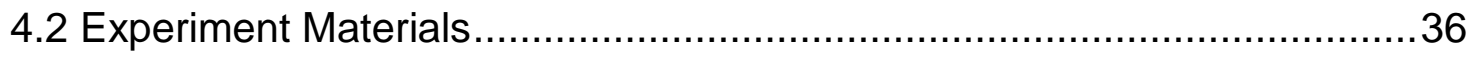

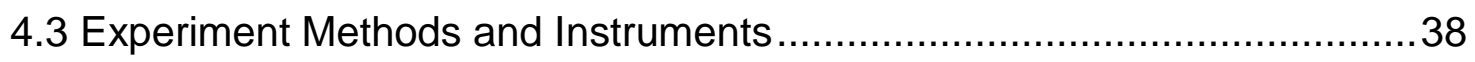

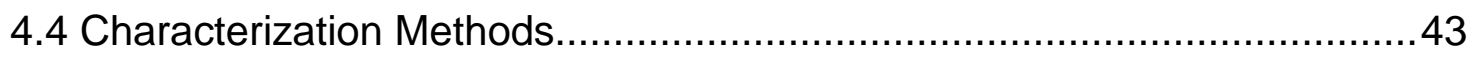

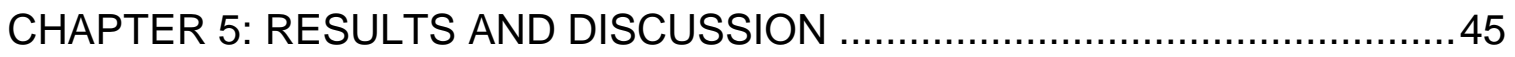

5.1 Analysis of Fabricated Powder .......................................................... 45

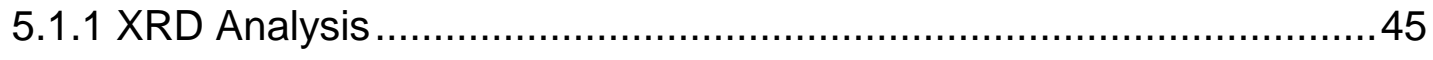

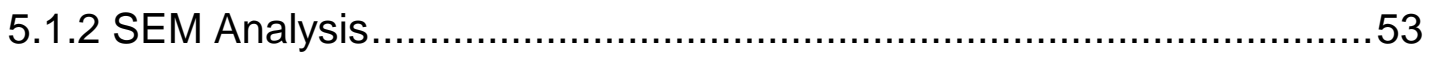

5.1.3 Size Distribution of Processed Powders .........................................58

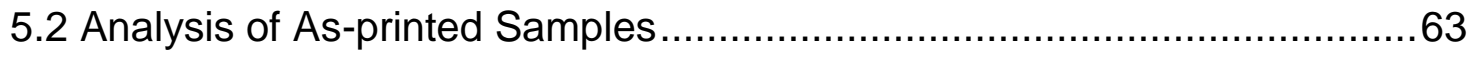

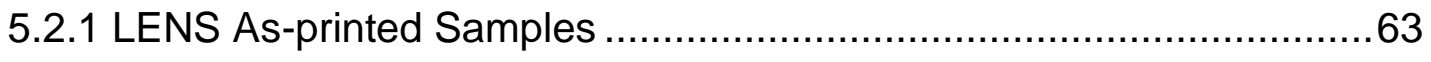

5.2.2 The Laser Cladding As-printed Sample ...........................................72

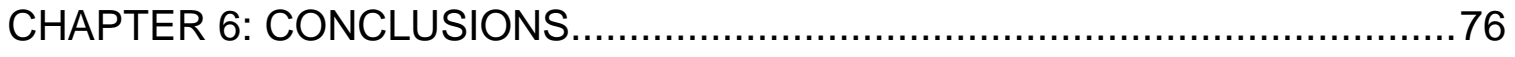

CHAPTER 7: RECOMMENDATIONS FOR FUTURE WORKS …...................78

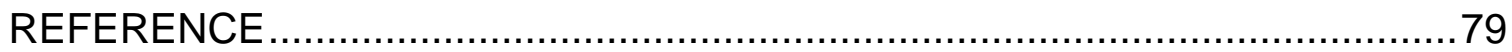




\section{LIST OF TABLE}

Table 2-1. Components of common superalloys (wt. \%) [17].............................

Table 2-2. Components of common ODS superalloys (wt. \%) [19] ..................... 8

Table 3-1. Compositional ranges of major alloying additions in Ni-based

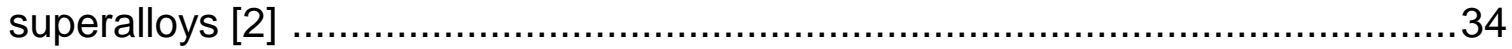

Table 3-2. Alloying elements present in ODS Ni-based superalloys [2] .............35

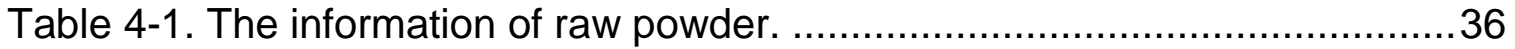

Table 4-2.Unique configurations of raw powder for the MCB-only, BM-only and

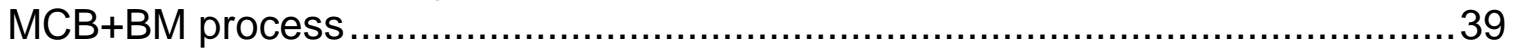

Table 4-3. Theoretical density of components ............................................42

Table 5-1. Micro-strain and crystal size of processed powders. ......................52

Table 5-2. The experimental density, relative density, and input linear energy of

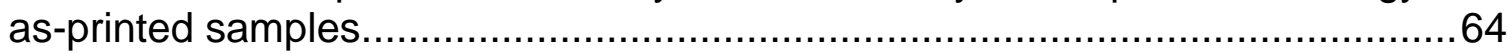




\section{LIST OF FIGURE}

Figure 1-1. Types of strengthening mechanisms and corresponding effective

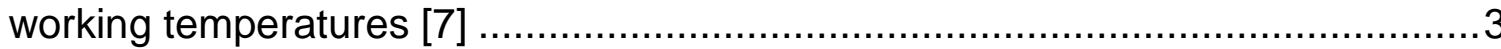

Figure 1-2. A schematic of the Gaussian model of powder size distribution [16]. .5 Figure 2-1. SEM images of $Y^{\prime}$ phase in conventional Ni-based superalloys: (a). Wrought alloy (x 3000); (b). Cast alloy (x 5000) [2]....

Figure 2-2. A schematic of mixture powders in the early stage of the MA process [32]

Figure 2-3. A schematic of mixture powders in the final stage of the MA process $[11,32]$

Figure 2-4. An SEM picture of powders under ball milling 400 rpm 41 hours. ....14

Figure 2-5. A schematic of the MCB machine.............................................. 15

Figure 2-6 The principle of the MCB process: (a). A schematic of the main inner vessel; (b). Structural patterns of nanocomposite particles [33,

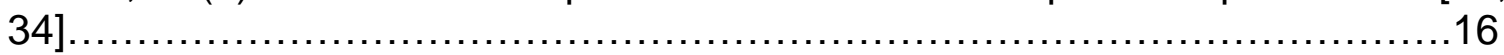

Figure 2-7. An SEM picture of powders under MCB processing 5000 rpm 11 hours.

Figure 2-8. TEM images of MCB processed ODS Ni-based superalloy powders (a) TEM BF image, (b) HRTEM image [35] .................................................. 18

Figure 2-9. An XRD analysis of powders under MCB processing $5000 \mathrm{rpm} 11$

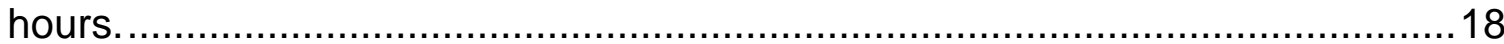

Figure 2-10. A schematic of a gas atomization process................................20

Figure 2-11.SEM images showing characteristic morphologies of as-produced atomized powder: (a). Gas atomized316 stainless steel [36]; (b). Water atomized 316 stainless steel [36]; (c). Gas atomized Ti-6Al-4V [37]; (d). Gas atomized IN718 [38]; (e). Cross sections of gas atomized IN718 [38] ... 21

Figure 2-12. XRD data revealing dispersoid formation after heat treatment of powders under different chemical compositions [12] .....................................22

Figure 2-13. A schematic of a water atomization process [40].........................23

Figure 2-14. A craft routine of the fabrication of TD-Ni [10].............................24

Figure 2-15. A schematic of a general powder bed system [41] ......................25

Figure 2-16. A schematic of a general powder feed system [41] ......................26

Figure 2-17. A schematic drawing of a general wire feed system [41] ...............27

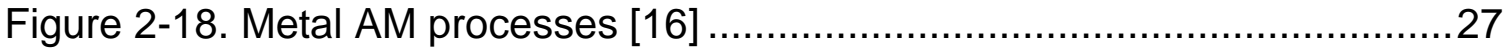

Figure 3-1. The dislocations pass particles by bowing mechanism [43].............29

Figure 3-2. A TEM picture of a dislocation ring [45] .....................................30

Figure 3-3. General view of the mechanical balance of the dislocation line ........30 
Figure 3-4. A schematic drawing of Ansell-Lenel Theory [47]

Figure 3-5. A TEM picture of a dislocation cutting a secondary phase particle [46]

Figure 4-1. A flow chart of experiments

Figure 4-2 SME morphology of (a). Pure Nickel powder; (b). Pure Chromium powder; (c). Pure Aluminum powder; (d). Pure Tungsten powder; (e). Pure Yttrium Oxide powder; (f). As-just-blended powder (unprocessed)...............................37

Figure 4-3. HOSOKAWA NOBILTA-130 MCB machine...................................38

Figure 4-4. A craft routine of MCB process....................................................

Figure 4-5. The MTI planetary BM machine ................................................40

Figure 4-6. A craft routine of MA process …................................................. 40

Figure 4-7. A schematic of hatching patterns employed in LENS 450 system. ...41

Figure 4-8. A schematic of Archimedes drainage. .......................................... 42

Figure 4-9. The Buehler Vibromet instrument. ............................................ 43

Figure 5-1. XRD patterns of pure elemental starting powders. ........................45

Figure 5-2. XRD patterns of the processed powders: (a). MCB-4000rpm1hour+BM-400rpm-40hours process (MCB+BM); (b).BM-only-400rpm41 housprocess (BM only); (c) As-just-mixed (0 hour); (d) MCB-only-4000rpm-

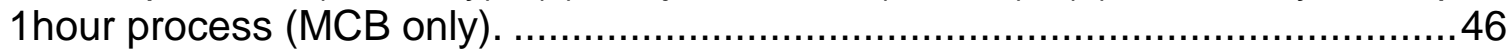

Figure 5-3. XRD spectrums of the MCB-only processed powders: Normal mode under 4000rpm: (a).18 hours; (b). 32 hours; (c). 50 hours. Normal mode under 5000rpm: (d). 22 hours; (e). 32 hours; (f) 50 hours; Step mode under 5000rpm: (g). 8 hours; (h) 11 hours. 47

Figure 5-4. XRD spectrums of the processed powders: Normal mode under 4000rpm: (a). 18 hours; (b). 32 hours; (c). 50 hours. (k). 1 hour; Normal mode under 5000rpm: (d). 22 hours; (e). 32 hours; (f). 50 hours; Step mode under 5000rpm: (g). 8 hours; (h). 11 hours; (i). MCB+BM; (j). BM-only. .50

Figure 5-5. Analysis of line-broadening effect of processed powders: B. BM-only Normal mode under 4000rpm: C. 1 hours; D. 18 hours; E. 32 hours; F. 50 hours; Normal mode under 5000rpm: G. 22 hours; H. 32 hours; I. 50 hours; Step mode under 5000rpm: J. 8 hours; K. 11 hours; L. MCB+BM. ..................................51

Figure 5-6. Analysis of peak broadening effect of processed powders..............52

Figure 5-7. SEM micrographs of: (a).BM-only (x 10k); (b). BM-only (x 1.5k) ......54

Figure 5-8. SEM images of the processed powders: Normal mode under 4000rpm: (a). 1 hours; (b). 18 hours; (c). 32 hours; (d). 50 hours; Normal mode under 5000rpm: (e). 22 hours; (f). 32 hours; (g). 50 hours; Step mode under 5000rpm: (h). 8 hours; (i). 11 hours (x 1k); (j). 11 hours (x 600). .56

Figure 5-9. SEM images of the surface of the processed powders: Normal mode under 4000rpm: (a).1 hours; (b). 18 hours; (c). 32 hours; (d). 50 hours; Normal 
mode under 5000rpm: (e). 22 hours; (f). 32 hours; (g). 50 hours; Step mode under 5000rpm: (h). 8 hours; (i). 11 hours (x 1k); (j). 11 hours (x 600)......................58

Figure 5-10. Variations of powder size distribution [18] …….........................59

Figure 5-11. Powder size distribution of MCB+BM processed powder ...............59

Figure 5-12. Powder size distribution of the BM-only processed powder............60

Figure 5-13. Powder size distribution of the MCB-only processed power (MCBnormal-4000 rpm-50 hours).

Figure 5-14. Powder size distribution of the MCB-only processed power (MCBnormal-5000 rpm-50 hours).

Figure 5-15. Powder size distribution of the MCB-only processed power (MCBstep-5000 rpm-8 hours).

Figure 5-16. Powder size distribution of the MCB-only processed power (MCB-

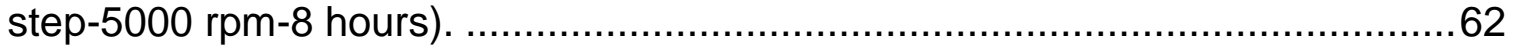

Figure 5-17. Powder size distribution of different processed powders: (a). MCB+BM process; (b). The BM-only process; the normal MCB-only process: (c). 4000 rpm 50 hours; (d). 5000 rpm 50 hours; the step MCB-only process: (e). 5000

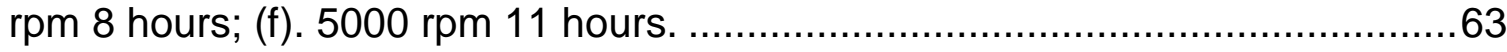

Figure 5-18. A schematic of the first batch of LENS as-printed samples.

Figure 5-19. SEM showing images of the characteristic microstructures of asprinted ODS parts at different laser powder and input linear energy: (a). 200W$6.06 \mathrm{~J} / \mathrm{mm}$; (b). $250 \mathrm{~W}-7.75 \mathrm{~J} / \mathrm{mm}$; (c). $275 \mathrm{~W}-8.33 \mathrm{~J} / \mathrm{mm}$ .65

Figure 5-20. High-magnification of SEM micrographs showing the characteristic microstructures of as-printed ODS parts in: (a). Figure 5-19 (a); (b). Figure 5-19 (b); (c). Figure 5-19 (c). 66

Figure 5-21. EDS point analysis of as-printed ODS parts at different laser powder and input linear energy: (a). $250 \mathrm{~W}-7.75 \mathrm{~J} / \mathrm{mm}$ in mid-layer; (b). $275 \mathrm{~W}-8.33 \mathrm{~J} / \mathrm{mm}$ in mid-layer.

Figure 5-22. A schematic (a) and images (b) of as-printed ODS part: 250W$25 \mathrm{~J} / \mathrm{mm}$. 68

Figure 5-23. SEM micrographs showing the characteristic microstructures of the cross-section of as-printed ODS part $(250 \mathrm{~W}-25 \mathrm{~J} / \mathrm{mm})$ : (a). The interface of the substrate and deposited part; (b). Mid-layer of the deposited part; (c). Top-layer of the deposited part.

Figure 5-24. High-magnification of SEM micrographs showing the characteristic microstructures of the as-printed ODS part in: (a). Figure 5-23 (a); (b). Figure 5-23 (b); (c). Figure 5-23 (c). .70

Figure 5-25. EDS point analysis of as-printed ODS part (250W-25J/mm): (a). midlayer; (b). top-layer. .71

Figure 5-26. XRD pattern of the cross-section of the as-printed ODS part: 250W$25 \mathrm{~J} / \mathrm{mm}$. 
Figure 5-27. Images of laser cladding as-printed samples.............................73

Figure 5-28. SEM micrographs showing the characteristic microstructures of the cross-section of as-printed ODS part (5kW): (a). The interface of the substrate and deposited part; (b). Mid-layer of the deposited part. .73

Figure 5-29. High-magnification of SEM micrographs showing the characteristic microstructures of the laser cladding as-printed ODS part in: (a). Figure 5-29 (a) block 1; (b). Figure 5-28 (a) block 2; (c). Figure 5-28 (b) block 1; (d). Figure 5-28

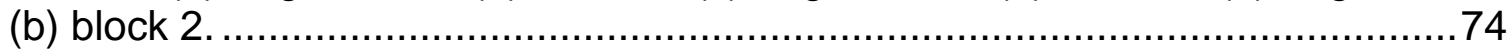

Figure 5-30. XRD pattern of the cross section of the laser cladding as-printed ODS

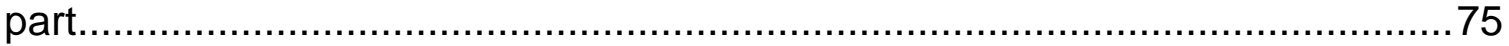




\section{CHAPTER 1: INTRODUCTION}

\subsection{Background}

The repaid development of industry has put forward more and more stringent requirements on the application range and properties of materials. People from science and industry now endeavor to open up new ways to seek new directions and effects of development. Additive manufacturing (AM) is a novel technology to build three dimensions objects by adding layer-upon-layer material which is typically plastic, metal and concrete. In metal-based AM, a direct source such as a laser or electron beam is applied to melt alloy powders locally gives rise to solidification. One of the most critical metal alloys that are applicable on AM is $\mathrm{Ni}$ alloy. Nonetheless, to 3D print conventional alloys such as high-strengtheningphase ( $\gamma^{\prime}$ phase), Ni superalloys cannot accomplish desired solidification conditions since they are unweldable. Thus, a new system of Ni-based superalloy with efficient properties needs to be developed.

$\mathrm{Ni}$ superalloy has been extensively used in oil field, marine industry, and aviation industry because it alloy has excellent mechanical properties, reasonable creep resistance, sufficient fatigue resistance, excellent corrosion resistance, adequate ductility, and serviceable weldability. However, traditional Ni superalloy has been unable to meet industrial needs with the development of industrial technologies. The aviation industry has higher demands in the mechanical property of $\mathrm{Ni}$ superalloys, especially the mechanical behavior under high temperatures. The strengthened phase in the conventional superalloy is unstable when being subject to high temperatures $\left(>1000^{\circ} \mathrm{C}\right)$.

Introducing a new strengthening element into superalloy is an important method to enhance the property of it. Dispersion strengthening is a useful metal strengthening mechanism besides strain strengthening; solution strengthening; fine-grain strengthening; precipitation strengthening in superalloy [1]. Oxidedispersion-strengthening (ODS) has become one the dominant method to strengthen superalloys. It relies on the addition or formation of stable secondary phase particles in the metal matrix to strengthen alloys. Secondary phase particles are artificially added to the alloy matrix system with favorable thermal and chemical stabilities. They are generally fine and uniform presenting in the matrix and able to pin movements of dislocations, grain boundaries, and sub-grain boundaries to inhibit grain growth. Thus, the alloy is strengthened by secondary phase particles. However, it has been proven that oversize secondary phase particles undermined the fracture resistance and ductility of alloys even though they effectively hinder the movement of dislocations. Hence, to achieve the desired strengthening effect, secondary phase particles must be evenly distributed into the matrix system with fine size by other techniques. 
ODS Ni-based superalloys (denoted as Ni-based ODS) is recently developed that strengthened by adding or in situ forming second phase particles with even and fine sizes (Nano sizes in general), i.e., $\mathrm{Y}_{2} \mathrm{O}_{3}, \mathrm{Al}_{2} \mathrm{O}_{3}, \mathrm{Zr}_{2} \mathrm{O}_{3}$, and $\mathrm{ThO}_{2}$. At high temperatures, the strengthening $\mathrm{Y}^{\prime}$ phase exists in conventional $\mathrm{Ni}$ superalloys reacts with carbon or carbon oxide to cause dissolve of itself into austenite matrix, thus leads to the failure of strengthening effect [2]. Nevertheless, $\mathrm{Ni}$-based ODS can withstand high temperatures due to the existence of secondary phase particles since they do not dissolve themselves into matrix under high temperatures. Strengthening phases enable Ni-based ODSs to maintain hightemperature strength, and high-temperature creep performance and oxidation resistances near the melting point.

Ni-based ODS owns advantages as follows:

I). High room temperature strength and high-temperature strength;

II). High creep strength;

III). Sufficient oxidation resistance and corrosion resistance;

IV). Good ductility;

V). Low swelling.

Therefore, Ni-based ODS is considered as a sufficient candidate for aircraft engines and gas turbines. Ni-based ODSs that apply to aircraft engines and gas turbines are MA6000 [3], IN738 with $\mathrm{Y}_{2} \mathrm{O}_{3}$ [4], and WAZ-D [5], etc. The hightemperature resistance of $\mathrm{Ni}$-based $\mathrm{ODS}$ is significantly improved than conventional Ni superalloy with a maximum increase of about $100^{\circ} \mathrm{C}$ [6]. Published results have shown that the fracture strength of ODS Ni-based superalloy (i.e., MA6000) is twice as conventional Ni-based superalloy at $1000^{\circ} \mathrm{C}[7,8]$.

Powder metallurgy technologies have gradually taken over the manufacturing of ODS superalloys. The Tho2 powder was affiliated into tungsten to inhibit the trend of grain growth of tungsten at high temperatures. In 1949, Irmann [9] fabricated sintered aluminum powder (SAP) by Surface Oxidation, this was the first ODS that used as a structural material in the world. In 1962, Anders [10] from DuPont Company manufactured Td-Ni alloy through Chemical Co-precipitation Method. But this method had limitations which were the difficulties of adding an active metal such as Ti and Al into the matrix system. Until the 1970s, Benjamin [11] successfully produced Ni-based ODS by Mechanical Alloying (MA) such that ODS techniques have been developed rapidly. MA has commercially produced various metal alloys, oxides and carbides which are widely used in nuclear reactors, advanced aircraft engines, gas turbines, and cars. The development of ODS materials is mainly concentrated in the United States, Britain, Japan, and Germany.

Ball-Milling (BM) machine and Mechano-Chemical-Bonding (MCB) machine are two primary instruments of the MA process. Laser-Engineering-Net-Shaping (LENS) system, Laser Cladding (LC) and Electro-Optical-System (EOS) are currently primary 3D printing methods in AM. This study aimed to develop new approaches to fabricate $\mathrm{Ni}-20 \mathrm{Cr}-5 \mathrm{Al}-3 \mathrm{~W}-1.5 \mathrm{Y}_{2} \mathrm{O}_{3}$ in weight percentage ODSs 
which are suitable for LENS, LC and EOS with reasonable particle size distributions, nearly spherical shapes, and excellent mechanical properties.

\subsection{Research Objectives}

The primary purpose of this study is to develop a material system to provide an improved level of thermal protection for hot-section components, such as turbine airfoils and gas turbines. To produce ODS Ni-based superalloy powders with proper sphericity and spreadability, which will be used in AM processes based on selective laser melting. The main strengthening phase of the Ni-based superalloy is $\mathrm{Y}^{\prime}$ phase. It is precipitate strengthening in conventional superalloys. However, when the Ni-based superalloy is working at high temperature (near the melting point of the matrix), $\gamma^{\prime}$ phase will become dissolute which loses the strengthening purpose of the superalloy. But the added $\mathrm{Y}_{2} \mathrm{O}_{3}$ in ODS Ni-based superalloy will improve the mechanical properties at high temperatures since $\mathrm{Y} 2 \mathrm{O} 3$ is the secondary particle in superalloys which satisfies the dispersion strengthening and able to pin the movements of dislocations and grain boundaries.

\begin{tabular}{|c|c|c|}
\hline $\begin{array}{c}\text { Strengthening } \\
\text { Mechanism }\end{array}$ & $\begin{array}{c}\text { Effective } \\
\text { Temperature }\end{array}$ & Comments \\
\hline Work Hardening & $\sim 0.3 \mathrm{~T}_{\mathrm{m}}$ & Dislocation/Dislocation Interaction \\
\hline $\begin{array}{c}\text { Grain Size } \\
\text { Refinement }\end{array}$ & $\sim 0.3 \mathrm{~T}_{\mathrm{m}}$ & $\begin{array}{c}\text { Grain Boundary Area - Dislocation } \\
\text { Interaction }\end{array}$ \\
\hline $\begin{array}{c}\text { Solid Solution } \\
\text { Strengthening }\end{array}$ & $\sim 0.4 \mathrm{~T}_{\mathrm{m}}$ & $\begin{array}{c}\text { Lattice Strain Fields: Modulus Change, } \\
\text { dislocation interaction }\end{array}$ \\
\hline $\begin{array}{c}\text { Precipitation } \\
\text { Strengthening }\end{array}$ & $\sim 0.6 \mathrm{~T}_{\mathrm{m}}$ & $\begin{array}{c}\text { Metastable } 2^{\text {nd }} \text { Phase Particles, impede } \\
\text { dislocation motion }\end{array}$ \\
\hline $\begin{array}{c}\text { Dispersion } \\
\text { Strengthening }\end{array}$ & $\sim 0.9 \mathrm{~T}_{\mathrm{m}}$ & $\begin{array}{c}\text { Insoluble } 2^{\text {nd }} \text { Phase, stabilize grain, } \\
\text { subgrains and creep }\end{array}$ \\
\hline
\end{tabular}

Figure 1-1. Types of strengthening mechanisms and corresponding effective working temperatures [7].

Figure 1-1 shows the types of strengthening mechanisms and corresponding effective working temperatures. ODS Ni-based superalloy falls in the dispersion strengthening category (Oxide-dispersion). Tm represents the melting points of alloys, and the melting point of $\mathrm{Ni}$ alloys is in the range of $1400 \sim 1500{ }^{\circ} \mathrm{C}$. Thus, the effective working temperature of ODS Ni-based superalloys is in the range of $1260 \sim 1350{ }^{\circ} \mathrm{C}$ by calculating from Figure 1-1. Besides, for gas turbines, the temperature of exhaust entering the turbine can be as high as $1200 \sim 1400^{\circ} \mathrm{C}$ while the effective working temperature of ODS Ni-based superalloys is in this range. Therefore, ODS Ni-based superalloys are suitable for providing high-level of thermal protection for turbines. 
Atomization is the most used technique for superalloy fabrication. However, it is incapable of producing ODS superalloys since atomization requires the melting of metals and the known highest temperature of atomization is $1700^{\circ} \mathrm{C}$. The added oxides in ODS superalloys usually have melting temperatures more than $2000{ }^{\circ} \mathrm{C}$. Recently, Joel $\mathrm{R}$. et al. have proposed a novel method called reactive gas atomization to produce ODS Fe-based superalloys [12]. They used $\mathrm{Cr}$ as an oxygen vehicle to transport oxygen to add yttrium to form yttrium oxide thus achieve ODS. But the evidence of the even distribution of yttrium oxide was not clear in their research. And post heat treatment still needed for the alloy, they have shown that the yttrium oxide did not form until heat treated to $120{ }^{\circ} \mathrm{C}$ [12]. Thus, an effective method for ODS superalloy fabrication needs to be developed.

Two techniques (the BM process and the MCB process) were employed to fabricate ODS Ni-based superalloy powders and investigate the efficiency of producing process. Except for Atomization methods, the MA process is the most widely used methodology to produce ODS superalloys. Since the difficulties of fabricating ODS by utilizing atomizations still exist. The BM machine is the instrument by using the mechanism of the MA process. It is capable of blending, breaking, and cold-welding the raw elemental powders and oxide compounds under high energy ball milling for long periods (usually up to 200 hours). The oxide compound is uniformly dispersed onto the hosting particles throughout the MA process. After the MA process, the processed powders are subjected to HIP to consolidate and heat treatment to relieve the residual stress. Furthermore, the HIPed material is usually processed by hot worked. Also, the hot worked material is heat treated to achieve the desired microstructures and mechanical properties to meet the requirements of multiple applications.

Since various post processes are involved after the MA process to fabricate ODS superalloys, commercially producing ODS superalloys become problematic which results in time-consuming and high cost. For instance, it costs about $\$ 345 / \mathrm{kg}$ for Ni-based ODS MA 956 alloy. However, it only costs about \$30-35/kg for Ni-based superalloys such as INCONEL 718 and 617 [13]. Besides, the MA process usually needs an extended period to produce ODS superalloys which will cause contamination from milling debris and gaseous environment [14].

There is another technique by using the mechanism of the MA process called MCB machine being developed recently. The raw elemental powders are under high-speed compression and shearing force through a small gap between the vessel and a press head. The added oxide particles (i.e., Y2O3) are homogeneously coated onto the hosting particles, forming the composite powders. The MCB process is a dry process without adding any binders to form alloys through the solid state diffusion. At present, the MCB technique has been used to make various composite materials applied in the area of pharmaceuticals, batteries, fuel cells, functional gradient materials, and cermets [14]. Kang et al. have shown that the MCB process was able to disperse $\mathrm{Y} 2 \mathrm{O} 3$ particles onto the based and hosting particles homogeneously to form the composite powders [15]. Furthermore, 
the newly developed MCB processing technique is simple, environmentally friendly, and can be scaled up to 300 liters per batch. Thus, MCB or its combination technique is considered as an enhancement or alternative to the conventional MA process using balling milling.

Another technique called Additive Manufacturing was utilized in this research since it can produce bulk and densified samples by laser or electron beam in three dimensions. It has gained significant academic and industry interests because it is capable of creating complex geometries with customized materials properties. Comparing to the post-processing of BM process alloy powders consolidation, AM technique is a much easier way to achieve densified samples. This research aimed to develop ODS Ni-based superalloy powders for AM techniques and investigate the feasibility of using BM processed and MCB processed alloy powders in the field of AM.

\subsection{Challenge of Research}

\section{I). Particle size distribution}

Based on the existing results of powder granulometry requirements for AM techniques, a Gaussian size distribution (Figure 1-2) of powder is desirable. BM and MCB techniques could achieve this Gaussian model. However, the size of the particle for AM also has strict requirements: the mean particle size of widely used GA powders is $20 \sim 40 \mu \mathrm{m}$. The particle size control of BM and MCB is a challenge.

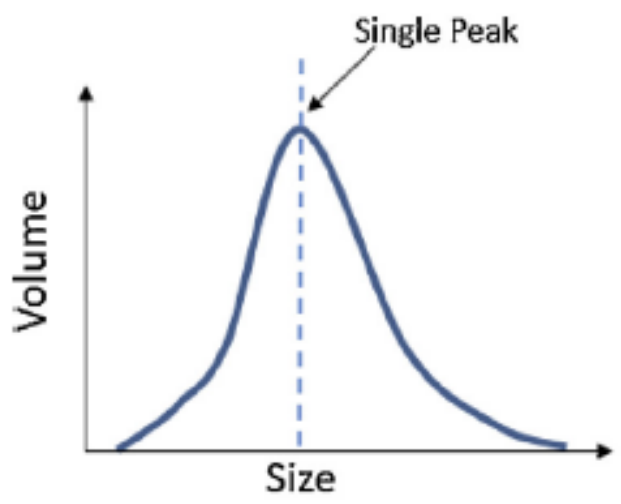

Gaussian

Figure 1-2. A schematic of the Gaussian model of powder size distribution [16].

II). Particle strengthening phase

It is known that the strengthening phase of ODS Ni-based superalloys is the Y' phase. Fabricating powders with y' phase is still a challenge in this area. Even 
the widely used atomization is only capable of generating pre-alloyed powders. It is noted that the BM process could produce powders with Y' phase, but the difficulty of MCB-only generating $\mathrm{Y}^{\prime}$ phase still exists.

III). Particle shapes

Atomization process produces the most spherical powders. But, BM and MCB could not generate perfectly spherical particles comparing to atomization process which would influence the flowability of powders during the AM process. The highest degree of roundness produced by MCB is known as 0.93.

IV). Microstructure control of post-printed samples

The dimensional accuracy of AM technique is still a problem since shrinkage usually happens after depositing alloy powders onto a substrate. Also, the flowability of powder, input laser energy, and laser scanning speed directly affect the shrinkage and density of as-printed samples. If the input energy density is relatively low, the as-printed will have more shrinkage and low density (i.e., more pores than conventional consolidation method). Thus, the processing parameter control is a big challenge for this research. 


\section{CHAPTER 2: REV IEW OF LITERATURE}

\subsection{Superalloys}

Superalloy refers to the alloy which uses $\mathrm{Fe}, \mathrm{Ni}$, and $\mathrm{Co}$ as the matrix, and is capable of working over $600{ }^{\circ} \mathrm{C}$ and under stress for a long time. Superalloy is also called refractory alloy or high-temperature alloy. Superalloy has good hightemperature strength, excellent oxidation resistance, good corrosion resistance, high creep strength, and good ductility. Superalloys are generally $\mathrm{Ni}, \mathrm{Fe}$, and Cobased alloys used above temperature $540^{\circ} \mathrm{C}$ [2]. The Fe-Ni-base superalloys such as the popular alloy IN718 is an extension of stainless steel technology and generally is wrought. Co-base and Ni-base superalloys may be wrought or cast, depending on the application/composition involved [2]. Table 2-1 shows the composition of conventional superalloys.

However, when the working temperature comes to $50 \%$ (on an absolute scale) of the melting point of an alloy, the strength must be weakened with the increase of time. Therefore, current superalloys could not meet the requirement of the industrial application. A new type of superalloys needs to be developed by adding dispersion to strengthen superalloys. Introducing a new strengthening element into superalloy is an important method to enhance the mechanical property. Dispersion strengthening is a useful metal strengthening mechanism besides strain strengthening; solution strengthening; fine-grain strengthening; precipitation strengthening in superalloys

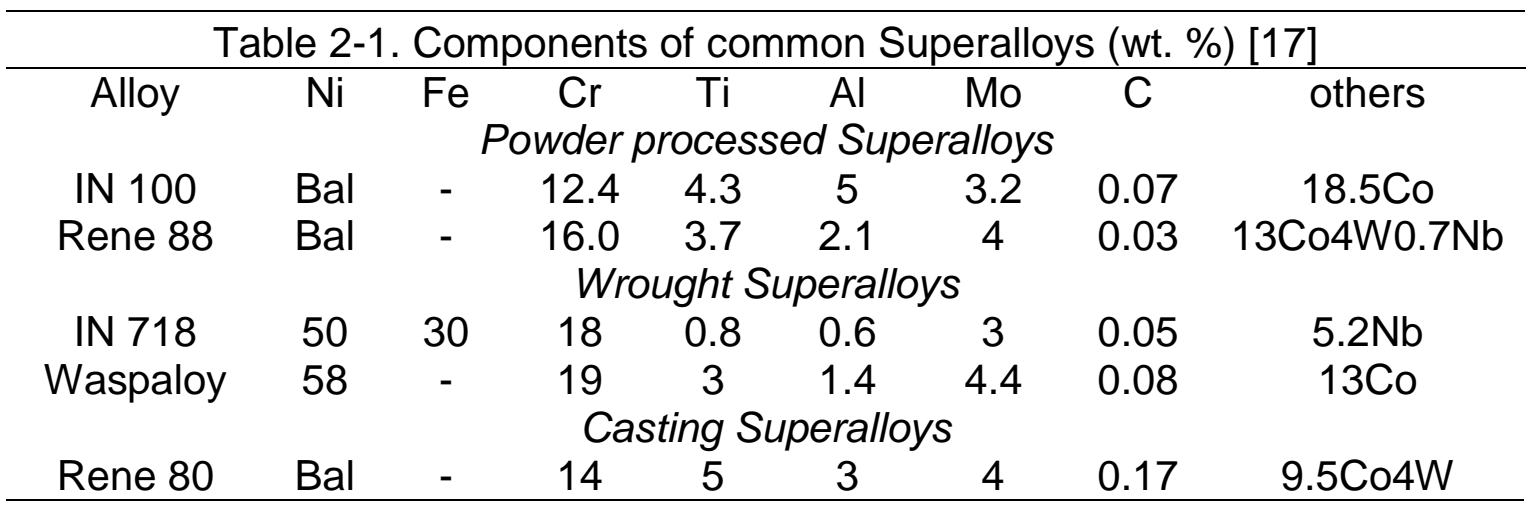

\subsection{Oxide -Dispersion-Strengthened (ODS) Superalloys}

ODS superalloys are one type of dispersion strengthened superalloys, the strengthening mechanism of ODS is dispersion strengthening by adding a new element which is harder than the matrix metals. The added compound is called the secondary phase particle. Ordinary strengthening particles are refractory Oxides (i.e., $\mathrm{Y}_{2} \mathrm{O}_{3}, \mathrm{Al}_{2} \mathrm{O}_{3}, \mathrm{HfO}_{2}$, and $\mathrm{ThO}_{2}$ ), Carbides (i.e., $\mathrm{TiC}, \mathrm{SiC}$, and $\mathrm{WC}$ ), Nitrides (i.e., $\mathrm{TiN}, \mathrm{BN}$, and $\mathrm{Si}_{3} \mathrm{~N}_{4}$ ), and Borides (i.e., $\mathrm{TiB}_{2}, \mathrm{ZrB}_{2}$, and $\mathrm{CrB}_{2}$ ). 
ODS superalloys are primarily distinguished from conventional superalloys by the dispersion strengthening $Y$ ' phase. There are two main categories of commercial ODS superalloys, the ODS Ni-based superalloy, and the ODS Febased superalloy. The temperature of the solid solution limits the maximum working temperature for ODS superalloys. When ODS superalloys are working over $1000{ }^{\circ} \mathrm{C}$, the aggregation, coarse and dissolve of strengthening $\mathrm{Y}^{\prime}$ phase is inevitable thereby impair the high-temperature strength of the ODS superalloys.

The choice of oxide is critical in ODS superalloys. The oxide with a high melting point, high chemical stability, the ability of insoluble in the matrix, low diffusion rate, and low interface energy is preferred for ODS superalloys. $\mathrm{ThO}_{2}$ was the earliest oxide that added into ODS superalloys, but $\mathrm{Y}_{2} \mathrm{O}_{3}$ substituted sit since it has radioactivity. Plus, $\mathrm{Y}_{2} \mathrm{O}_{3}$ can form a more stable metal composite oxide with the excess oxygen and $\mathrm{Al}$ in the matrix $\left(3 \mathrm{Y}_{2} \mathrm{O}_{3} \cdot 5 \mathrm{Al}_{2} \mathrm{O}_{3}\right)$. Significant evidence has shown that the dispersion actually consists of mixed oxides, i.e., $\mathrm{Y}_{3} \mathrm{Al}_{5} \mathrm{O}_{2}(\mathrm{YAG})$, $\mathrm{YAIO}_{3}$ (YAP), $\mathrm{YAH}$, etc. [18]. $\mathrm{Al}_{2} \mathrm{O}_{3}$ is another alternative for ODS superalloy due to its well-known stability. The ODS Ni-based superalloy and the ODS Fe-based superalloy are the most studied and applied alloys.

\begin{tabular}{ccccccccc}
\hline \multicolumn{10}{c}{ Table 2-2. Components of common ODS superalloys (wt. \%) [19] } \\
\hline Alloy & $\mathrm{Ni}$ & $\mathrm{Fe}$ & $\mathrm{Cr}$ & $\mathrm{Ti}$ & $\mathrm{Al}$ & $\mathrm{C}$ & Y2O3 & others \\
MA 754 & $\mathrm{Bal}$ & 1.0 & 20 & 0.5 & 0.3 & 0.05 & 0.6 & \\
MA 757 & $\mathrm{Bal}$ & - & 16 & - & 4.5 & - & 1 & \\
MA 758 & $\mathrm{Bal}$ & - & 20 & 0.5 & 0.3 & - & 0.6 & \\
PM 1000 & $\mathrm{Bal}$ & - & 20 & - & 0.3 & - & 0.6 & $0.5 \mathrm{Mo}$ \\
MA 6000 & $\mathrm{Bal}$ & - & 15 & 2.5 & 4.5 & 0.05 & 1.1 & 2Mo4W2Ta \\
MA 956 & - & $\mathrm{Bal}$ & 20 & 1 & 4.5 & 0.02 & 0.5 & \\
PM 2000 & - & Bal & 20 & 0.5 & 5.5 & $<0.04$ & 0.5 & \\
\hline
\end{tabular}

\subsubsection{ODS Ni-based Superalloys}

Material scientists have been conducting researches since the $20^{\text {th }}$ century concerning ODS superalloys. The first ODS Ni-based superalloy was produced in the 1950s by DuPont company though co-precipitation method. The company had generated some conventional alloys such as Td-Ni alloys. Until the 1970s, Benjamin et al. invented MA to produce ODS superalloys thus he boosted the development of ODS superalloys, especially ODS Ni-based superalloys. Currently, MA753, MA754, MA6000, and MA956 ODS Ni-based superalloys have been produced and commercialized [17]. MA754 was the first commercialized ODS Nibased superalloy. It could be working at $1250{ }^{\circ} \mathrm{C}$. In the 1970 s, it was applied to some aircraft high-temperature components, i.e., American military engines F404, F110. It was adopted to machine blades and ring units. MA6000 has a tensile strength of $222 \mathrm{MPa}$, Yield strength of $192 \mathrm{MPa}$ at $1100{ }^{\circ} \mathrm{C}$ [20].

In ODS Ni-based superalloys, the selection of an oxide particle is the crucial point. The choice of oxide particle should be in line with these characteristics: 
Chemically stable, non-dissoluble in a matrix, low diffusion coefficient, and low interphase energy. The first chosen oxide particle was $\mathrm{ThO}_{2}$. But it was eliminated from the ODS since it is radioactive. $\mathrm{Y}_{2} \mathrm{O}_{3}$ was then researched mostly to produce ODS superalloys. Its creep strength at $850^{\circ} \mathrm{C}$ could sustain over $185 \mathrm{MPa}$ over 6000 hours. Russia OKBM considered MA6000 was the only standard materials for turbine disk. MA6000 was mainly used on turbine blades [3].

The strength of most alloys normally decreases with temperatures, except some intermetallic compounds, such as $\mathrm{Y}^{\prime}-\mathrm{Ni}_{3} \mathrm{Al}$ which increases with temperatures up to about $900^{\circ} \mathrm{C}$. Precipitates of $\mathrm{Y}^{\prime}-\mathrm{Ni}_{3}(\mathrm{Al}, \mathrm{Ti})$ is considered as the primary strengthener for $\mathrm{Ni}$-based superalloys. However, because the precipitates are metastable, they will coarsen when heated at high temperatures, so that the mechanical properties decrease with time. Efforts have been made to involve more stable nanosize oxide particles such as $\mathrm{Y}_{2} \mathrm{O}_{3}, \mathrm{ThO}_{2}$, and $\mathrm{ZrO}_{2}$ which can disperse homogeneously in the alloy grains through the ODS Ni-based superalloy is currently much more widely used than ODS Fe-based superalloy, and ODS Cobased superalloy because the working temperature of ODS Ni-based superalloy is $150 \sim 250^{\circ} \mathrm{C}$ higher than ODS Fe-based superalloy and ODS Co-based superalloy [17].

In conclusion: the development of ODS Ni superalloys went through three stages [21]:

I). From 1905 when Ni-Cr electro resistance alloy was produced to 1940 when Nimonic80 alloy was fabricated, Ni superalloys improved from single crystal to $y^{\prime}$ phase strengthening alloy. The working temperature rose from $650{ }^{\circ} \mathrm{C}$ to $750 \sim 800{ }^{\circ} \mathrm{C}$.

II). The compositions of alloys were continuously adjusted. The work temperature rose to $950 \sim 980^{\circ} \mathrm{C}$.

III). New synthesis processes were employed such as directional casting, welding. And oxide particles were added to achieve ODS Ni-based superalloys which have better performances.

ODS Ni-based superalloy falls into two main categories. The first class is represented by alloys that contain a low content of Al and Ti, i.e., MA754, MA758, and PM 1000, etc. These alloys do not include strengthening $Y^{\prime}$ phase. Their hightemperature strengths mainly depend on the solid solution strengthening of $\mathrm{Cr}$. Adding $\mathrm{Cr}$ and $\mathrm{Al}$ also improves the oxidation resistance of alloys. But their medium-temperature strength is not as good as expected. The MA process produces these ODS Ni-based superalloys with $\mathrm{Y}_{2} \mathrm{O}_{3}$ as secondary phase particle. Extrusion, rolling and hot compressing are usually applied on these alloys to obtain desired columnar grain structures which grow along the deformation direction. The columnar grain structures improve the endurance strength and creep resistance of 
alloys. The second class is represented by alloys that composed of higher $\mathrm{Al}$ and Ti contents. This leads to more strengthening $Y^{\prime}$ phase existing in the matrix (up to $60 \%$ or higher). Mo, W, and Ta play an important role in stabilizing strengthening $\mathrm{Y}^{\prime}$ phase. These alloys have higher medium-temperature strength than the first class alloys.
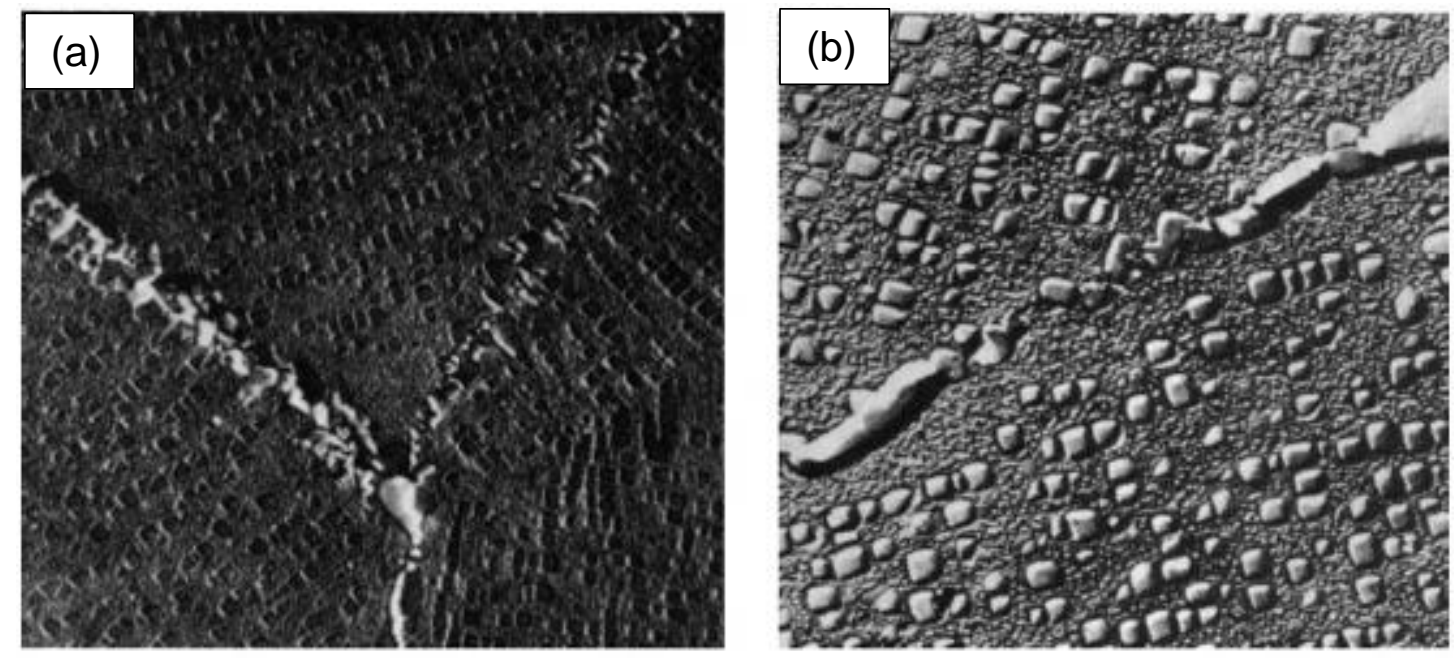

Figure 2-1. SEM images of $\mathrm{Y}^{\prime}$ phase in conventional Ni-based superalloys: (a). Wrought alloy (x 3000); (b). Cast alloy (x 5000) [2]

Figure 2-1 shows the $y^{\prime}$ phase of conventional Ni-based superalloys. It is noted that $\gamma^{\prime}$ phase is spheroidal and cuboidal with some degree of coherence. It has been noted that $\gamma^{\prime}$ phase tends to occur as spheres for 0 to $0.2 \%$ mismatches, becomes cuboidal for mismatches of about 0.5 to $1 \%$, and is plate-like at mismatches above about 1.25\% [2]. Another significant strengthening phase of $\mathrm{Ni}$ based superalloy is $\mathrm{Y}^{\prime \prime}$ phase. It is not discussed in this study since the designed nominal composition does not contain the $\mathrm{Y}^{\prime \prime}$ phase former elements: $\mathrm{Nb}$ and $\mathrm{Ta}$.

\subsubsection{ODS Fe-based Superalloys}

$\mathrm{Cr}$ and Mo were added into ODS Fe-based Superalloy to induce solid solution strengthening. Oxidation resistance of ODS Fe-based Superalloy was improved by adding $\mathrm{Cr}$ and Al. The nanosize added $\mathrm{Y}_{2} \mathrm{O}_{3}$ not only pinned the movement of dislocation but also inhibited the migration of atoms to cause the formation of oxide layers on the surface. This enhances the oxidation resistance and corrosion resistance. Studies of ODS Fe-based Superalloy are mostly about ODS low-activity ferrite steel and ODS low-activity ferrite steel/double-phase martensitic steel; the main difference is the content of $\mathrm{Cr}$. Low activity ferrite steel has 14 $20 \mathrm{wt}$. \% Cr, low activity ferrite steel/double-phase martensitic steel has 9 12 wt. \% Cr. The common ODS Fe-based Superalloys are: ODS ferrite steelPM2000 [22], MA 957 [23], 14YWT [24], ODS ferrite steel/double-phase martensitic steel-ODS Eurofer97 [25], 9Cr-ODS [26] etc. 
In general, ODS ferrite steel has higher creep strength than ODS ferrite steel/double-phase martensitic steel. And ODS ferrite steel has lower stability than ODS ferrite steel/double-phase martensitic steel in anisotropy.The characteristics of ODS Fe-based superalloys are as follows: 1). The ODS Fe-based superalloy powders processed by MA when after hot sintering, has fine grains from 100 to about a few hundred nanometers. 2). $\mathrm{Y}-\mathrm{Ti}-\mathrm{O}, \mathrm{Y}_{2} \mathrm{Ti}_{2} \mathrm{O}_{7}$, and $\mathrm{YTiO}_{5}$ were observed to present in the matrix with 2 5 nm [27]. These two characteristics ensure that the ODS Fe-based superalloy has a stable grain structure which provides excellent conditions for high-temperature creep strength.

The strengthening phases of ODS Fe-based superalloy are as follows: TEM characterization of MA957 has shown that the strengthening phase is the $\mathrm{Y}_{2} \mathrm{Ti}_{2} \mathrm{O}_{5}$ particle with a smaller size of added $\mathrm{Y}_{2} \mathrm{O}_{3}$ [23]. Ukai et al. found that Ti could be dissolved into the matrix and acted as a refiner of the strengthening phase. The strengthening phase $\mathrm{Y}-\mathrm{Ti}-\mathrm{O}$ was formed through reaction $\mathrm{TiO}_{2}+\mathrm{Y}_{2} \mathrm{O}_{3}$, the strengthening phase could be refined down to $2 \mathrm{~nm}$ [26]. TEM was frequently used to analyze the strengthening phase in ODS steels. Based on previous TEM researches, the major strengthening phases of ODS steels are $\mathrm{Y}_{2} \mathrm{TiO}_{7}$ and $\mathrm{YTiO}_{5}$ [27].

In order to improve the corrosion behavior of ODS steels, Al was later added into the system. For instance, PM2000 ODS steel has four types of Y-AI-O strengthening phases [22]. They are $\mathrm{YAIO}_{3}$ with Yttrium-Al-Perovskite (YAP) and Yttrium-Al-Hexagonal (YAH) structure; $\mathrm{Y}_{4} \mathrm{AlO}_{9}$ with Yttrium-Al-Monoclinic (YAM) structure; $\mathrm{Y}_{3} \mathrm{Al}_{5} \mathrm{O}_{12}$ with $\mathrm{Yttrium}-\mathrm{Al}-\mathrm{Garnet}(\mathrm{YAG})$ structure.

\subsubsection{ODS Al-based Superalloys}

ODS Al-based superalloys are different from other ODS superalloys since a dense alumina film naturally exists on the surface of Al powders. ODS Al-based superalloys can be achieved by compression, extrusion and strengthened by alumina when subject to severe deformation. Common Al superalloys are age strengthening Al alloys and particle strengthening Al alloys. Age strengthening Al superalloys mainly depends on the secondary phase precipitate during age strengthening, common alloys in this category are 2000 series and 7000 series $\mathrm{Al}$ alloys. Age strengthening Al superalloys have a limitation which is the secondary phase would dissolve into the matrix at high temperatures. Particle strengthening Al superalloys are strengthened by added hard particles, the standard alloy in this category is $\mathrm{SiC}$ strengthened $\mathrm{Al}$ alloy. But $\mathrm{SiC}$ is usually coarsened in the matrix which affects the ductility of Al superalloys. Besides, the unevenly distributed SiC in the matrix influences the mechanical properties of ODS Al-based superalloys.

ODS Al-based superalloys have been developed since the 1940s; they are mostly fabricated by surface oxidation method and the MA process. They also contain nanosize secondary strengthening particles, i.e., $\mathrm{Al}_{2} \mathrm{O}_{3}, \mathrm{Al}_{4} \mathrm{C}_{3}$, and $\mathrm{AIN}$. The commercialized ODS Al-based superalloys are A19052 and A19021 [28]. 
A19052 has higher corrosion resistance than 7000 series alloys. A19021 has better ductility than other common Al superalloys. These alloys above involve multiple strengthening mechanisms, i.e., Mg solid solution strengthening, super fine strengthening, and $\mathrm{Al}_{2} \mathrm{O}_{3}, \mathrm{MgO}$, and $\mathrm{Al}_{4} \mathrm{C}_{3}$ dispersion strengthening.

\subsubsection{ODS Cu-based Superalloys}

The first ODS Cu-based superalloy was $\mathrm{Cu}-\mathrm{Al}_{2} \mathrm{O}_{3}$ produced by internal oxidation processing in the 1970s by SCM company.Al2O3 was added to the ODS Cu-based superalloy to improve the high fracture strength and low processing cost. And the $\mathrm{Al}_{2} \mathrm{O}_{3}$ particle in the matrix is usually small. The $\mathrm{Cu}-\mathrm{Al}_{2} \mathrm{O}_{3}$ can be produced by using several routes which include the mixing of $\mathrm{Cu}$ and $\mathrm{Al}_{2} \mathrm{O}_{3}$ powder followed by casting, such as the Comalco process [29], and internal oxidation of $\mathrm{Cu}-\mathrm{Al}$ alloy powders [30] followed by consolidation.

\subsubsection{ODS Co-based Superalloys}

Most of the Co-based superalloys have a low forgeability because they contain more carbon than other superalloys. And these carbons would form carbides in superalloys which impairs the forgeability [31]. $\mathrm{Y}^{\prime}$ precipitates also strengthen ODS Co-based superalloy. Also, the added oxide particle play as a secondary phase would improve the medium and high-temperature strength of ODS Co-based superalloys [31]. When the ODS Co-based superalloy is working at medium temperatures, the $\gamma^{\prime}$ precipitation is treated as more useful to strengthen the alloy. However, the oxide dispersion enhances the high-temperature mechanical properties due to the thermal stability of oxide particles. It is generally accepted that the components of $\mathrm{Al}$ and $\mathrm{W}$ in Co-Al-W alloy can hardly dissolve into Co matrix except at high temperature [31].

\subsection{Fabrication Techniques of ODS Superalloys Powder}

\subsubsection{Mechanical Alloying (MA)}

The MA process is a technique that combines two different or more powders into a high energy ball milling machine to obtain fine-grained powders [sy dashu]. In the initial stage of MA, the base powders are mixed with other raw elemental powders and blended in stainless steel jars or ceramic jars that contain different sizes of balls. Figure 2-1 shows the early stage of MA processing, and the powder particles are relatively soft before plastic deformations. The ball to powder ratio is usually in the range of 1:10 1:20. The powders are sealed in the jars with Argon or Nitrogen gas to prevent oxidation during the process, and the jars are placed and rotated on a horizontal or vertical level. 


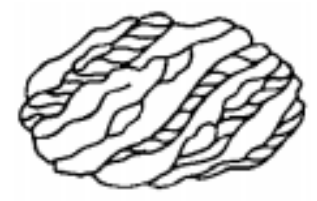

Lamellar structure

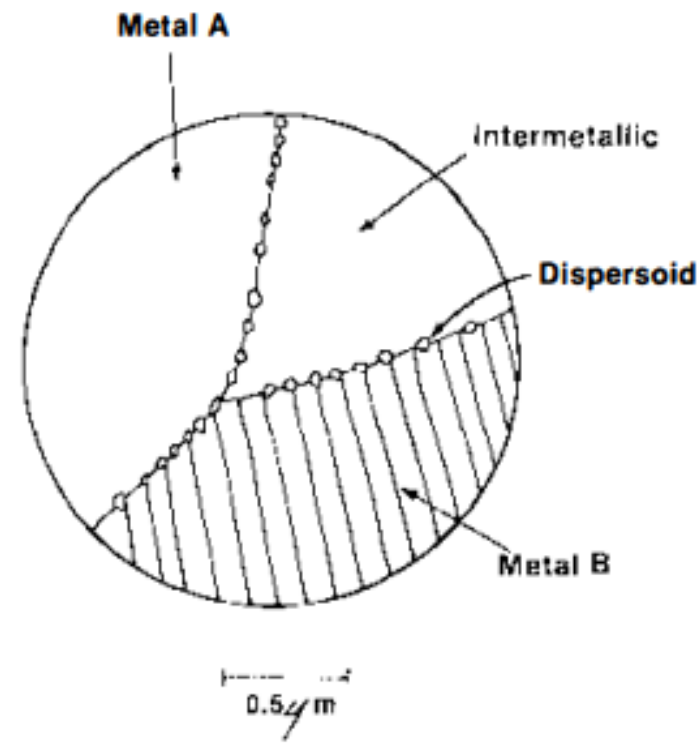

Figure 2-2. A schematic of mixture powders in the early stage of the MA process [32].

The powder particles are impacted and crashed by the balls, in such way, compression, impaction, break-down, cold welding and extrusion might happen among powders, balls, and walls of jars. The powder particles are subjected to intense plastic deformation when they are under break-down and extrusion. Thus, the surface area of powder particle enlarges, thereby results in the appearance of atomized surfaces of metals. The surfaces are clean and fresh, and they are bonded to each other under cold welding and compression which leads to lamellar structures existing in particles. They tend to deform and grow when the grinding hour increases, work hardening of powder particles happens. Larger particles will have cracks and be broke apart. The processing tends to arrive equilibrium stage, so the size distribution of powder particles is narrow.

For ODS Ni-based superalloy, the raw elemental powders are still distinguishable in the early stage. However, the oxide dispersoid is distributed into matrix powders. In addition, the oxide dispersoid is dispersed along the welding surfaces and adjacent powder particles (Figure 2-2). Cold welding and breaking keep repeating during the processing, which results in the refinement of matrix powders and the exposure of fresh unreacted powder particles. It observably increases the contact area between particles, decrease the diffusion range of metal atoms and increase the diffusion coefficient. Generally, the MA process is dominated by solid diffusion. Because high-density crystal defects emerge during the process, thus providing a thermal driving force, to actuate the metal atoms diffuse and grow along the free surface of crystals, grain boundaries and lattice until the raw components deplete to form alloys [11]. Figure 2-3 shows a schematic of a schematic of powders in the final stage of the MA process. The dispersion was coated onto the surface on metal A and metal B. And metal A and metal B were interrelated. 


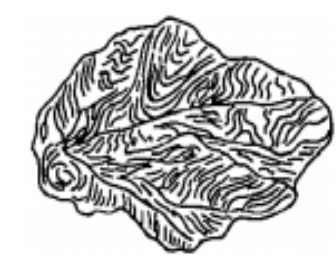

Lamellar structure

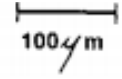

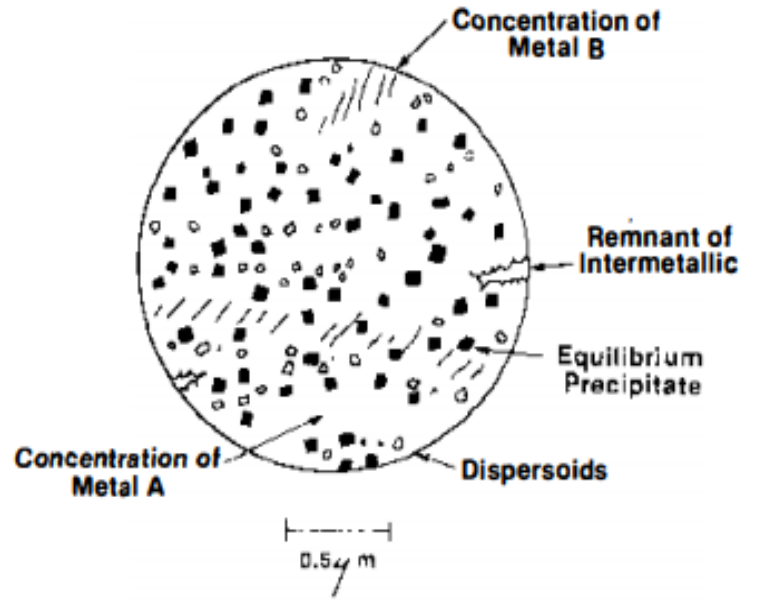

Figure 2-3. A schematic of mixture powders in the final stage of the MA process $[11,32]$.

This technique usually requires a long duration to achieve alloyed powders. According to published results, the MA process requires 10 70 hours for most of common ODS superalloys [14]. Figure 2-4 shows the morphologies and shapes of the MA processed powder particles. As indicated by the red circle in Figure 2-4, the lamellar structure of MA processed powders is clear shown (refer to Figure 23 ). And the powders are in irregular shapes. Usually, the particle size range of mechanical alloying is $20 \sim 45 \mu \mathrm{m}$ which is narrow. Lamellar structures of particles were observed, suggesting powders were under cold-welding and fracture during the process.

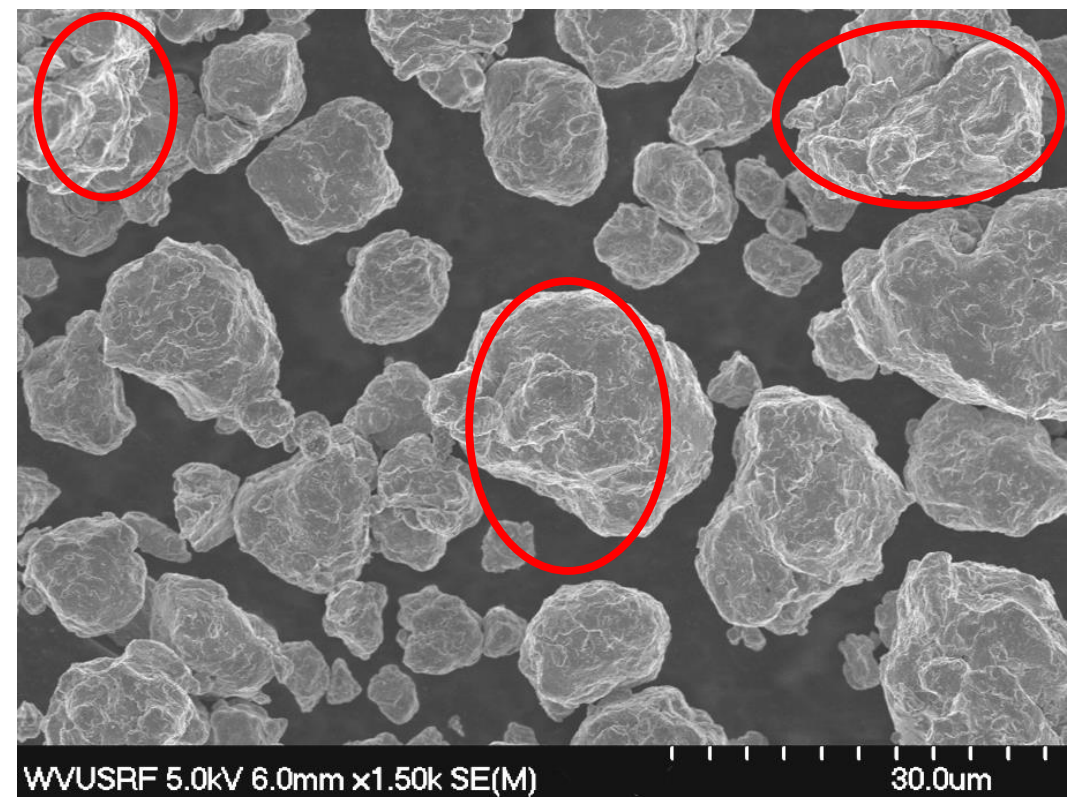

Figure 2-4. An SEM picture of powders under ball milling 400 rpm 41 hours. 


\subsubsection{Mechano-Chemical Bonding (MCB)}

The MCB processing is a dry complex mechano-chemical technique for applying mechanical energy to different material particles to cause a mechanochemical interaction between particles. The advantage of the MCB process is that it is a process by only using the internal mechanical energy without using any binders comparing to the BM process. The BM process usually adds a processing control agent to the powder to boost the MA effect. The solid solution may form during the process, i.e., smaller particles may diffuse onto or through the hosting particles. In principle, the MCB technique takes the advantages of passing dry powder mixtures with preferred particle size ratios through a narrow gap, so that smaller guest particles are bonded and coated onto the surface of larger core particles under the influences of various types of mechanical forces [14].

This instrument is capable of producing Ni-based and Fe-based ODS superalloy powders. The MCB machine is composed of three parts: Control panel, Motor Box and Main Vessel. As shown in Figure 2-5, the main vessel contains a rotor and blades with press heads. The powder mixture could be imported through the feeding port. The rotor and blades rotate at high speeds when the machine is working. As shown in Figure 2-6, a powder casing may form during the process, and the rotating speed of MCB could be up to 6000 Revolutions per Minute (rpm). When the blade and rotor are rotating, and the press head is passing through, the powder particles are under compression and friction, and the particle casing might migrate along the rotation direction which both will cause short local temperature spikes between the powders, i.e., at the contact points of powder particles. Thus, the powder particles are under plastic deformation.

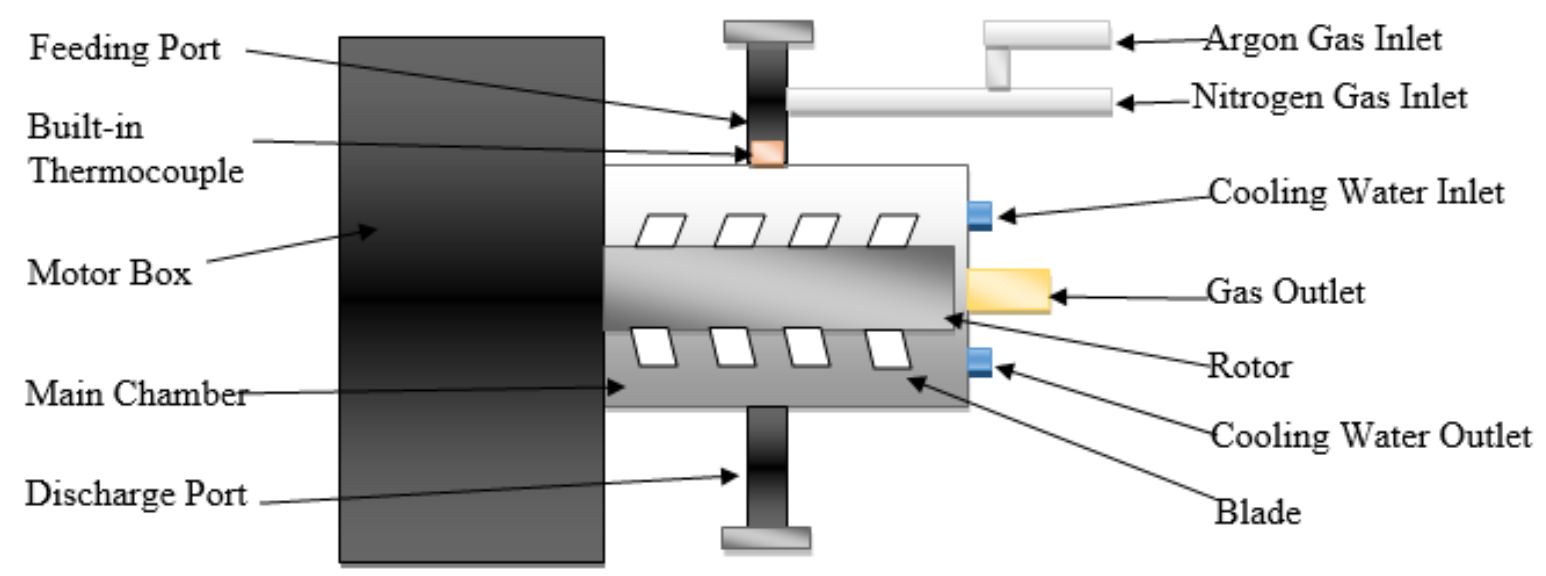

Figure 2-5. A schematic of the MCB machine. 

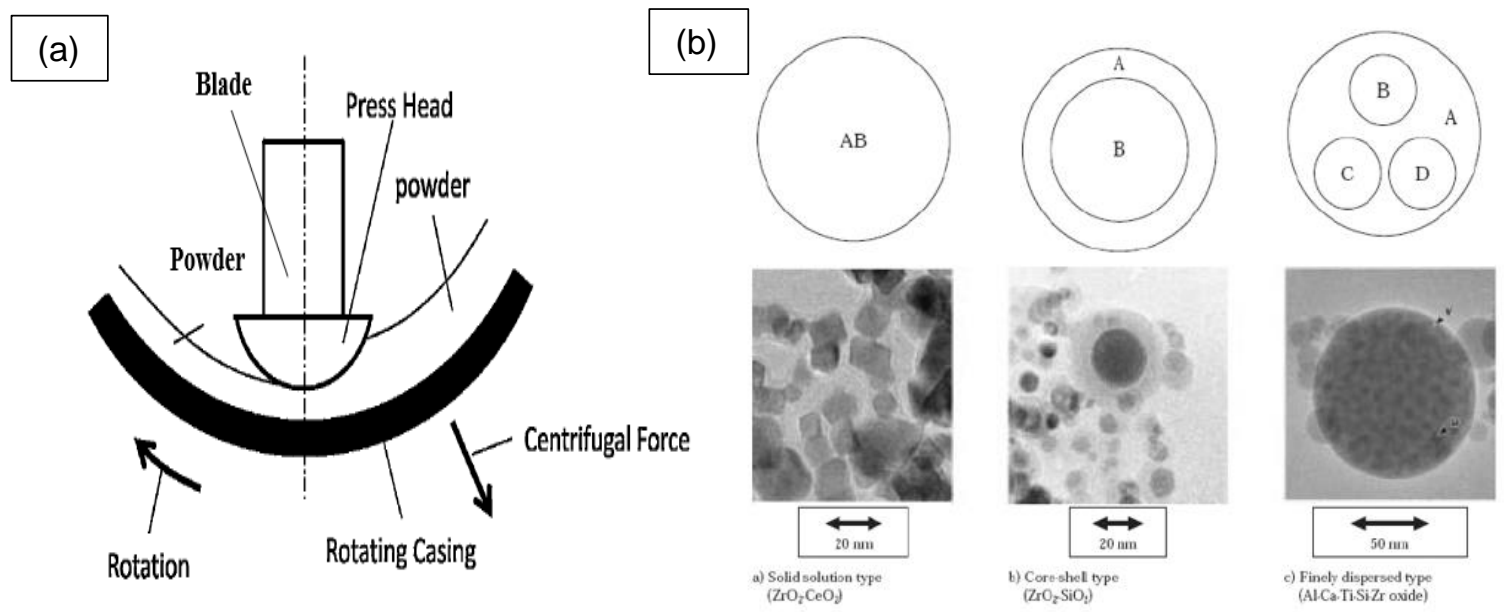

Figure 2-6. The principle of the MCB process: (a). A schematic of the main inner vessel; (b). Structural patterns of nanocomposite particles [33, 34]

By applying the MCB treatment, powders can achieve particle coating, precision mixing, sphericalization, and surface modification in one processing step [26]. Figure 2-6 (b) shows the basic principle of structural patterns of nanocomposite particles processed by the MCB process. It is noted that pattern is similar to the final stage of the BM process. In the final stage of the BM process, the element $A$ and element $B$ were interrelated with each other, and the dispersoids were coated onto the surface of element $A$ and element $B$. While for the MCB process, it could achieve the interrelation of element $A$ and element $B$, or the coating from $A$ onto the surface of $B$, and even coated on the surface of other major particles such as element $C$ and element $D$. The coating is depending of the selected size of each added element.

In this research, the MCB processing provides a unique way to produce ODS Ni-based Superalloy powders with the composition of Ni-20Cr-5Al-3W$1.5 \mathrm{Y} 2 \mathrm{O} 3$ (in wt. \%) through a drying processing without using any binders or introducing any contaminations. Although, individually, there are various types and sizes of ODS superalloy powders fabrication methods. Separately, however, the MCB processing has three significant advantages:

I). Shapes of particles: The MCB processing could achieve particle coating, precision mixing, sphericalization, and surface modification, in such way powder particles would come out with high roundness that could be up to the degree of 0.93 . Figure 2-7 shows the powder particle morphologies after MCB processing. 


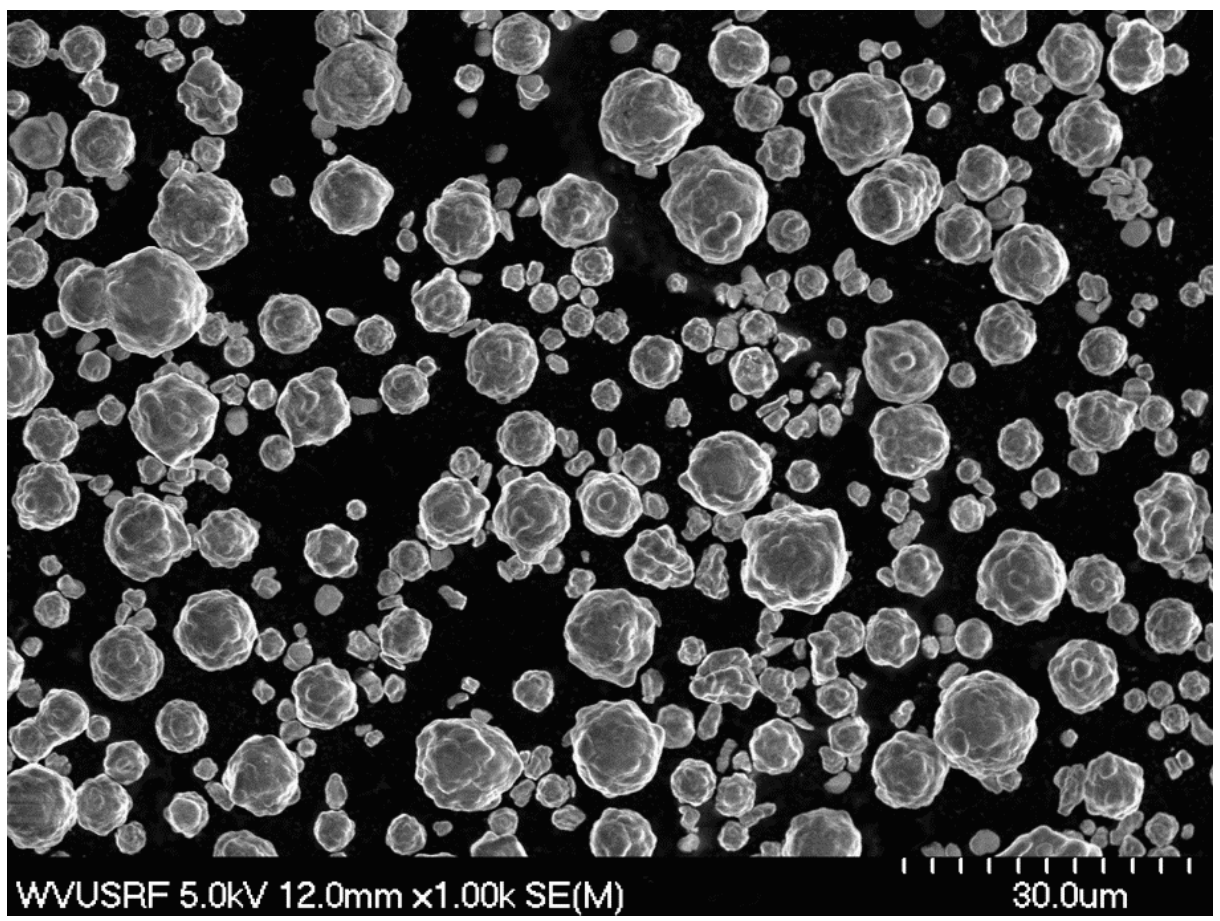

Figure 2-7. An SEM picture of powders under MCB processing 5000 rpm 11 hours.

I). Uniform distribution of $\mathrm{Y}_{2} \mathrm{O}_{3}: \mathrm{Y}_{2} \mathrm{O}_{3}$ could be evenly distributed onto the hosting particles as a coating to form solid solution through surface diffuse. It is also possible to create other alloy phases and different microstructures. For the currently available MA process, $\mathrm{Y}_{2} \mathrm{O}_{3}$ could be diffused onto the hosting particles, but it is difficult to achieve uniform distribution since MCB has precision mixing, sphericalization, and surface modification. For the current available Atomization, since $\mathrm{Y}_{2} \mathrm{O}_{3}$ or other oxide dispersion has a high melting point, Atomization could only achieve up to $1700{ }^{\circ} \mathrm{C}$. $\mathrm{Y}_{2} \mathrm{O}_{3}$ will be difficult to melt and form a composite with other content. However, according to published results (As shown in Figure 2-8) [35], MCB is capable of distributing and coating $\mathrm{Y}_{2} \mathrm{O}_{3}$ at lower temperatures. Figure 2-7 (a) shows a roughly $25 \mathrm{~nm}$ thin film coating in lighter contrast coated onto the hosting particles in darker contrast ( $\mathrm{Ni}$ and $\mathrm{Cr}$ in this study), 2-6(b) implies that the thin film coating is amorphous $\mathrm{Y}_{2} \mathrm{O}_{3}$ [35]. 

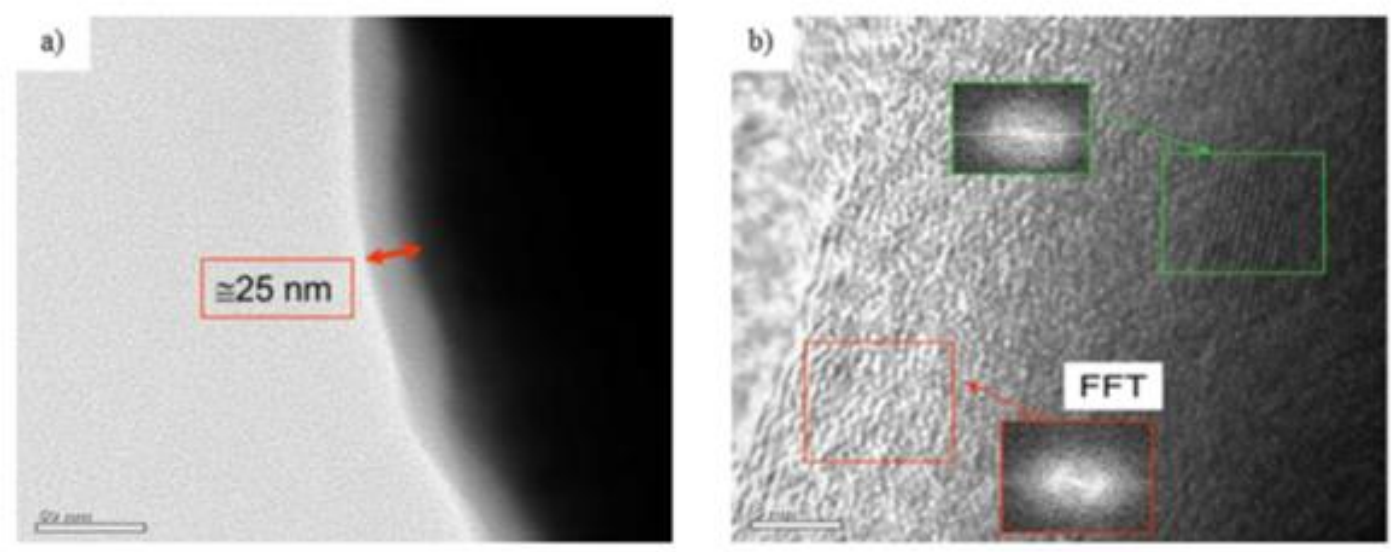

Figure 2-8. TEM images of MCB processed ODS Ni-based superalloy powders (a) TEM BF image, (b) HRTEM image [35].

II). Forming alloys: The MCB process has the capability to pre-alloy the powder mixture. As shown in Figure 2-9, the XRD analysis shows that the y matrix (NiAl phase) exists. In addition, the absence peak of $\mathrm{Y}_{2} \mathrm{O}_{3}$ indicates that $\mathrm{Y}_{2} \mathrm{O}_{3}$ is uniformly distributed and coated as an amorphous coating onto hosting particles.

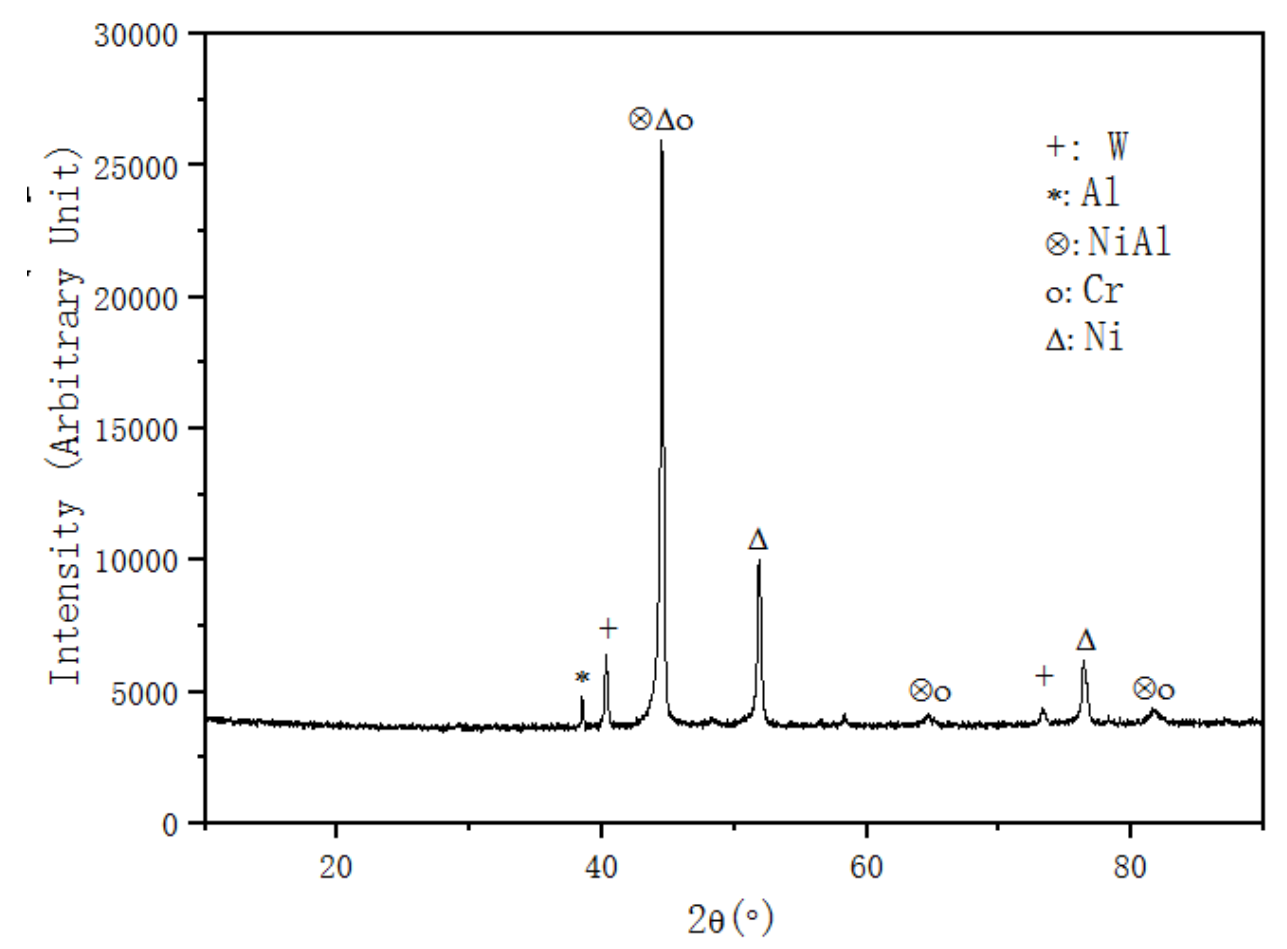

Figure 2-9. An XRD analysis of powders under MCB processing $5000 \mathrm{rpm} 11$ hours. 


\subsubsection{Atomization}

Atomization is a process that uses the principle of low mechanical strength of liquid metal to break apart liquid metal droplets. It is easier to break the molten metal droplet than when it is solid. High-pressure gas (i.e., $\mathrm{H}_{2}$, air, and inert gases) or solution (i.e., Water and Oil) is adapted to be sprayed at high speeds on liquid metal droplets to force the metal to solidify in a high cooling rate. The solidified metal particle is spun and filtered by ordinary rotation. Atomization processes are capable of producing high-quality metal powders, such as $\mathrm{Ni}, \mathrm{Fe}$, and $\mathrm{Al}$ superalloys with uniform particle distribution and spherical shapes.

Atomization is a two-step process. First, shearing of liquid metal occurs; second, freezing of liquid droplets takes place. In the first step, a relatively large volume of liquid is sheared into smaller liquid particles. The energy needed for shearing is supplied by such sources as high-velocity gas jets, water jets, centrifugal action, and by plasma jets [advance GA processing for Ti and Ti Alloy powder manufacturing]. Major Atomization processes are Gas Atomization (GA) and Water Atomization (WA).

\subsubsection{Gas Atomization (GA)}

GA is a conventional and widely used method for metal powder production. As shown in Figure 2-10, GA uses inert gas jets to atomize molten metal powders into fine droplets, which cools down as the droplets drop in the chamber and form spherical powders with uniform size distribution. During the GA process, the molten metal is atomized thanks to inert gas jets into fine metal droplets which cools down during their fall in the atomizing tower. And pre-alloyed powders form.

GA is widely used in metal powder metallurgy and is capable of producing spherical and uniform structured superalloy powders (As shown in Figure 2-10a), the known highest melting temperature that GA could achieve is around $1700{ }^{\circ} \mathrm{C}$ which is lower than the melting temperatures of most of the oxides. The low melting temperature of the GA process introduces the difficulties of adopting GA to produce ODS superalloy powders, i.e., $\mathrm{Y}_{2} \mathrm{O}_{3}$ could not be uniformly distributed into the matrix metals since it has a higher melting point $\left(2425^{\circ} \mathrm{C}\right)$ and it would not be melted in the first step. However, post-processing and alternation usually are introduced after gas atomization in order to achieve ODS superalloy powders. Conventionally, gas atomized powders are mechanically alloyed post process with $\mathrm{Y}_{2} \mathrm{O}_{3}$ in order to obtain uniform oxide dispersion and monocrystalline microstructure [14]. 


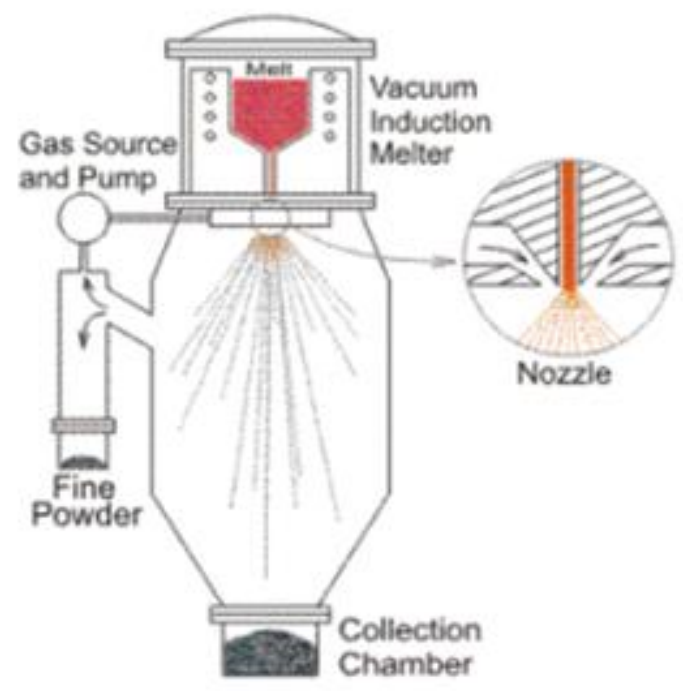

Figure 2-10. A schematic of a gas atomization process [https://www.lpwtechnology.com/technical-library/powder-production/]
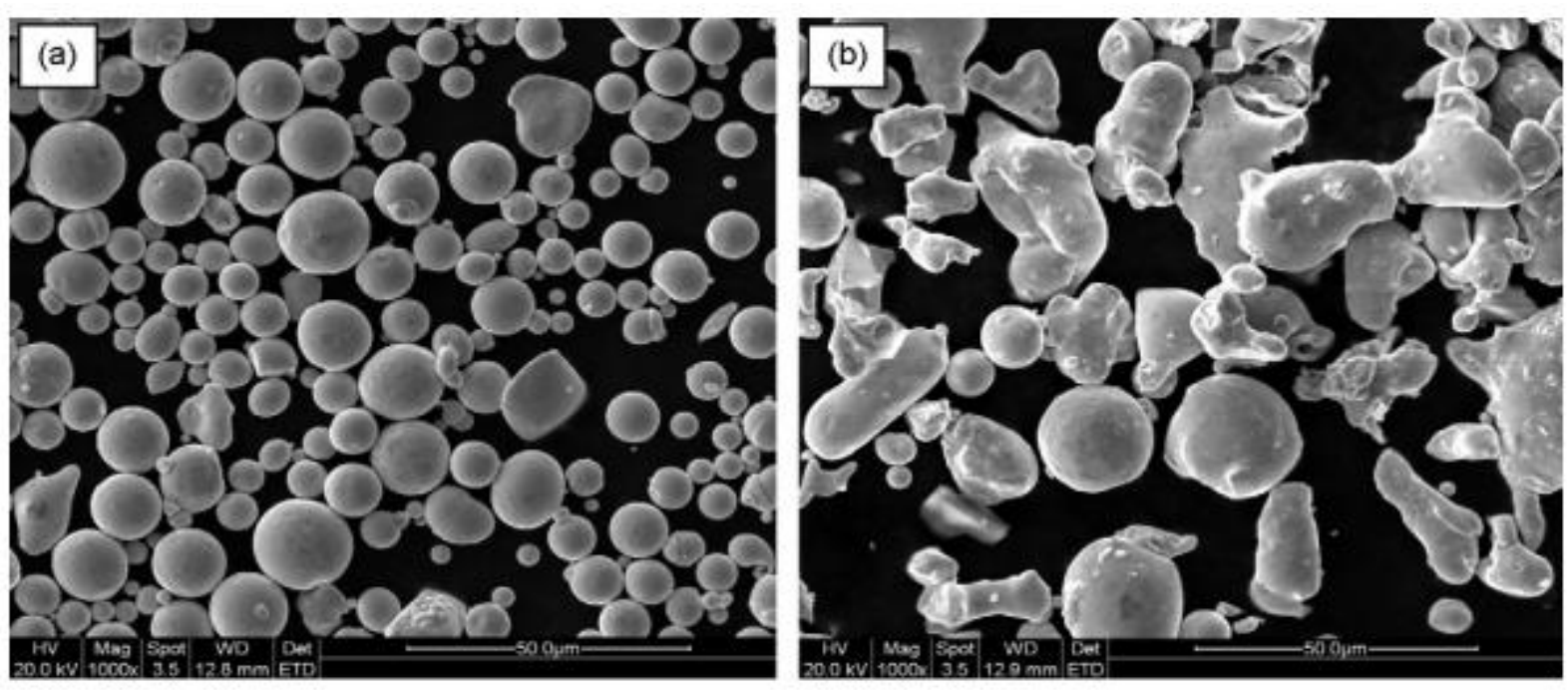

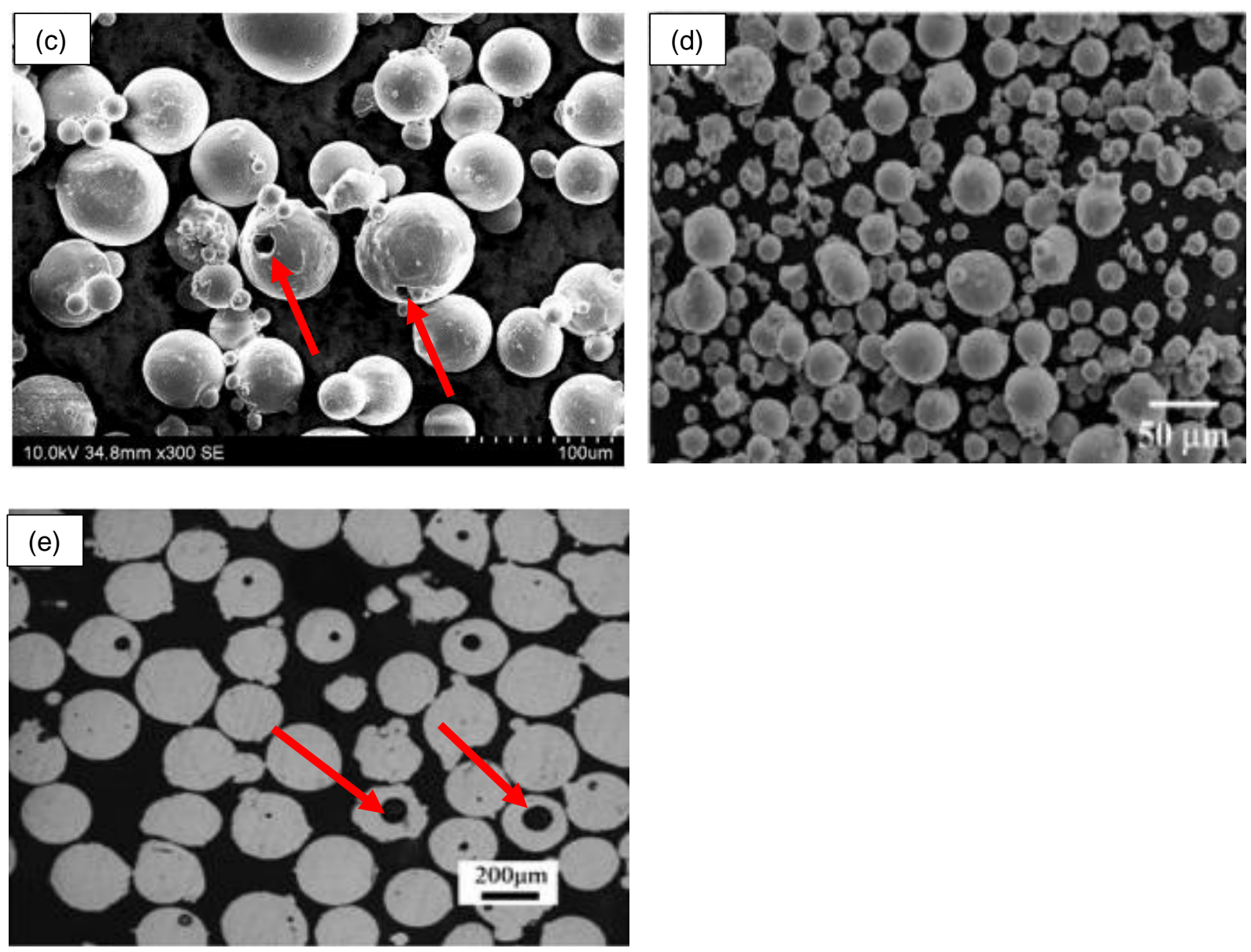

Figure 2-11.SEM images showing characteristic morphologies of as-produced atomized powder: (a). Gas atomized316 stainless steel [36]; (b). Water atomized 316 stainless steel [36]; (c). Gas atomized Ti-6Al-4V [37]; (d). Gas atomized IN718 [38]; (e). Cross sections of gas atomized IN718 [38]

In addition, there are pores trapped inside the GA particles during the solidification as shown in Figure 2-11 (c) and (e) (indicated by red arrows). Narra et al. have found that pores inside of the particles would affect the density and microstructure of AM as-printed samples [39]. A reactive gas atomization synthesis method to produce Fe-based ODS superalloy powders was published by I.E Anderson et al. [12]. The surface of gas atomized particles was oxidized at an elevated temperature by utilizing MA to obtain uniform oxide dispersion. Figure 212 demonstrates the presence of the oxide dispersoid during all stages for the aforementioned reactive gas atomization process. It is evident from the XRD plot of the as-atomized powder, and the hot isostatic pressed (HIP) powder does not show oxide dispersoid formation until after heat treatment at $1200^{\circ} \mathrm{C}$ [12].

It is noted that $\mathrm{Y}_{2} \mathrm{O}_{3}$ was coated as an amorphous thin film onto the hosting particles, and the XRD result of MCB powders confirms that. Even though the absence of $\mathrm{Y}_{2} \mathrm{O}_{3}$ peak of the reactive gas atomized powders is apparent, no 
evidence has shown that $\mathrm{Y}_{2} \mathrm{O}_{3}$ was evenly distributed into the matrix. $\mathrm{Y}_{2} \mathrm{O}_{3}$ did not appear until HIP and heat treatment. Besides, heat treatment will alter the strengthening phase of powders. Alternation is still required which is timeconsuming. Moreover, the formation of the dispersoids did not appear until further heat treatment of the atomized powders, which in turn will cause coarsening of the grain size. However, the MCB process excels in the production of ODS superalloy powders with uniformly distributed oxide dispersoid without extra processing.

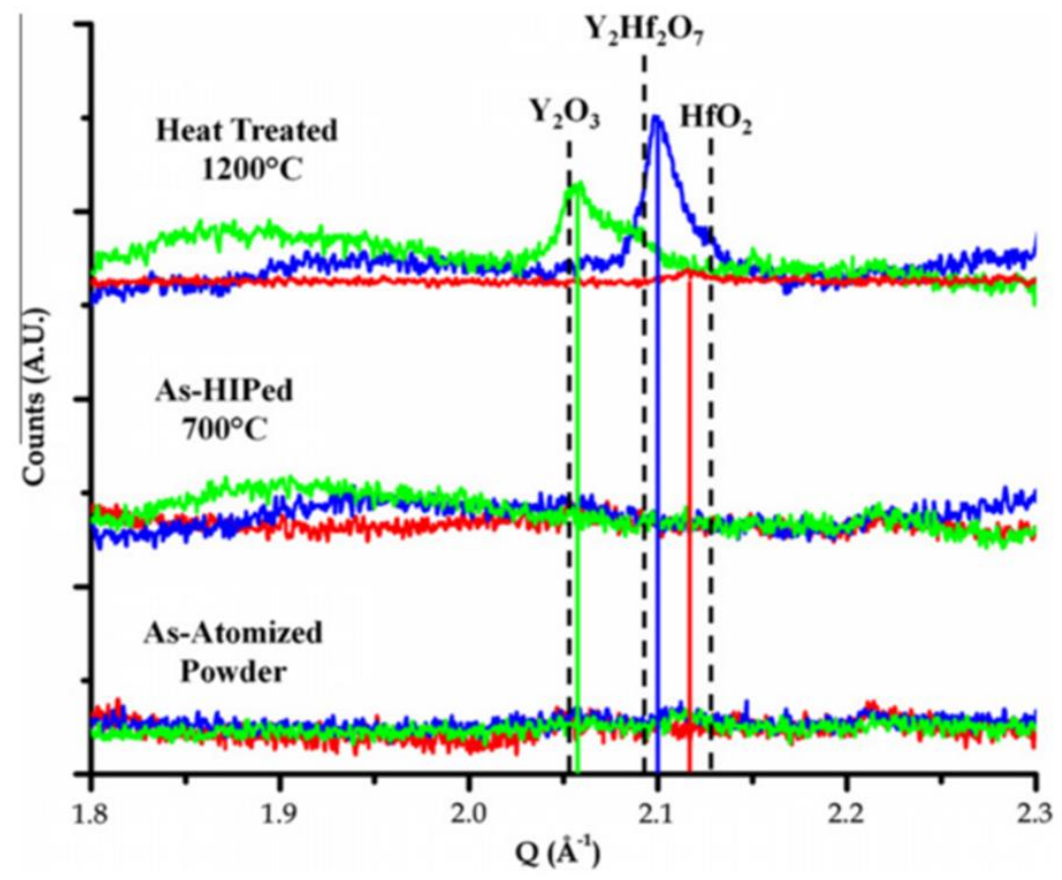

Figure 2-12. XRD data revealing dispersoid formation after heat treatment of powders under different chemical compositions [12]

\subsubsection{Water Atomization (WA)}

This technique uses water jets to atomize the molten metal (Figure 2-13). The metal is melted in a furnace in the first step and poured into a tundish. The resulting metal stream is blown out in a fine jet while water from a high-pressure pump blows until the metal becomes atomized. The resulting powder is dried and classified for particle size depending on its intended usage [40]. 


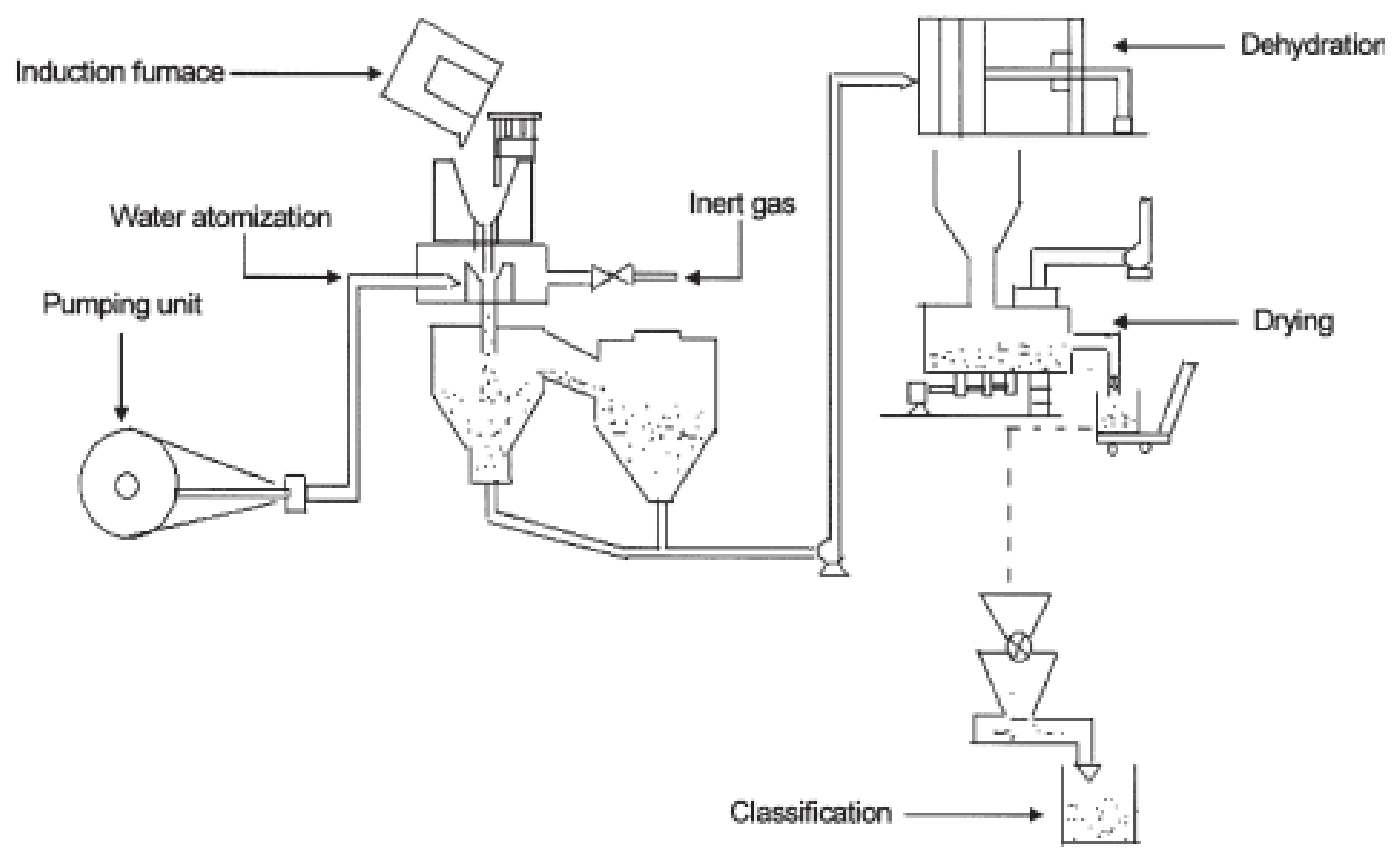

Figure 2-13. A schematic of a water atomization process [40]

WA is similar to GA which is also capable of producing high-quality metal powders, such as $\mathrm{Ni}$, Fe, and Al superalloys with uniform particle distribution. But Figure 2-11 (b) shows that the shape of WA particles is not perfectly spherical with some irregular shapes. And the difficulties of using WA to produce ODS particles still exist.

\subsubsection{Surface Oxidation}

Surface Oxidation is a method that obtains oxide dispersion through oxide thin film which exists on the surface of particles. Compression and extrusion usually are employed after surface oxidation to produce ODS superalloy. Irmann et al. adopted surface oxidation to produce sintering Al. Flaky Al powders were chosen to form a $0.1 \sim 0.2 \mu \mathrm{m}$ thin film on the surface of Al powders. The oxidized Al powders are then compressed and extruded to break apart the oxide film and blend it into the matrix in order to obtain powders with evenly distributed oxide dispersions [9].

\subsubsection{Internal Oxidation}

The internal oxidation method is designed according to the principle of preferential oxidation of solute elements in dilute solid solution. Hence, this method requires that the solute elements have a higher free energy of formation of an oxide with oxygen than the solvent elements. The typical dispersion strengthened alloy fabricated by internal oxidation is $\mathrm{Cu}-\mathrm{Al}_{2} \mathrm{O}_{3}$ alloy. $\mathrm{Cu}$ and $\mathrm{Al}$ were first melted into metal liquid and then atomized to powder forms, and the atomized powders were then mixed with oxidant and heated at 1073 1223 K to utilize internal oxidation. 
During this processing, the decomposed oxygen from the oxidant reacts with $\mathrm{Al}$ since $\mathrm{Al}$ is more reactive than $\mathrm{Cu}$. The extra oxygen was then drained from the system. Hence, ODS Cu-based superalloy powders were produced with distributed $\mathrm{Al} 2 \mathrm{O} 3$ [30].

\subsubsection{Co-precipitation}

Co-precipitation is a methodology that utilizing chemical reaction to obtain ODS. A mixed solution is made with nitrate, ammonium carbonate, ammonium nitrate, and oxide gel to form a metallic oxide on oxide particles. The mixture is then filtered, washed, dried, ball milled and dehydrogenized to achieve ODS superalloy powders. DuPont company has produced ODS Ni-based superalloy by using this method:

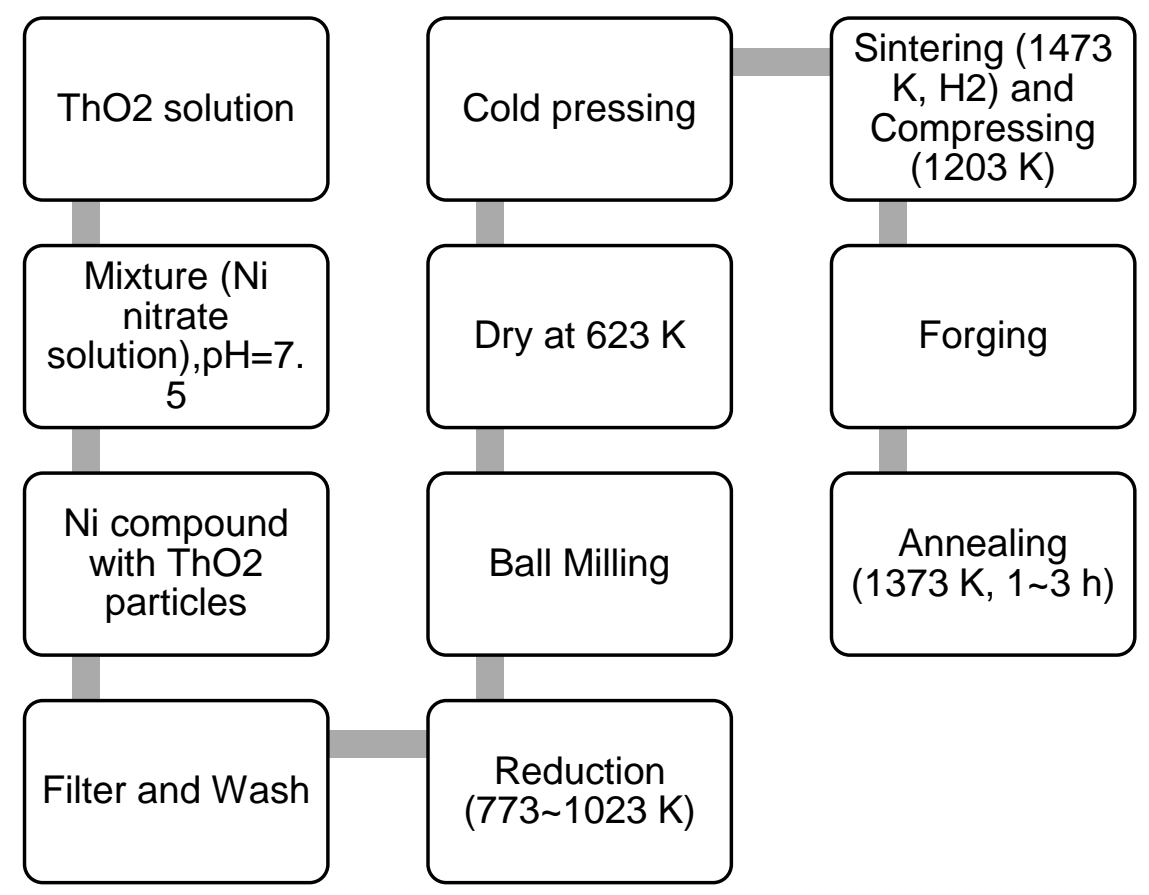

Figure 2-14. A craft routine of the fabrication of TD-Ni [10]

\subsubsection{Mechanical Mixing}

Mechanical Mixing is using a roller mixer, a ball milling machine, and a rotating arm mixer to mix matrix metal powders with oxide particles through a dry or wet processing. This method has limitations: when the size of matrix particles and oxide particles have big difference, bigger particles tend to float, and smaller particles tend to sink during the mixing. Especially, when the oxide particle is nanosize, agglomeration would happen between oxide particles. 
In summary, all these methods above could fabricate ODS superalloy powders with different mechanical properties, sizes, morphologies, and shapes. In order to obtain densified ODS superalloys, powders produced by these methods could be subjected to sintering, cold pressing, extrusion, hot isostatic pressing and spark plasma sintering. However, in this research, the aim is to develop fine ODS Ni-based superalloy powders for AM which is a novel and under-developed technique. Even though Atomization is the principal and widely used technique for producing superalloy powders, the difficulties of fabricating ODS superalloy powders still exist comparing to BM and MCB.

\subsection{AM Techniques}

AM is the latest manufacturing technique that has high degree-of-freedom and allows product customization. To be specific, AM is defined as "a process of joining materials to make objects from 3D model data, usually layer upon layer, as opposed to subtractive manufacturing methodologies", referred from ASTM's definition. Since there are several ways to deposit materials and different energy sources (laser and electron beam) can be chosen, the systems are categorized into three different types according to the material feeding: powder bed systems, powder feed systems, and wire feed systems [41].

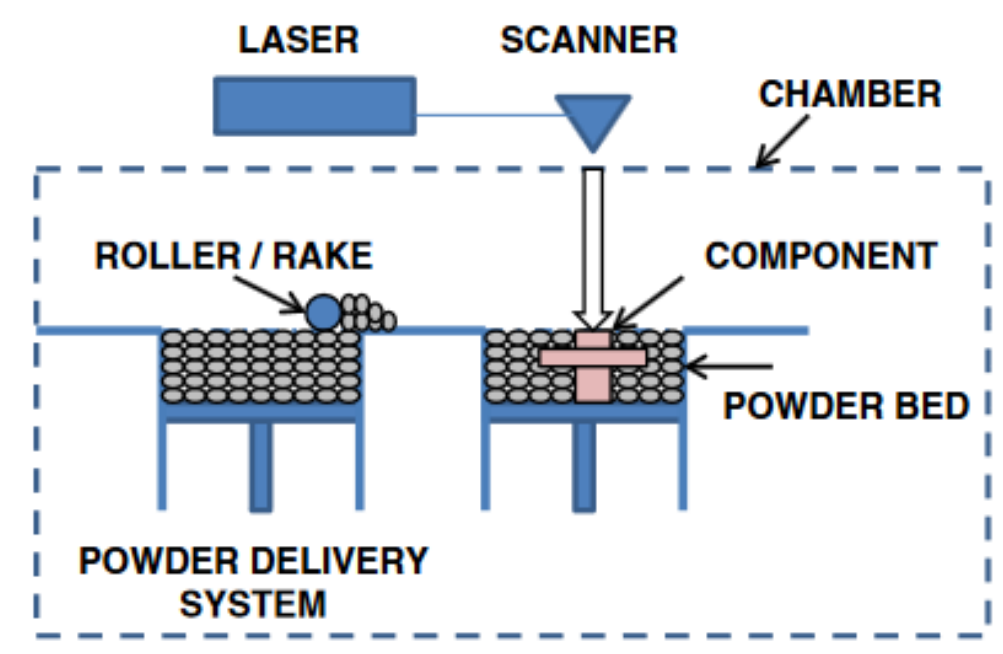

Figure 2-15. A schematic of a general powder bed system [41]

\subsubsection{Powder bed systems}

Powder bed systems typically have lower unit build volumes which are smaller than $0.03 \mathrm{~m}^{3}$. Figure 2-15 shows a schematic diagram of a typical powder bed system. A roller rakes powder from the reservoir across the work area. The energy source is then delivered to the surface of the bed, and the powder is either melted or sintered into a desirable shape. By repeating the process of racking and melting/sintering, a 3D solid is formed. The workpiece of powder bed systems has higher resolution features so that the dimension of the work piece can be produced 
precisely. The most prevailing powder bed system is the EOS M290, which has been fully commercialized and widely applied in many top notch industries for customizing tool parts and for some research purposes [36].

\subsubsection{Powder feed systems}

Instead of racking a layer of material powder by a roller, powder feed systems utilize a nozzle to convey powders onto the build surface of the workpiece. The energy source melts a monolayer or more of the powder into the shape desired, and a 3D solid is formed by repeating the process (Figure 2-16). There are two types of feeding system that either the workpiece remains static and the energy source/powder nozzle moves, or work piece moves while the energy source/powder nozzle fixed in a position. The powder feed systems have a larger build volume, Optomec450 LENS (Laser Engineered Net Shaping-LENS) as an example, which has $1.2 \mathrm{~m}^{3}$ build volume. Also, powder feed systems can be utilized to refurbish and repair damaged part of the workpiece. LENS is the most popular direct energy deposition AM process for powder development and testing. Thus it is suitable for research applications.

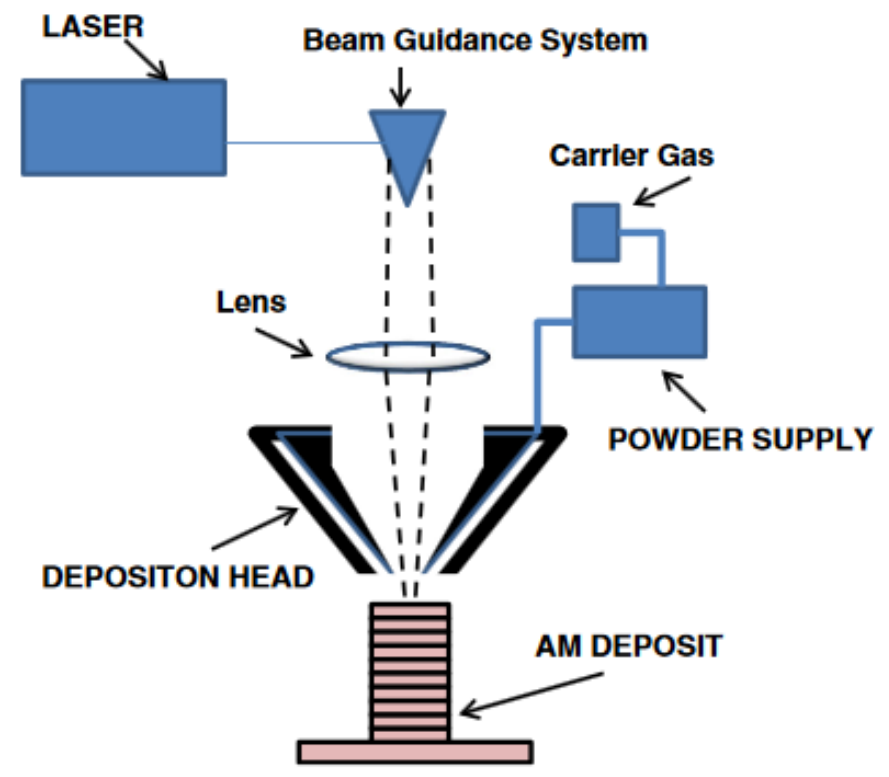

Figure 2-16. A schematic of a general powder feed system [41]

\subsubsection{Wire feed systems}

Wire feed systems can use plasma arc as energy source besides electron beam and laser. At first, a single bead of material is deposited and upon subsequent passes is built upon to develop a 3D structure. Although wire feed systems have a high deposition rate, the extensive machining and polishing are required. 


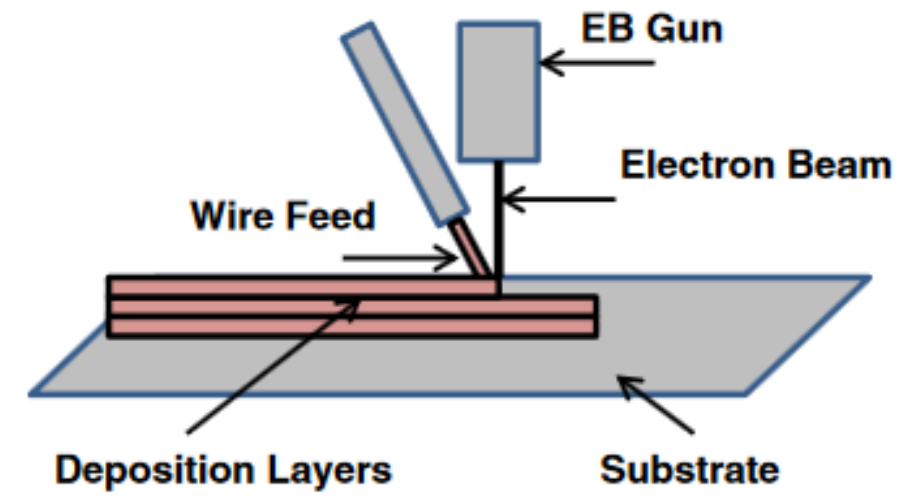

Figure 2-17. A schematic drawing of a general wire feed system [41]

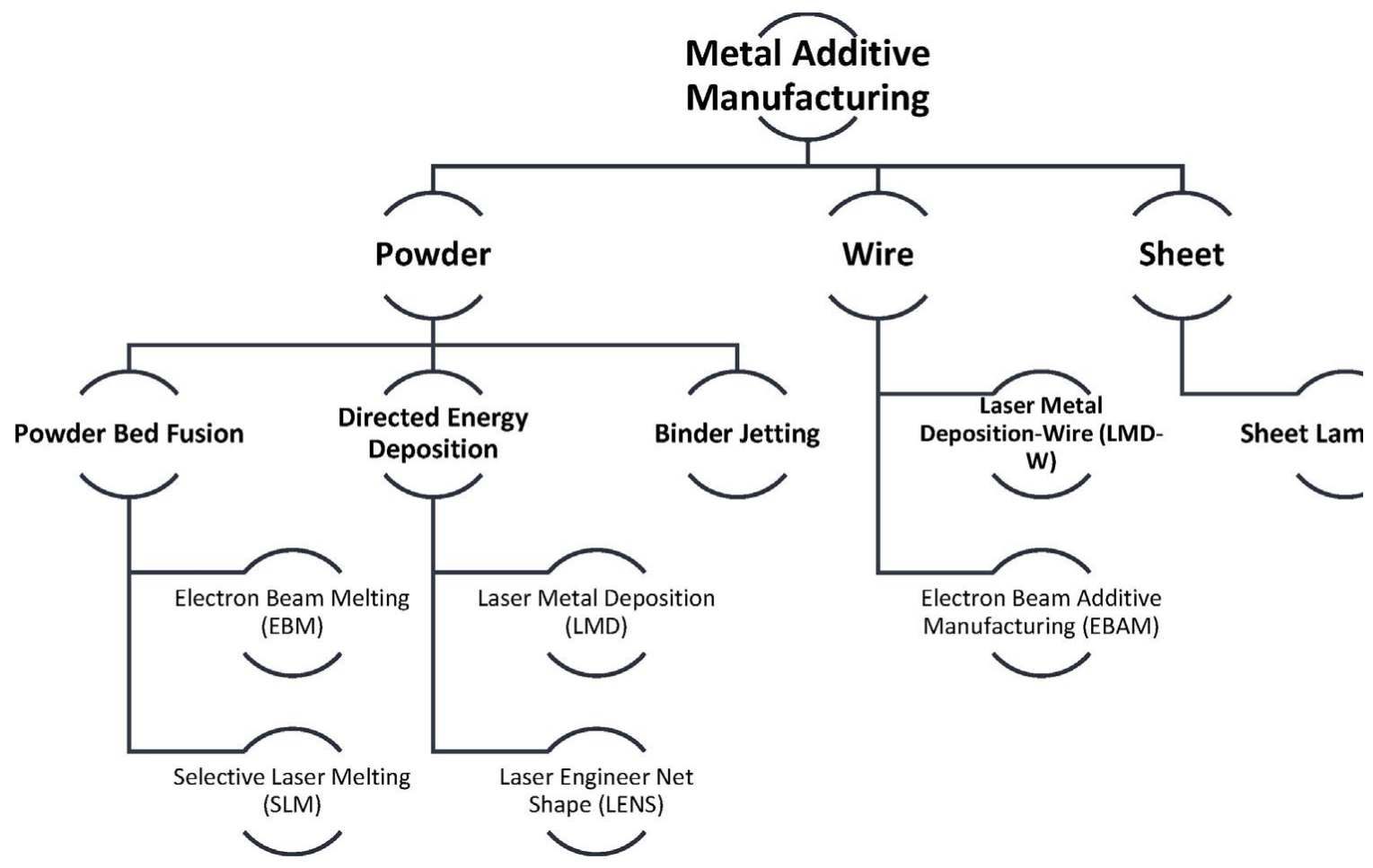

Figure 2-18. Metal AM processes [16]

The overall metal AM processes are all summarized in Figure 2-18. Besides the three widely utilized AM processes mentioned above, there are some other metal powder deposition methods, for instance, the binder jetting that uses an organic binder to coagulate the metal powder together and cures in the oven to form a green body that is ready for sintering in the next step. The critical challenge for binder jetting is the shrinkage of sample dimension after sintering process (up to $40 \%$ length shrinkage). 
On the other hand, an electron beam is another energy source that can reach $\sim 60 \mathrm{~kW}$, which is superiorly higher than laser beam $(450 \mathrm{~W})$. The electron beam could provide sufficient energy for metal powder to melt and form desirable microstructures with faster scanning speed. The downside is the electron beam system needs to be operated in a vacuum. Thus, electron beam melting is less widespread than laser melting due to its high requirement in vacuums.

Selective laser melting (SLM) is another prominent powder bed AM technique that has higher precision and has better as-built surface quality with compare to electron beam and LENS. It has been fully commercialized (EOS Company) and becomes the leading technology in AM. The only restriction for the SLM is the size requirement of metal powder, which is lying in a narrow range between $40 \mu \mathrm{m} \sim 60 \mu \mathrm{m}$, and spherical in morphology. The purpose of setting this restriction is to ensure the powder bed has high packing density, and the GA processed powder is the only way to provide the desired powder size and morphology. Other powder processes, such as the BM process, has very few reports in SLM application. However, another type of AM technique called Laser Cladding (LC) has a higher tolerance for powder shapes and sizes. The input energy of LC is much higher than LENS, and it is widely used in the industry. The objective in LC is to fuse an alloy layer or coating, onto the surface of a substrate.

In accordance with above, LENS system and LC are two appropriate candidate AM techniques ore this study:

I). Higher tolerance with powder size and morphology

II). requirement in a vacuum environment

III). The processing parameters control determines the density of the printed sample.

In summary, LENS system and LC are suitable for metal powder development for AM, and in this thesis, the ODS powder processed by MCB-only and its combined technique (MCB+BM) was utilized. 


\section{CHAPTER 3: THEORETICAL BACKGROUND}

\subsection{Strengthening Mechanisms of ODS Ni-Based Superalloys}

\subsubsection{Dispersion Strengthening}

Dispersion strengthening is a mechanism that adding chemically stable secondary or ternary phase particle into matrix metals to strengthen alloys. Secondary phase particles are artificially added into the matrix, they are uniform, fine, thermally stable and chemically stable and are capable of pinning dislocation, grain boundaries, and sub-grain boundaries. The secondary phase particle is also sufficient to inhibit the migration and movement of dislocations and prevent grain from growing. Therefore, the mechanical properties of alloys are enhanced.

Although secondary phase particles could improve the mechanical property, they could also weaken the ductility and breaking resistance. Secondary phase particle usually has high melting points which enable dispersion strengthened metals to have high yield strength, tensile strength, creep resistance and abrasive resistance. The working temperature of dispersion materials could be up to $0.8 \sim 0.9 \mathrm{Tm}[42]$.

The theory of dispersion strengthening is the theory of dislocation. The effect of secondary phase particle mainly depends on the pinning of dislocations by the secondary phase particle. Common secondary phase particle is refractory Oxides (i.e., $\mathrm{Y}_{2} \mathrm{O}_{3}, \mathrm{Al}_{2} \mathrm{O}_{3}, \mathrm{HfO}_{2}$, and $\mathrm{ThO}_{2}$ ), Carbides (i.e., $\mathrm{TiC}$, $\mathrm{SiC}$, and $\mathrm{WC}$ ), Nitrides (i.e., TiN, BN, and $\mathrm{Si} 3 \mathrm{~N} 4$ ), and Borides (i.e., $\mathrm{TiB}_{2}$, $\mathrm{ZrB}_{2}$, and $\mathrm{CrB}_{2}$ ). They are harder than the matrix metals, so they are obstacles of the migration and movement of the dislocation line. The dislocation line needs higher stress as a driving force to migrate. Secondary phase particle falls into two categories: deformable particle and non-deformable particle. These two types of particles interact with dislocation differently in two different theory.

\subsubsection{Orowan Theory}

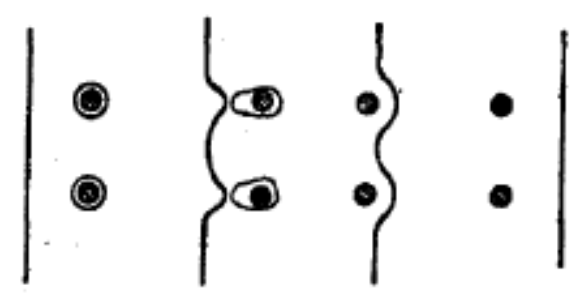

Figure 3-1. The dislocations pass particles by bowing mechanism [43]

Orowan proposed this theory in 1948 [44], as shown in Figure 3-1. When the dispersion strengthened alloy is under external loading, the dislocation which migrates along glide plane meets the harder non-deformable secondary particle, 
the particles bow the dislocation line. As the loading increases, the bowing part becomes stronger, and the dislocation line bypasses the particles so that a positive dislocation meets a negative dislocation. Positive dislocation tends to counteract the negative dislocation. Therefore, a dislocation ring forms which increases the density of dislocation and the resistance of dislocation migration. Figure 3-2 shows a TEM picture of a dislocation ring which confirms this theory.

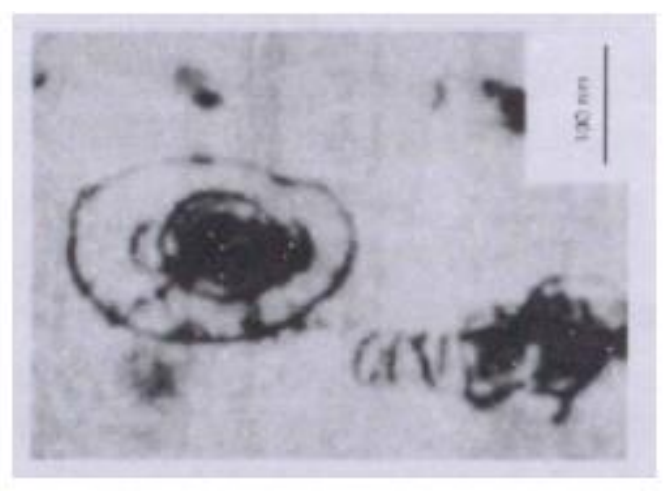

Figure 3-2. A TEM picture of a dislocation ring [45]

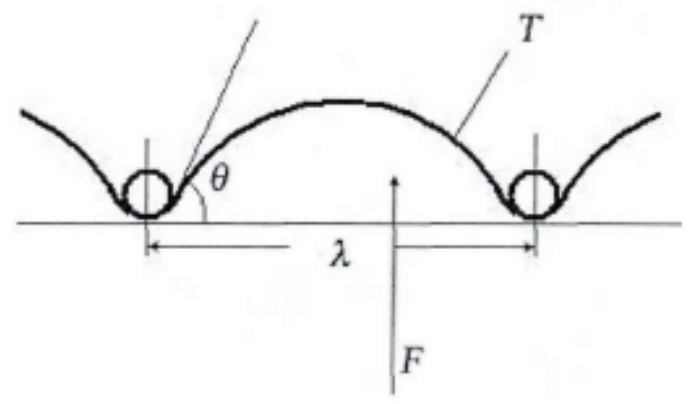

Figure 3-3. General view of the mechanical balance of the dislocation line

As shown in Figure 3-3, when the dislocation line bypasses the particle, the resistant force from particle to dislocation line $F$ and the tension $T$ of dislocation line satisfies:

$$
F=2 T \sin \theta
$$

Where $\theta$ is the angle of dislocation line where it bypassed. When $\theta=\frac{\pi}{2}$, the dislocation ring is a semicircle. When $\mathrm{F}$ reaches its maximum value, $T=\frac{1}{2} G b^{2}$ where $\mathrm{G}$ is the shear modulus, $\mathrm{b}$ is the Burgers Vector of a dislocation. Therefore, $F_{\max }=G b^{2}$ Apply balancing condition, $F_{\max }=\lambda \mathrm{b} \tau_{c}$ Substitute $F_{\max }=\lambda \mathrm{b} \tau_{c}$ into formula (1) will get: 


$$
\tau_{c}=\frac{G b}{\lambda}
$$

Where $\tau_{c}$ is the critical stress, $\mathrm{G}$ is the shear modulus, $\mathrm{b}$ is the Burgers Vector of a dislocation, and $\lambda$ is the distance between secondary particles. Only when the external stress exceeds the critical stress, the dislocation line is able to migrate and bypass. From formula (3.1), the yield stress is inversely proportional to $\lambda$. When the distance is smaller, metals perform high yield strength which explains the size of added secondary phase particle is usually around $50 \mathrm{~nm}$.

\subsubsection{Ansell-Lenel Theory}

Ansell et al. [46] proposed this theory after Orowan. When the secondary phase particle is deformable, the dislocation line will cut the secondary phase particle instead of bypassing and encircling it. They used the crack of secondary phase particle which caused by dislocation pile up as the criterion of yielding.

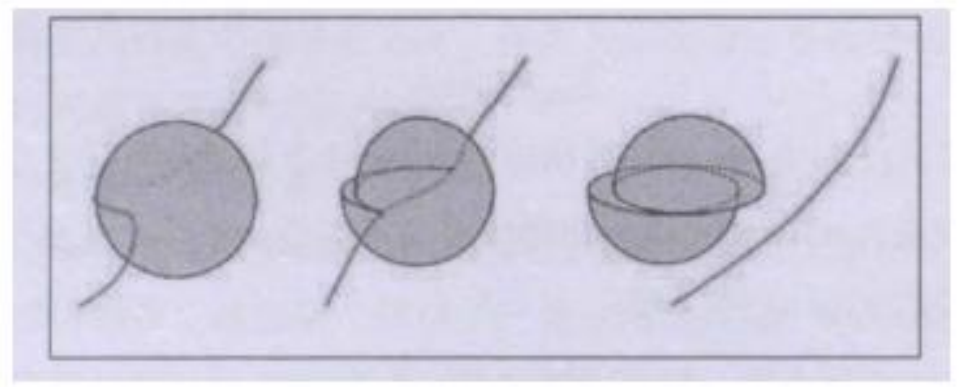

Figure 3-4. A schematic drawing of Ansell-Lenel Theory [47]

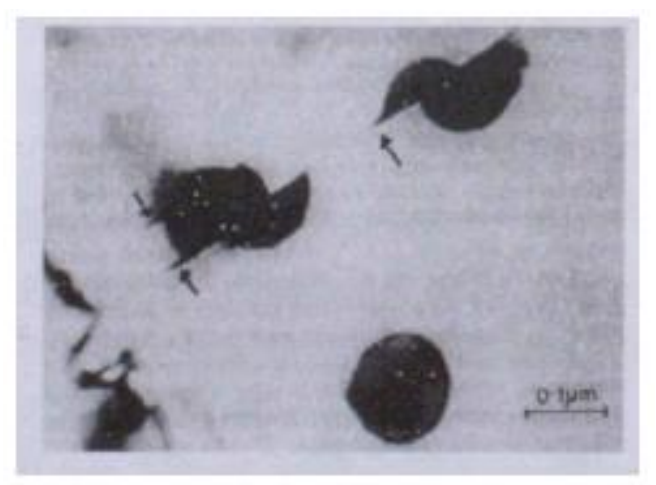

Figure 3-5. A TEM picture of a dislocation cutting a secondary phase particle [46]

When the stress applied on the particle is equal to the breaking stress of particle, the dislocation line will move as this pattern. Thus, the metal will yield. The cracking of secondary phase particle consumes the driving force of dislocation migration, which increases the resistance of dislocation. This theory could be formulated as follows: 


$$
\tau_{c}=\sqrt{\frac{G b G^{*}}{2 \lambda C}}
$$

Where $\mathrm{G}$ is the shear modulus of the matrix, $G^{*}$ is the shear modulus of secondary phase particle, $b$ is the Burgers Vector of a dislocation, and $\lambda$ is the distance between secondary particles, $\mathrm{C}$ is a constant $\approx 30$.

\subsubsection{Strain Strengthening [42]}

Strain strengthening is a mechanism that metals are cold processed or deformed below the temperature of recrystallization. Hence the density of dislocation is increased. Every single dislocation is more challenging to migrate since density is increased. The resistance between different grains is stronger. Thus the mechanical properties of metals are improved. This method is usually applied to ductile superalloys. But the recrystallization temperature of most metals is in the range of $1 / 3 \sim 1 / 2 \mathrm{Tm}$, where $\mathrm{Tm}$ is the melting temperature of metals. When heat the cold-deformed metals to their recrystallization temperature would deduce the dislocation which caused by the deformation.

\subsubsection{Solution Strengthening [42]}

Solution strengthening is a method that adding other metal elements into the matrix system to utilize lattice distort of $\gamma^{\prime}$ phase, thus the atomic binding force of metal atoms is increased, the diffusion rate of elements is decreased, and the growth of defects is prevented. For FCC solid solution, the deformation is nonhomogenous. And such this deformation is through the climbing of dislocations which is associated with short-range domain boundary energy. These short-range domain boundary energy will induce friction stress to inhibit dislocation. Therefore, the alloy is strengthened. Pettinary et al. published researches about $\mathrm{Ni}-\mathrm{Cr}$ alloys that contain Mo, W, Re, etc. instead of Al and Ti which are elements of forming Y'. They confirmed that the short-range domain boundary energy in FCC solid solution caused the non-homogenous distribution of dislocations, hence caused the nonhomogenous deformation. It could be summarized for ODS nickel-based superalloys as follows:

I). Soluble elements in the Ni matrix is capable of forming an infinite solid solution so that the degree of solution strengthening is increased.

II). Most of the metal atoms have a larger radius than $\mathrm{Ni}$, thus adding these elements into solid solution will increase the lattice constants.

III). The non-homogenous dislocation and clustering particle is a stable phenomenon. It is helpful for the mechanical property at high temperatures.

IV). Added elements could pin non-homogenize dislocation which inhibits dislocation climbing. Thus the mechanical property at high temperatures is improved. 


\subsubsection{Fine-grain strengthening}

Hall-Petch [48] proposed that fine-grain strengthening is an effective strengthening mechanism for superalloys. The alloy is strengthened by the fine grain and grain boundaries. The finer the grain, and the more grain boundaries, the higher mechanical properties at room temperature. This theory could as presented in a formula as follows:

$$
\sigma_{s}=\sigma_{0}+K d^{-\frac{1}{2}}
$$

Where $\sigma_{s}$--Yield strength of the alloy

$\sigma_{0}-$-The resistant force inside the grain in terms of dislocation

$\mathrm{K}$-Coefficient

$d$ - The diameter of the grain

\subsubsection{Precipitation Strengthening [42]}

Precipitation strengthening is a mechanism that adds elements into the matrix and then quenching of rapid cooling to obtain a metastable solid solution. When the alloy is heat treated after rapid cooling, metallic compound forms as clustering group or particle. These groups and particles interact with dislocation within the elastic stress field in order to prevent dislocation from migrating. These particles are commonly small and uniform in the matrix. Precipitation Strengthening is one of the most effective strengthening methods for superalloys. Even though $y^{\prime}$ is coherent with the matrix, their lattice parameters are different. When $\gamma^{\prime}$ is coherently precipitate from the $y$ matrix, $y^{\prime}$ will cause elastic stress field around itself. The mismatch degree of $\gamma^{\prime}$ and $\gamma$ could be formulated as follows:

$$
\delta=\frac{2\left(a_{\gamma^{\prime}}-a_{\gamma}\right)}{a_{\gamma^{\prime}}+a_{\gamma}}
$$

Where $a_{\gamma^{\prime}}-$ - Lattice parameter of $\gamma^{\prime}$ phase

$a_{\gamma}$-- Lattice parameter of the $\gamma$ matrix.

The mismatch stress field exists on the interfaces of $y^{\prime}$, and $y$ is capable of inhibiting the migration of dislocation which strengthens the alloy. 


\subsection{The Effect of Elements}

\begin{tabular}{cc}
\hline \multicolumn{2}{c}{ Table 3-1. Compositional ranges of major alloying } \\
additions in Ni-based superalloys [2] \\
\hline Elements & Ranges (wt. \%) \\
$\mathrm{Cr}$ & $5 \sim 25$ \\
$\mathrm{~W}$ & $0 \sim 12$ \\
$\mathrm{Al}$ & $0 \sim 6$ \\
$\mathrm{Ni}$ & - \\
\hline
\end{tabular}

Table 3-1 shows the compositional ranges of principal alloying additions in Ni-based superalloys. Table 3-2 shows that role of added elements in ODS Nibased superalloys. There were only five elements added into the developed material system. The effect of each added element is discussed below.

Nickel: Ni has Face-center-cubic (FCC) unit cell. It has high chemical stability, and the structure stability enables it maintains FCC from room temperature to melting point. Ni matrix is capable of fully forming alloys with other elements through solid solution strengthening instead of generating harmful phases. Thus, $\mathrm{Ni}$ is a good candidate for matrix system. More importantly, Ni forms strengthening $Y^{\prime}$ phase with L12 structure by interacting with other metal elements in the system during aging processing [13]. All Ni-base alloys contain this phase as the matrix. And it is also the element of forming the $y$ matrix and $y "$ phase with $\mathrm{Nb}$ and $\mathrm{Ta}$. This makes $\mathrm{Ni}$ alloy suitable for producing ODS superalloys.

Chromium: $\mathrm{Cr}$ is the solid solution strengthener in ODS $\mathrm{Ni}$-based superalloys. $\mathrm{Cr}$ could enhance the corrosion resistance and high-temperature oxidation resistance. It is a significant component in ODS superalloys. $\mathrm{Cr}$ could form a densified $\mathrm{Cr}_{2} \mathrm{O}_{3}$ oxide film on the surface of metals to improve the passivation ability of metals. But high content of $\mathrm{Cr}$ could promote the formation of alpha phase which would undermine the ductility of alloys. Considering the corrosion resistance and ductility of ODS superalloys, Cr was chosen as 20 wt. \% in this research.

Tungsten: $\mathrm{W}$ is the element to facilitate the solid solution strengthening in ODS superalloys. According to published results, the creep strengths of ODS super alloys increases with W contents. But when W is over 3 wt. \%, the creep strength reaches saturated, W could cause some unstable phases such as Laves phase which would weaken the creep strengths of ODS super alloys. So W was chosen as 3 wt. \% in this study.

Aluminum: Al forms the $\mathrm{y}$ matrix with $\mathrm{Ni}$. It goes into solid solutions to provide oxidation resistance since a stable $\mathrm{Al}_{2} \mathrm{O}_{3}$ film could form on the surface of Ni-based superalloys. It is also a booster for the $y^{\prime}$ precipitates which enhance the mechanical properties of Ni-based superalloys. But existing results have shown 
that when $\mathrm{Al}$ is over $5 \mathrm{wt}$. \%, the $\mathrm{y}^{\prime}$ phase tends to mismatch with the $\mathrm{y}$ matrix. So the content of $\mathrm{Al}$ is set to $5 \mathrm{wt}$. \% in this study.

Yttrium Oxide: Based on previous results, when $\mathrm{Y}_{2} \mathrm{O}_{3}$ is over $0.2 \mathrm{wt}$. \%, the strengthening of metals is apparent. But when it is higher than $0.5 \mathrm{wt}$. \%, microvoid would form along with grain boundary which increases the diffusion of oxygen to decrease the oxidation resistance of alloys: the higher content of $\mathrm{Y}_{2} \mathrm{O}_{3}$, the higher oxidation rate of alloys.

Other elements: Generally, N, O, and C, etc. would decrease the ductility of metals. But recent results showed that the influence of Nitrite, Oxide, and Carbide which formed by $\mathrm{N}, \mathrm{O}$, and $\mathrm{C}$ in metals depends on the size, distribution, and shape of these compounds. When $\mathrm{V}$ and $\mathrm{Ti}$ are contained in alloys, moderate content of $\mathrm{N}, \mathrm{O}$, and $\mathrm{C}$ could form MxCy compounds with $\mathrm{V}$ and $\mathrm{Ti}$, which would enhance the high-temperature strengths of alloys, especially the creep strength. When $\mathrm{C}$ is high in alloys, $\mathrm{C}$ will combine with $\mathrm{Cr}$ forming carbides which would cause the loss of $\mathrm{Cr}$ to decrease the corrosion resistance of alloys. When alloys contain $\mathrm{S}, \mathrm{P}, \mathrm{Si}$, and $\mathrm{Cu}$, these elements will impair the ductility.

Table 3-2. Alloying elements present in ODS Ni-based superalloys [2] $\begin{array}{cc}\mathrm{Y} \text { former } & \mathrm{Ni}, \mathrm{Fe}, \mathrm{Co}, \mathrm{Cr}, \mathrm{W}, \mathrm{Mo}, \mathrm{V}, \mathrm{Y} \\ \mathrm{Y} \text { ' former } & \mathrm{Al}, \mathrm{Ti}\end{array}$ $\mathrm{Zr}, \mathrm{Hf}, \mathrm{B}, \mathrm{C}$ 


\section{CHAPTER 4: EXPERIMENT}

\subsection{Experiment Procedure}

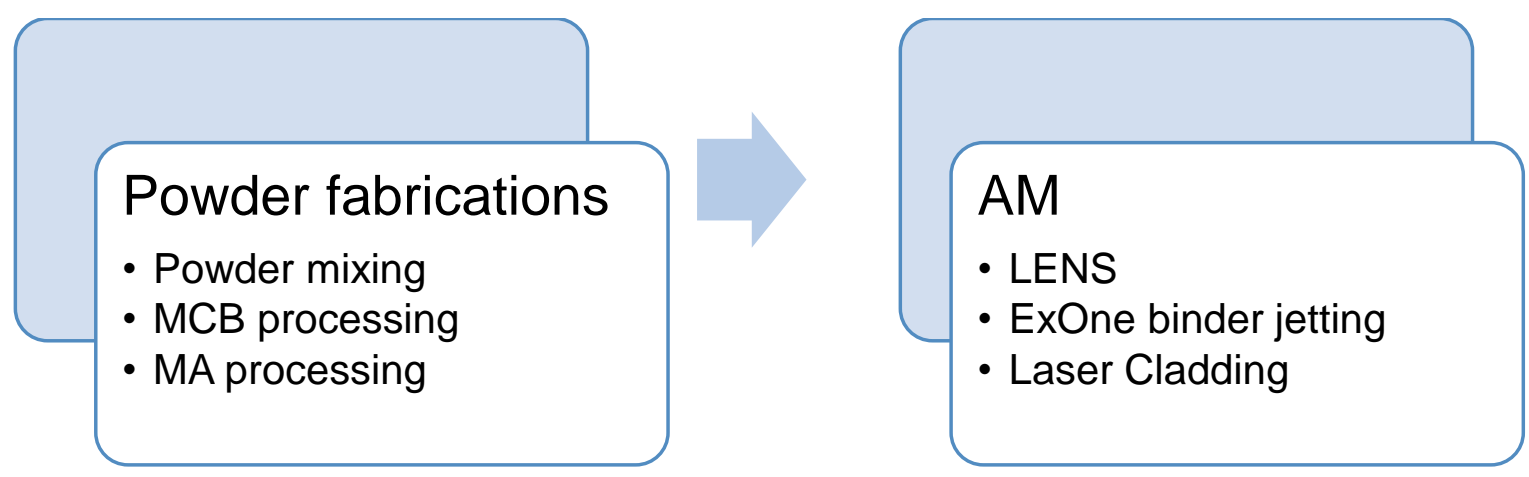

Figure 4-1. A flow chart of experiments

\subsection{Experiment Materials}

I). Raw elemental powders

\begin{tabular}{cccc}
\hline \multicolumn{4}{c}{ Table 4-1. The information of raw powder. } \\
\hline Elemental powder & Average Size & Degree of purity & Weight Percentage \\
Nickel & $3 \sim 7 \mu \mathrm{m}$ & $99.9 \%$ & $70.5 \%$ \\
Chromium & $3 \sim 7 \mu \mathrm{m}$ & $99.2 \%$ & $20 \%$ \\
Aluminum & $4.5 \sim 7 \mu \mathrm{m}$ & $97.5 \%$ & $5 \%$ \\
Tungsten & $<1 \mu \mathrm{m}$ & $99.95 \%$ & $3 \%$ \\
Yttrium Oxide & $50 \sim 70 \mathrm{~nm}$ & $99.995 \%$ & $1.5 \%$ \\
\hline
\end{tabular}

The raw powders that were used in this study are from Alfar Aesar. The average size, degree of purity and weight percentage are shown in Table 4-1. These powders were storage separately and sealed in bottles with Argon gas. The just-blended powder was mixed, sealed in bottles with Argon gas, and storaged in a glove box with Argon atmosphere. A digital scale with accuracy $0.001 \mathrm{~g}$ was used to weight powders. Each bottle contained the just-blended powder sample which had weights approximately $300 \mathrm{~g}$. Considering the short processing time of MCB and no ball to ball, ball to powder, and powder to container wall collision happened during MCB process, the average size of starting raw powders are from $50 \mathrm{~nm}$ to $7 \mu \mathrm{m}$ in this study [49-52]. Figure 4-2 shows SEM morphology of raw powders. As shown in Figure 4-2, the Ni particle is spiky with some degree of roundness. Al is the most spherical powder. Cr particle is chunky. Tungsten particle is block-like with a smaller size. And $\mathrm{Y}_{2} \mathrm{O}_{3}$ particle is nanosize plate. 

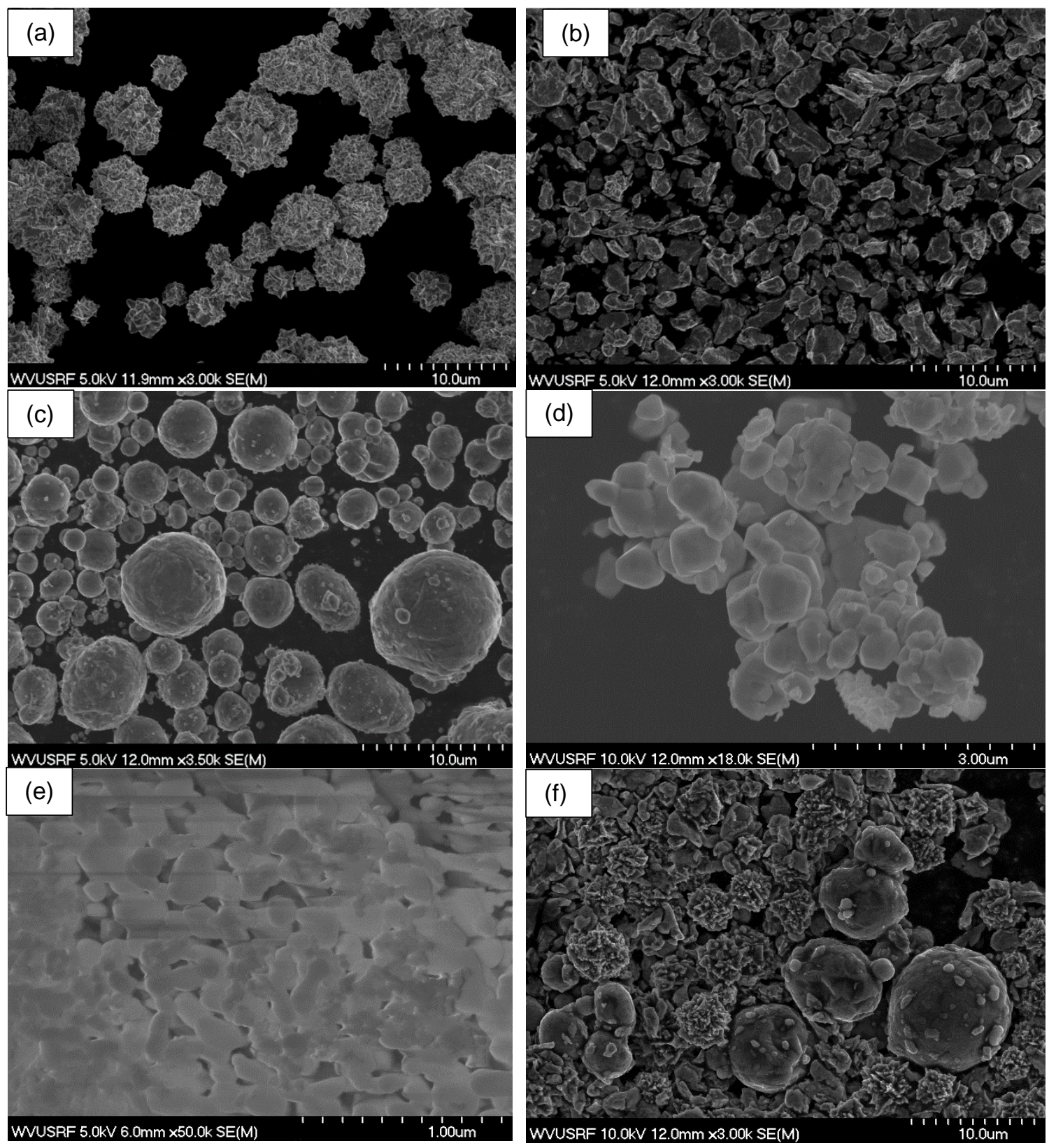

Figure 4-2 SME morphology of (a). Pure Nickel powder; (b). Pure Chromium powder; (c). Pure Aluminum powder; (d). Pure Tungsten powder; (e). Pure Yttrium Oxide powder; (f). As-just-blended powder (unprocessed).

II). Processing control agent

A processing control agent (PCA) was used to function as a lubricant and to enhance powder flowability [53]. The PCA is stearic acid from Alfar Aesar with a formula of $\mathrm{CH}_{3}\left(\mathrm{CH}_{2}\right){ }_{16} \mathrm{CO}_{2} \mathrm{H}$. The purity of stearic acid is $98 \%$. 


\subsection{Experiment Methods and Instruments}

Two types of processing technique, $\mathrm{MCB}+\mathrm{BM}$ and $\mathrm{MCB}-\mathrm{only}$ were employed to process as-just-blended starting powder to fabricate experimental ODS Ni-based superalloy powders. In order to investigate and compare the MA effect of the MCB process, a BM process under 400rpm 41 hours (denoted as BMonly) was employed. And the powder processed by the BM-only process is used a benchmark material in further research. Note: BM experiments were carried out with the corporation from another Master student Markova Macpherson under Dr. Bruce S. Kang's supervision. Markova Macpherson shares the credits in BM experiments.

\section{I). The MCB machine}

The model of MCB machine is NOBILTA-130 from HOSOKAWA Micron LTD. The capacity of the main chamber is 0.5 liters, and $350 \mathrm{~g}$ powder can be produced for each batch. The maximum inner pressure of the main vessel is 0.49 $\mathrm{MPa}$. A thermal couple is attached in the powder feeding port to monitor the temperature of the inner vessel wall. Figure 5-3 shows the actual image of HOSOKAWA NOBILTA-130 MCB machine.

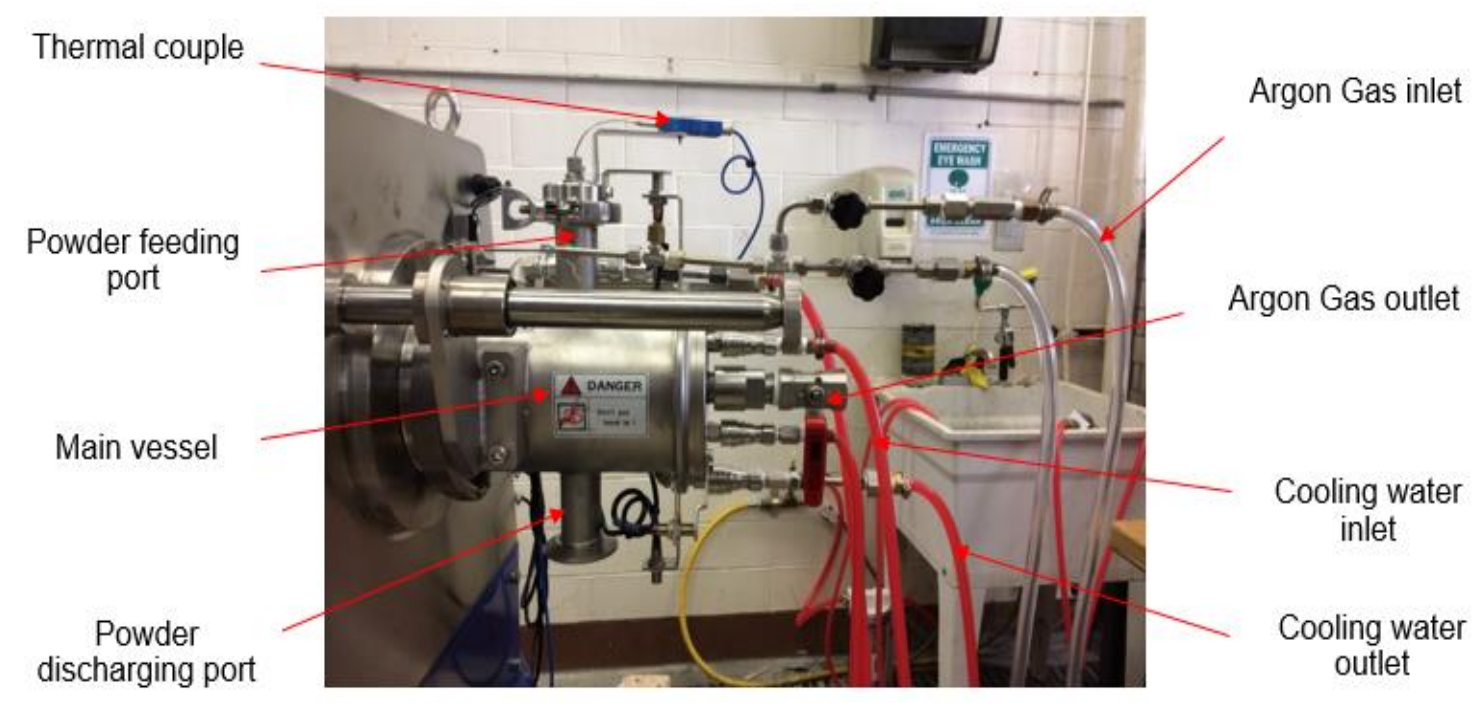

Figure 4-3. HOSOKAWA NOBILTA-130 MCB machine.

In this study, the raw powder was weighed on a digital scale in a glove box. And then the raw powder was mixed and sealed in a polyethylene bottle with Argon gas. Before feeding the raw mixed powder into the vessel, Argon gas was used to purge out the air in the vessel for three times. Each time is 15 seconds. After feeding the powder into the vessel, Argon gas was filled for 10 seconds. Figure 44 shows the craft routine of MCB processing. 


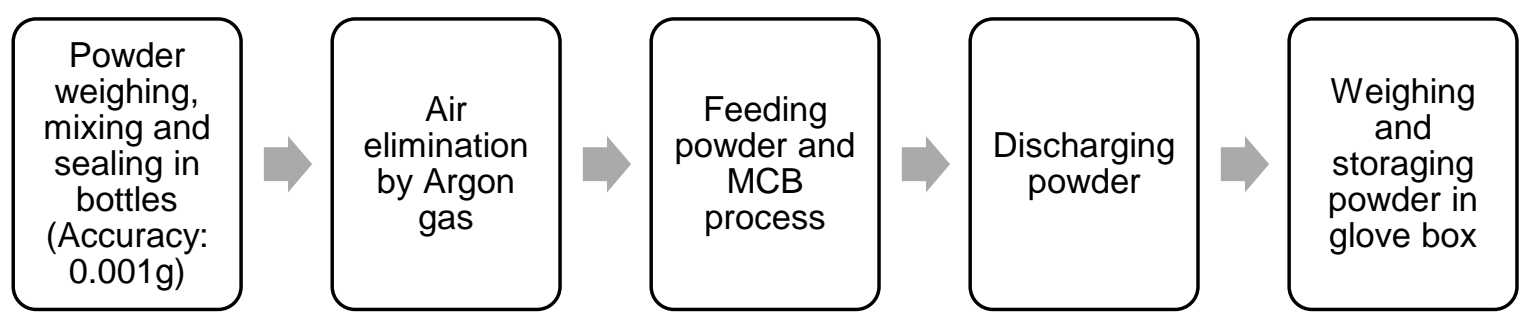

Figure 4-4. A craft routine of MCB process

\begin{tabular}{cccc}
\hline \multicolumn{4}{c}{ Table 4-2.Unique configurations of raw powder for the MCB-only, BM-only and } \\
\multicolumn{4}{c}{ MCB+BM process } \\
\hline Configuration & Rotation Speed (rpm) & Running Mode & Time (hours) \\
M1 & 4000 & Normal & 1 \\
M2 & 4000 & Normal & 18 \\
M3 & 4000 & Normal & 32 \\
M4 & 4000 & Normal & 50 \\
M5 & 5000 & Normal & 22 \\
M6 & 5000 & Normal & 32 \\
M7 & 5000 & Normal & 50 \\
M8 & 5000 & Step-running & 8 \\
M9 & 5000 & Step-running & 11 \\
BM-only & 400 & - & 41 \\
MCB+BM & MCB 4000+BM 400 & MCB Normal & $1+40$ \\
\hline
\end{tabular}

Table 4-2 shows 11 different process parameters for the MCB-only, BMonly and MCB+BM process. Where, Normal mode denotes: The just-blended powder was processed for varying periods with the duration of 4 hours of each, the total running hours accumulated up to 50 hours. Step-running mode denotes: The just blended powder was processed for different periods with the duration of 1.5 hours of each, the off interval was 10 mins, the total running hours accumulated up to 11 hours. And the MCB main vessel was shook and hammered by a plastic hammer during the off intervals.

\section{II). The BM machine}

MCB first processed As-just-blended power under 4000rpm 1 hour in an Argon gas atmosphere. Each run has a yield of $300 \mathrm{~g}$. It was expected to have $\mathrm{Y}_{2} \mathrm{O}_{3}$ nanoparticles evenly dispersed and bonded onto the surfaces of $\mathrm{Ni}$ and $\mathrm{Cr}$ particles (host particles) which created oxide dispersion and MA effects. The MCB processed powder was then processed by a planetary BM with 4 stainless still jars under different rotation speed (i.e., 300rpm and 400rpm), different Ball to Powder (BPR) ratio (i.e. 10:1, 15:1 and 30:1), and different processed durations (i.e. 15 hours, 20 hours, 25 hours, 40hours and 45hours). A PCA Stearic Acid with the composition of $\mathrm{C}_{17} \mathrm{H}_{35} \mathrm{CO}_{2} \mathrm{H}$ at 0.5 wt. \% was added to each jar to boost the MA effect. Size distribution of four $20 \mathrm{~mm}$ balls, four $15 \mathrm{~mm}$ balls, two $10 \mathrm{~mm}$ balls and 
two $5 \mathrm{~mm}$ balls were used. And each run has a yield of $64 \mathrm{~g}$ which is relatively low comparing to the MCB process. The powder was processed in Argon atmosphere during the BM process. The optimization of BM parameters has been investigated by Markova Macpherson. In this study MCB-4000rpm-1hour+BM-400rpm40hours-BPR 15:1 (denoted as MCB+BM) was used as a reference to investigate the MA effect of MCB+BM, MCB-only, and BM-only processed powders.

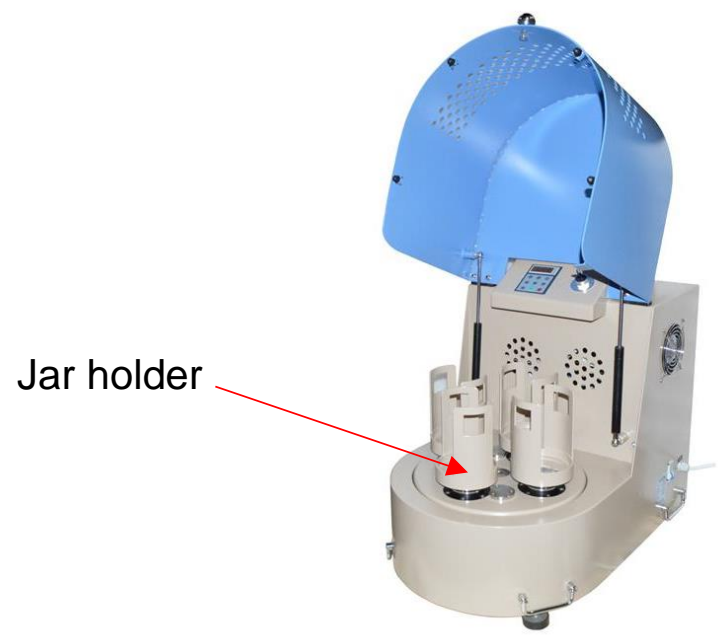

Figure 4-5. The MTI planetary BM machine

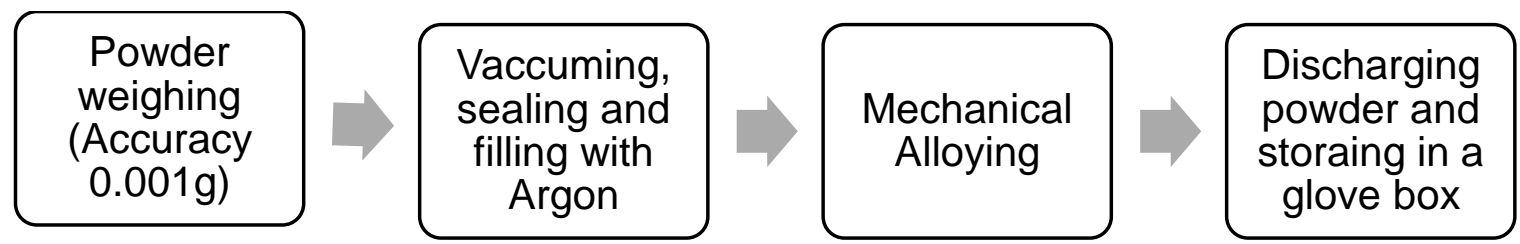

Figure 4-6. A craft routine of MA process

III). Particle size distribution

The size distribution of particle is analyzed by a Laser particle analyzer from Malvern Panalytical company (Model: Master Sizer 2000). The solution that was used to disperse the powder into the laser system was distilled water. And the chamber of the analyzer was purged by distilled water after each test.

IV). Laser engineering net shaping (LENS)

Produced $\mathrm{MCB}+\mathrm{BM}$ and $\mathrm{MCB}-$ only powders were sent to the University of Pittsburgh to conduct experiments on LENS 450 system. The LENS system in the University of Pittsburgh is LENS 450 system. Three input laser energies were selected: $200 \mathrm{~W}, 250 \mathrm{~W}$, and $275 \mathrm{~W}$ refer to the nominal parameters of LENS 450 system. Two laser scanning speeds were chosen: $33 \mathrm{~mm} / \mathrm{s}$ and $10 \mathrm{~mm} / \mathrm{s}$. Two powder feeding rates were used: $8 \mathrm{rpm}$ and $11 \mathrm{rpm}$. Two different flat substrates 
were adapted: MAR-247R (Ni alloy) and Stainless steel. The hatching spacing was $0.1524 \mathrm{~mm}$ and the layer thickness was $0.1 \mathrm{~mm}$. Hatching lines were made at $0{ }^{\circ}$ horizontally in the first layer and then were rotated $90^{\circ}$ for the next layer by repeating this order. Figure 4-7 shows the schematic of the hatch spacing.

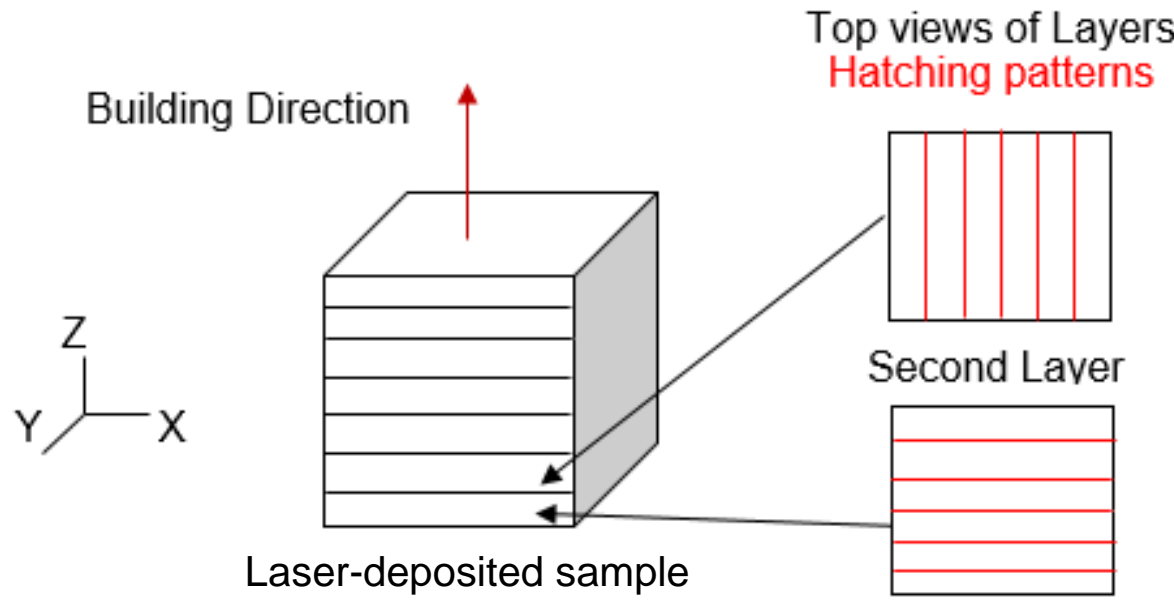

First Laver

Figure 4-7. A schematic of hatching patterns employed in LENS 450 system.

V). Laser Cladding

The MCB-only processed powders were sent to Siemens Company, Pittsburgh to conduct Laser Cladding. The input laser power was $~ 5 \mathrm{~kW}$. A MAR247R flat substrate was chosen. The laser scanning speed, hatch spacing, laser thickness, and hatching patterns are confidential from Siemens Company. So the as-printed samples will be used a reference to compare the as-printed microstructure between large input laser energy and low input laser energy.

VI). Density Testing

The density testing is based on Archimedes drainage. Since voids and cracks cannot be totally eliminated after printing, achieving the theoretical density of as-printed samples is difficult. A relative density should be employed to examine the density of as-printed samples:

$$
\rho_{R}=\frac{\rho_{E}}{\rho_{T}} \times 100 \%
$$

Where, $\rho_{R}$-- Relative density

$\rho_{E}$-- Experimental density of as-printed samples measured by Archimedes drainage

$\rho_{T}-$ Theoretical density of as-printed samples 


$$
\rho_{T}=\rho_{a} \cdot W_{a}+\rho_{b} \cdot W_{b}+\cdots+\rho_{x} \cdot W_{x}
$$

Where, $\rho_{x}$-- The theoretical density of component $\mathrm{x}$

$W_{x}$-- The weight fraction of component $x$

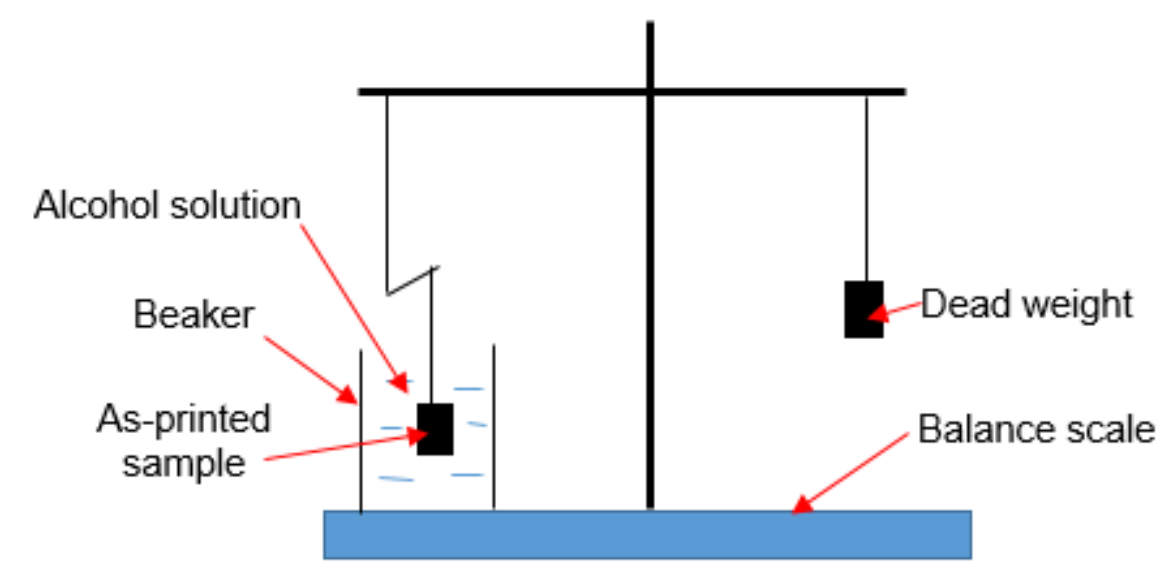

Figure 4-8. A schematic of Archimedes drainage.

The as-printed samples were tested for density in an alcohol solution. The steps of the test and calculation are as follows:

$$
\begin{aligned}
& m_{1}=\rho_{E} V-\rho_{1} V \\
& m_{2}=\rho_{E} V-\rho_{2} V
\end{aligned}
$$

Combine (4.3) and (4.4) would get

$$
\rho_{E}=\frac{m_{1} \rho_{2}-m_{2} \rho_{1}}{m_{1}-m_{2}}
$$

Where $m_{1}$ and $m_{2}$ are the weights of the as-printed sample in air and in the alcohol solution respectively. $\rho_{1}$ and $\rho_{2}$ are the density of the as-printed sample in air and in the alcohol solution respectively. Table 4-3 shows that theoretical density of components in this study. Thus, the calculated theoretical density of as-printed sample should be $8.51 \mathrm{~g} / \mathrm{cm}^{3}$.

\begin{tabular}{cccccc}
\hline \multicolumn{6}{c}{ Table 4-3. Theoretical density of components } \\
\hline Component & Nickel & Chromium & Aluminum & Tungsten & $\begin{array}{c}\text { Yttrium } \\
\text { Oxide }\end{array}$ \\
$\begin{array}{c}\text { Theoretical Density } \\
\left(\mathrm{g} / \mathrm{cm}^{3}\right)\end{array}$ & 8.908 & 7.190 & 2.699 & 19.300 & 5.100 \\
$\begin{array}{c}\text { Weight Fraction } \\
(\%)\end{array}$ & 70.5 & 20 & 5 & 3 & 1.5 \\
\hline
\end{tabular}


VII). The grinding and polishing of as-printed samples.

All the as-printed were grinding and polishing under the same condition for the following characterization. The as-printed samples were cut cross-sectionally, grinded with sandpapers in according grit size: 240, 400, 800, 1200, 2000, and polished with diamond suspension $9 \mu \mathrm{m}, 3 \mu \mathrm{m}$, and $1 \mu \mathrm{m}$. Buehler Vibromet was employed for final polishing in 0.05 diamond suspension. The samples were then etched by Marble's Reagent for 2 seconds etching time.

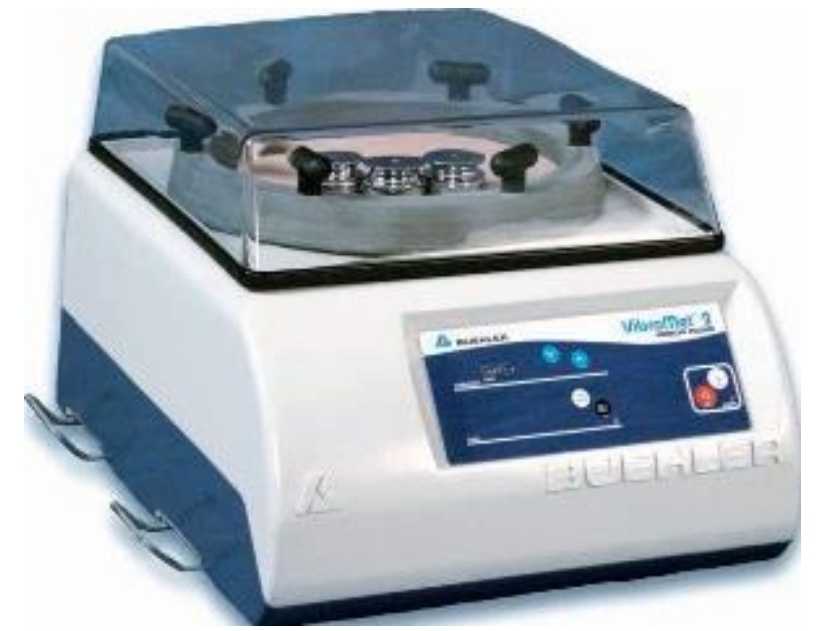

Figure 4-9. The Buehler Vibromet instrument [https://www.azom.com/equipmentdetails.aspx?EquiplD=3101].

\subsection{Characterization Methods}

After the MCB-only, BM-only and MCB+BM processes, a small amount of powders $(5 \sim 20 \mathrm{~g})$ were taken and sealed in glass vials and stored in an inert environment. And then they were subjected to the non-destructive micro-structural analysis: X-ray Diffractometer (XRD), Scanning Electron Microscope (SEM) and Energy Dispersive Spectrum (EDS).

\section{I). XRD}

The X-ray Diffractometer is PANalytical X'Pert Pro with a CuK alpha radiation $(45 \mathrm{kV}, 40 \mathrm{~mA})$ from SRF WVU. A spinner stage was used. The mixed raw powder, MCB processed powder, BM processed powder, MCB+BM processed powder and as-printed samples were analyzed by PANalytical X'Pert Pro. And the powders were consolidated into a disk. For the as-printed powder, the laser deposited layers were analyzed by the XRD and the signal of the substrates have been removed by curve fitting. The XRD patterns were recorded at room temperature with step-sizes of $0.0167^{\circ}$ of $2 \theta$ and 40 s per step which ranges in $10^{\circ}$ to $90^{\circ}$. 


\section{II). SEM}

The scanning electron microscope is Hitachi S-4700 from SRF WVU. The mixed raw powder, MCB-only processed powder, BM-only processed powder, $\mathrm{MCB}+\mathrm{BM}$ processed powder, and as-printed samples were analyzed by Hitachi S4700. The processed powders were dispersed into an alcohol solution to become a suspension solution. And then they were dispersed and fixed onto a carbon tape for SEM characterizations. The as-printed samples were also fixed onto a carbon tape for cross-section characterizations.

III). EDS

EDS was utilized to analyze the distribution of elements in the cross section as-printed samples. Especially, point scan was used to pinpoint the location and analyze the distribution, density, and phases. Mapping was also employed to observe the element distribution, but the result will be considered as a reference in the appendix. 


\section{CHAPTER 5: RESULTS AND DISCUSSION}

The processed powders were analyzed by XRD, SEM, and XPS. In order to investigate the MA effect of the MCB-only process, BM-only process and $\mathrm{MCB}+\mathrm{BM}$ process. An experiment denoted as BM-only (refers to Chapter 5) was carried out under Ball Milling 400 rpm 41 hours. XRD patterns and SEM images of BM-only would be considered as a benchmark to compare with MCB-only, and $\mathrm{MCB}+\mathrm{BM}$ processed powders.

\subsection{Analysis of Fabricated Powder}

\subsubsection{XRD Analysis}

The processed powders were characterized by XRD using a PANalytical X'Pert PRO X-Ray diffractometer with a CuKa radiation $(45 \mathrm{kV}, 40 \mathrm{~mA})$ and a spinner stage. The processed powders were consolidated into a disk. The XRD patterns were recorded at room temperature with step-sizes of $0.0167^{\circ}$ of $2 \theta$ and $40 \mathrm{~s}$ per step which ranges in $10^{\circ}$ to $90^{\circ}$. The XRD pattern broadening effect would be calculated to investigate the MA effect.

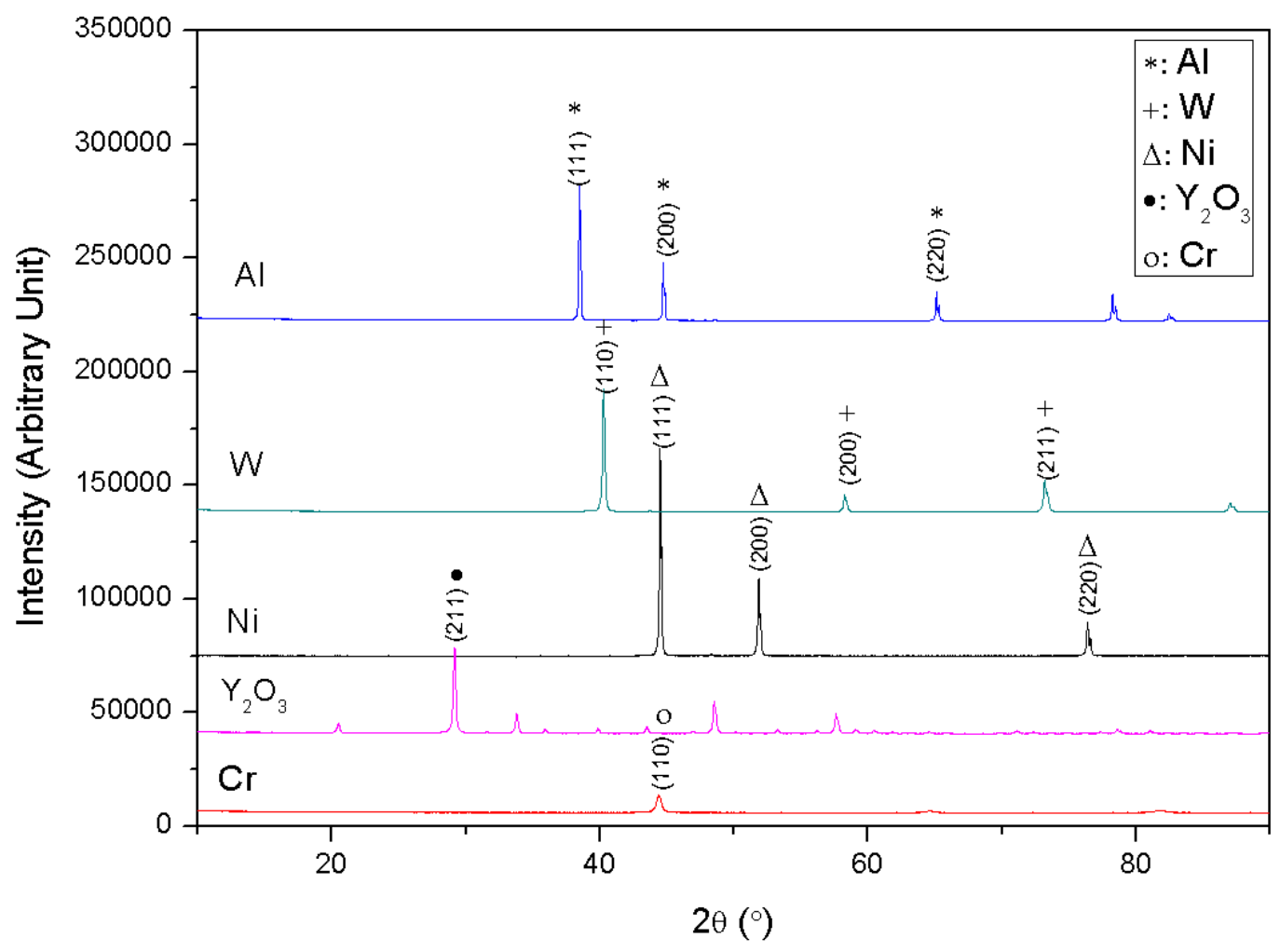

Figure 5-1. XRD patterns of pure elemental starting powders. 
Figure 5-1 shows the XRD patterns of as-received pure elemental starting powders. The Al powder shows three major peaks around $38^{\circ}, 45^{\circ}$, and $65^{\circ}$ respectively. The W powder also shows three major peaks around $40^{\circ}, 58^{\circ}$, and $73^{\circ}$ respectively. The base material Ni shows three major peaks around $45^{\circ}, 52^{\circ}$, and $78^{\circ}$ respectively. While there is only one obvious major peak for $\mathrm{Y}_{2} \mathrm{O}_{3}$ and $\mathrm{Cr}$ powders which are around $30^{\circ}$ and $45^{\circ}$ respectively. It is noted that the first major peak is overlapped with the only major peak of $\mathrm{Cr}$ and the second major peak of Al. Since the $\mathrm{Y}_{2} \mathrm{O}_{3}$ is nanosize, the spectrum of $\mathrm{Y}_{2} \mathrm{O}_{3}$ displays line-broadening effect.

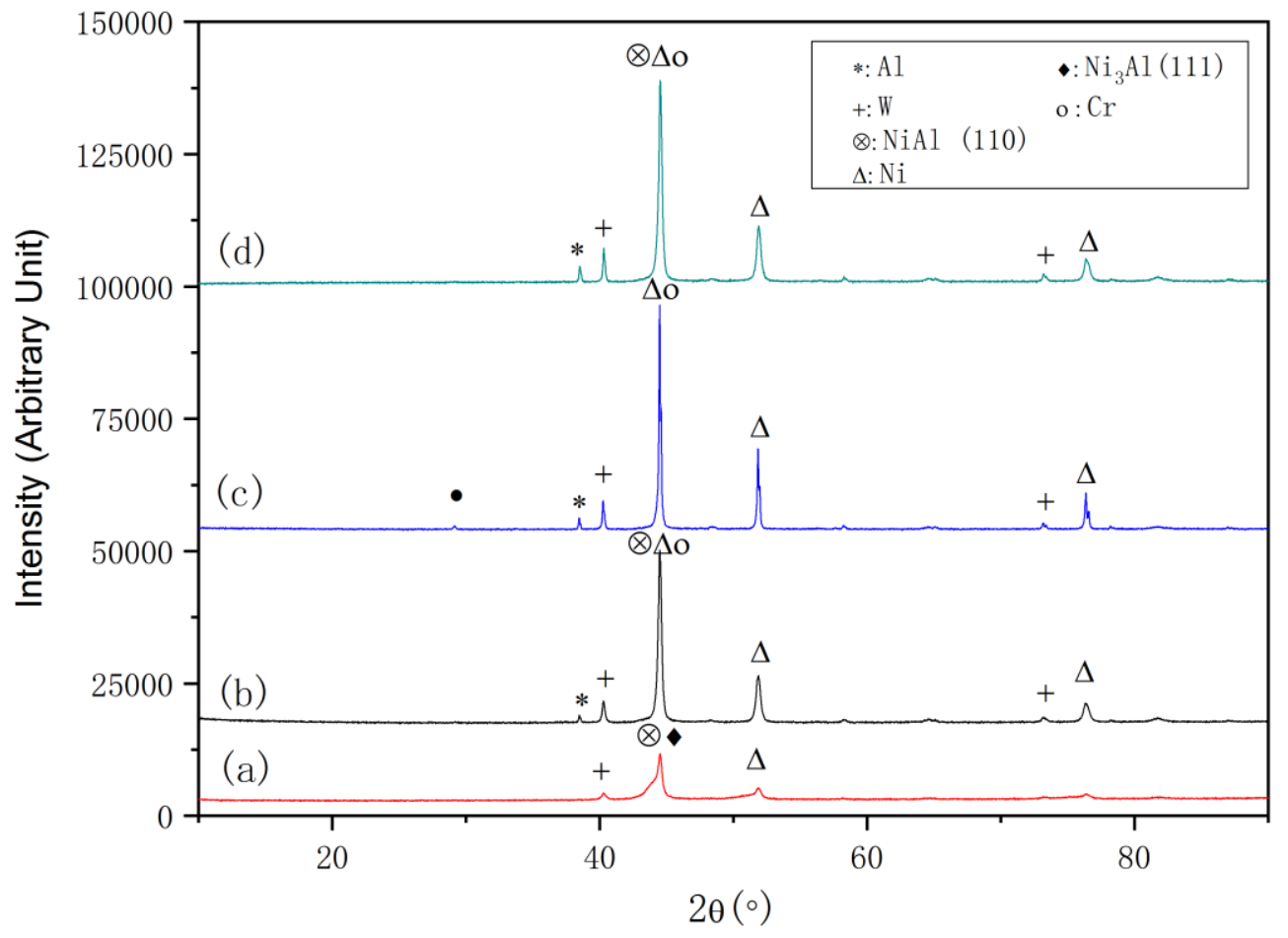

Figure 5-2. XRD patterns of the processed powders: (a). MCB-4000rpm1 hour+BM-400 rpm-40hours process (MCB+BM); (b).BM-only-400rpm41 housprocess (BM only); (c) As-just-mixed (0 hour); (d) MCB-only-4000rpm1 hour process (MCB only).

As shown in the XRD spectrums, the as-just-mixed $(0 \mathrm{~h})$ powder still displays $\mathrm{Y}_{2} \mathrm{O}_{3}(211)$ peak. But since the content of $\mathrm{Y}_{2} \mathrm{O}_{3}$ is low, the intensity of $\mathrm{Y}_{2} \mathrm{O}_{3}$ (211) peak is low. Also, $\mathrm{Al}$ (111) and W (110) are apparent in as-just-mixed powder. However, $\mathrm{Ni}(111)$ and $\mathrm{Cr}(110)$ overlapped at $45^{\circ}$ and the overlapped of $\mathrm{Al}$ (200) with $\mathrm{Ni}(111)$ and $\mathrm{Cr}(110)$ is hidden.

When the as-just-mixed powder was under MCB-4000rpm-1hour, the $\mathrm{Y}_{2} \mathrm{O}_{3}$ (211) peak disappeared which confirms that $\mathrm{Y}_{2} \mathrm{O}_{3}$ was uniformly distributed onto the hosting particles as an amorphous thin film. The $\mathrm{Y}_{2} \mathrm{O}_{3}$ (211) peak also disappeared after MCB+BM process and the BM-only process. It is because $\mathrm{Y}_{2} \mathrm{O}_{3}$ 
was decomposed as yttrium and oxygen during the BM process. But the uniform distribution of $\mathrm{Y}_{2} \mathrm{O}_{3}$ during the $\mathrm{BM}$ process is still unclear. The spectrums of the MCB-only process and BM-only process are identical, residual Al (111) and W (110) peaks are still observed, meaning powder particles did not form fully alloys during these processes. But the NiAl (110) is observed after the MCB-only process and $B M-o n l y$ process, suggesting the MCB-only process and the BM-only process could generate pre-alloys. The $\mathrm{Al}$ (111) disappeared after the MCB+BM process, indicating the $\mathrm{Al}$ went into the matrix to form solid solution with hosting $\mathrm{Ni}$ and $\mathrm{Cr}$ particles. Also, $\mathrm{Ni}_{3} \mathrm{Al}$ (111) and $\mathrm{NiAl}$ (110) are observed in MCB+BM processed powders. Individual elemental peaks except for W are not observed in MCB+BM processed powder and the major peak is the broadest among these spectrums, suggesting a significant change of crystallographic structure due to the formation of solid solutions formed during the $\mathrm{MCB}+\mathrm{BM}$ process. In addition, the existence of $\mathrm{NiAl}$ and $\mathrm{Ni}_{3} \mathrm{Al}$ is evidence of solid solutions. Also, the strong broadening effect of $\mathrm{MCB}+\mathrm{BM}$ means severe plastic deformation happened during the process. Therefore, the $\mathrm{MCB}+\mathrm{BM}$ process could generate powder with a better crystallographic structure from Figure 5-2.

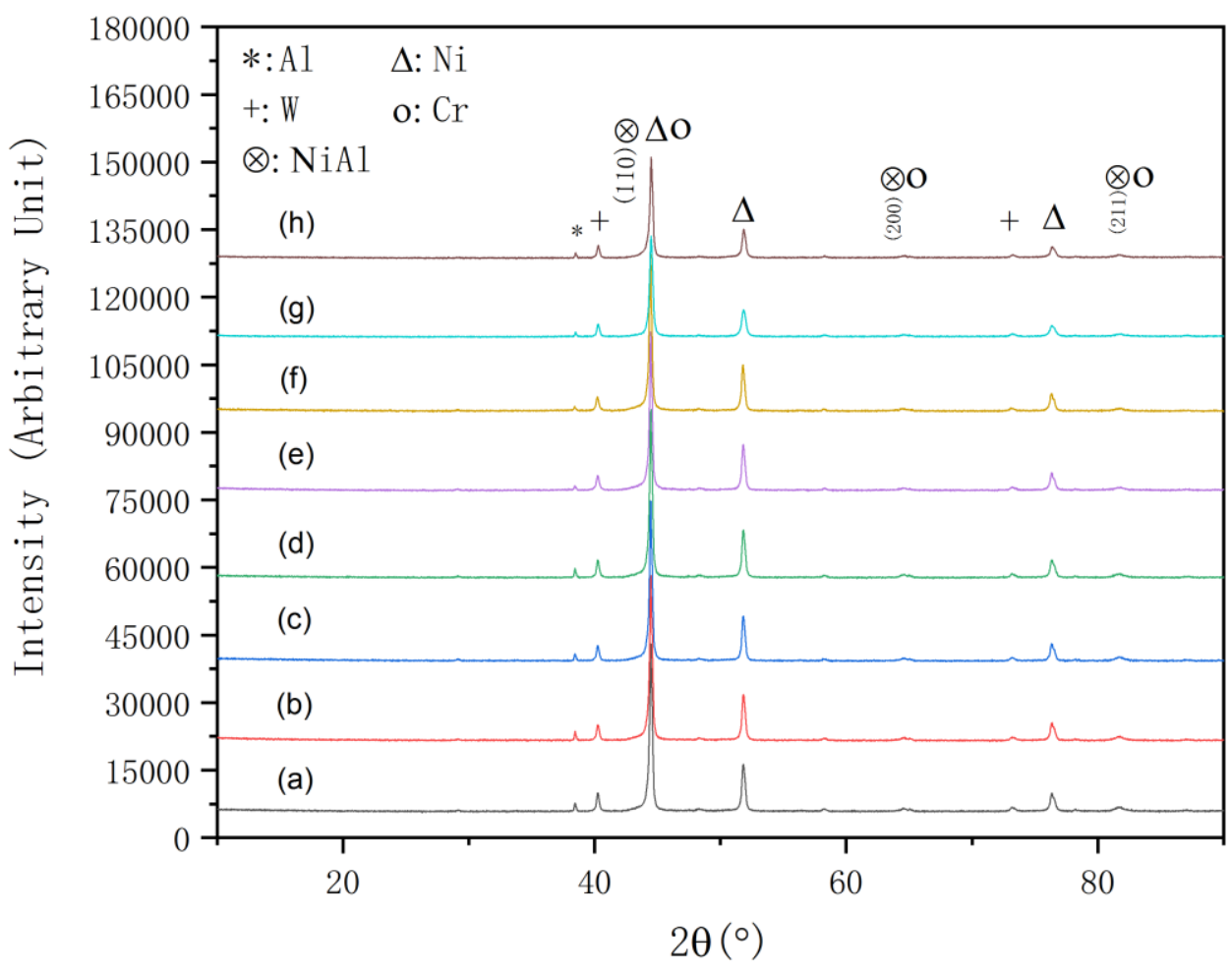

Figure 5-3. XRD spectrums of the MCB-only processed powders: Normal mode under 4000rpm: (a).18 hours; (b). 32 hours; (c). 50 hours. Normal mode under 5000rpm: (d). 22 hours; (e). 32 hours; (f) 50 hours; Step mode under 5000rpm:

(g). 8 hours; (h) 11 hours. 


\section{I). The influence of milling time on powders}

Figure 5-3 shows the XRD spectrums of the MCB-only processed powders under different milling time, rotation speed and running mode. The spectrums are almost identical but have some tiny differences. $\mathrm{Cr}$ (110), Ni (111) and NiAl (110) peak are displayed in every XRD spectrum, meaning the smaller particle was coated onto the surface of the hosting $\mathrm{Ni}$ and $\mathrm{Cr}$ particle according to the principle of the MCB process. And Al formed a small amount of NiAl with Ni when it was coated onto the surface of Ni particle. Figure 5-3 (a), (b) and (c) are the XRD patterns of powders under the same ration speed 4000rpm (i.e., input energy) and different milling time. Residual Al (111) and W (110) peak still exist in these three patterns, but the intensity of $\mathrm{Al}(111)$ and $\mathrm{W}$ (110) peak decreased as the increase of milling time. However, the NiAl (110), $\mathrm{Ni} \mathrm{(111)} \mathrm{and} \mathrm{Cr}$ (110) peaks did not change significantly. Similarly, Figure 5-3 (d), (e) and (f) are the XRD patterns of powders under the same ration speed 5000rpm and different milling time. Residual $\mathrm{Al}$ (111) and W (110) peaks still exist in these three patterns, but the intensity of Al (111) and W (110) peak also decreased as the increase of milling time. Other peaks in these three XRD spectrums also did not change significantly. In the same way, Figure 5-3 (g) and (h) are the XRD patterns of powders under the same ration speed 4000rpm, step mode and different milling time. Residual Al (111) and W (110) peak still exist in these three patterns, but the intensity of $\mathrm{Al}$ (111) and W (110) peak also decreased as the increase of milling time. Other peaks in these two XRD spectrums also did not change significantly.

\section{II). The influence of rotation speed (input energy) on powders}

It is obvious that a higher rotation speed would provide more shearing force, compression, and break-down during the process when confining powder particles through the narrow gap. Figure 5-3 shows, the higher the rotation speed, the less the residual elemental content. For instance, the intensity of Al (111) and W (110) peaks in spectrum (d), (e) and (f) are lower than spectrum (a), (b) and (c), meaning a higher rotation speed would force the $\mathrm{Al}$ and $\mathrm{W}$ to go into the matrix to form solid solutions.

III). The influence of running mode on powders

Figure 5-3 shows the MCB running mode has a higher efficiency for blending and generating powders since spectrums $(\mathrm{g})$ and $(\mathrm{h})$ has lower Al (111) and W (110) peak intensity than other spectrums in Figure 5-3, suggesting there was more NiAl matrix forming in MCB-only step mode processed powders. In addition, the step mode processed powders were only milled for up to 11 hours, but the normal mode processed powder was milled up to 50 hours which is timeconsuming. Because when the powders were under normal mode, they tended to stick on the inner vessel wall due to the high centrifugal force. A thermal couple of the main vessel recorded that the temperature of the inner vessel wall rose in the 
first couple of hours. Then dropped to a constant temperature and remained at this temperature until the end. However, for the step mode, the milling times were divided into 90 minutes of each. The temperature of the inner vessel wall rose to a spike and then the machine is off for a 10 minutes break. During this break, the main vessel were shaken by a plastic hammer to force the powder particles to fall from the inner vessel wall. It was noted that each cycle of step mode has a relatively inner vessel temperature comparing to the normal mode.

There could be two different kinds of temperature effects during the MCB process. One is due to the plastic deformation and friction of the particle squeezing through the confined gap between the blades and the inner chamber wall. And the efficiency of heat transfer is also part of the reason. The second one is the overall temperature in the main chamber. The temperature rose during the MCB process is mainly due to powder to wall collision and frictional effects among particles, blade tips, and the inner vessel wall. The overall temperature rose during the MCB process can be due to more than one reason. First, as mentioned above, one is the plastic deformation and frictional effects due to the kinetic energy of the rotation speed rise the temperature of powder. The higher the energy (i.e., rotation speed, size of the particle, size of the confined gap and running time, etc.), the higher is the temperature rise. Second, it is possible that exothermic processes occurring during MCB process cause the particles to ignite and generate additional heat. While the temperature of the vessel increases gradually with running time in the early stages, a sudden increase in temperature is noted when an exothermic reaction occurs among the particles, i.e. ignite occurs in the particles. Third, the transfer of energy from the blade to the vessel wall might also cause intrinsic temperature rise. Therefore, the step mode was adjusted and adopted in order to decrease the processing time of the MCB process. And the XRD results show that the MCB step mode has a higher efficiency than the MCB normal mode.

In order to investigate the difference among MCB milling time, rotation speed and running mode. The major peak of spectrums which is around $45^{\circ}$ is magnified as shown in Figure 5-4. It is obvious in the spectrums of the MCB-only processed powders that the MCB-only process did not generate $\mathrm{Ni}_{3} \mathrm{Al}$ phase in powders which implies it is only capable of producing pre-alloys with a uniform distribution of $\mathrm{Y}_{2} \mathrm{O}_{3}$. As shown in Figure 5-4, the XRD of the MCB+BM processed powder is the broadest, indicating powders were under severe plastic deformations. When powders were subject to MCB normal mode under different milling time and rotation speed, as indicated by spectrums $(\mathrm{k}) \sim(\mathrm{f})$, the peak did not shift and the intensity did not change significantly, meaning there was no much lattice deformation during the MCB normal mode process. However, the peaks of MCB step mode processed powders shifted toward higher diffraction angles, meaning solid diffusion happened during the process and lattice deformation occurred. It is possible that the large grain was substituted the small grain to decrease the lattice parameters. In other words, the MCB step mode would cause more lattice defects. For the BM-only processed powder, as displayed in spectrum (j), the major peak 
is much similar to the XRD of the MCB-only processed powders, meaning the MCB-only process is a potential alternative method of the BM process.

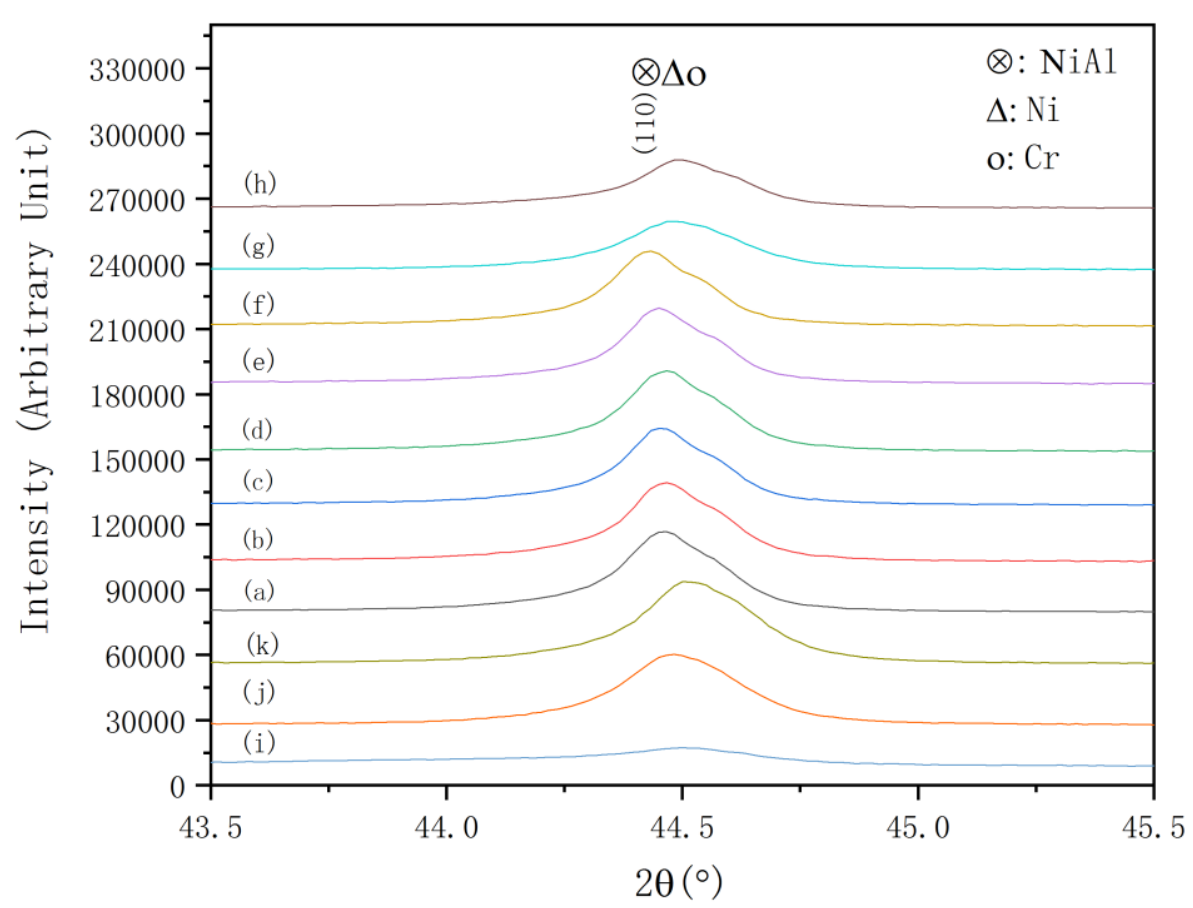

Figure 5-4. XRD spectrums of the processed powders: Normal mode under 4000rpm: (a). 18 hours; (b). 32 hours; (c). 50 hours. (k). 1 hour; Normal mode under 5000rpm: (d). 22 hours; (e). 32 hours; (f). 50 hours; Step mode under 5000rpm: (g). 8 hours; (h). 11 hours; (i). MCB+BM; (j). BM-only.

Utilizing the Full Width at High Maximum (FWHM) of XRD spectrums of processed powders, the peak broadening effect could be employed to estimate the micro-strain and crystal size of powder particles. Micro-strain, fine crystal size, and a systematic error of instrument usually contribute to XRD peak broadening. The following equation could represent the effect of XRD peak broadening [14]:

$$
B_{\mathrm{r}} \cos \theta=\frac{k \lambda}{L}+\eta \sin \theta
$$

Where, $B_{\mathrm{r}}-\mathrm{FWHM}$

$\theta$ - Diffraction Angle

$\mathrm{K}$ - Constant (0.89 1.39), in this study is 0.93

$\lambda-\mathrm{X}$-ray wavelength, in this study is $1.54060 \mathrm{~A}$

L-Crystal Size

$\eta$ - Micro-strain of crystal 


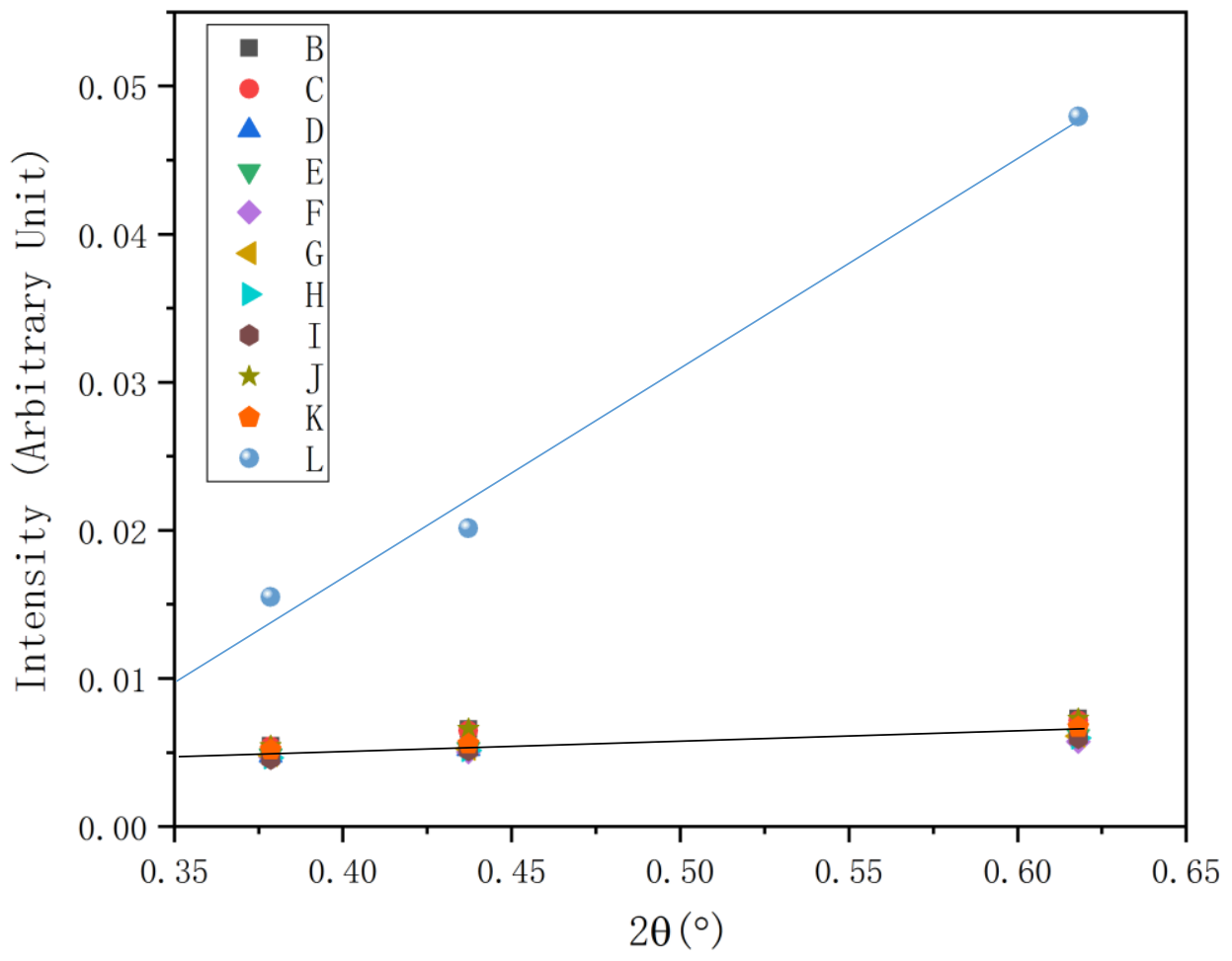

Figure 5-5. Analysis of line-broadening effect of processed powders: B. BM-only Normal mode under 4000rpm: C. 1 hours; D. 18 hours; E. 32 hours; F. 50 hours; Normal mode under 5000rpm: G. 22 hours; H. 32 hours; I. 50 hours; Step mode under 5000rpm: J. 8 hours; K. 11 hours; L. MCB+BM.

Equation (5.1) was plotted by using the FWHM $B_{r}$ times cos (corresponding diffraction angle $\theta$ ) as $\mathrm{Y}$-axis, and $\sin$ (corresponding diffraction angle $\theta$ ) as $\mathrm{X}$-axis. Figure 5-5 and 5-6 show $B_{r} \times \cos \theta$ as a function of $\sin \theta$. The scattered points were linearly fit and analyzed by linear regression in Origin. The intercept and slope of the fitting line represent the crystal size of powder and micro-strain. In order to observe the line-broadening effects of the XRD of the MCB-only process and the $\mathrm{BM}$-only process except for the MCB+BM process. Figure $5-5 \mathrm{~B} \sim \mathrm{K}$ is enlarged in Figure 5-6. All the scattered points were linearly fit and analyzed by linear regression in Origin. The slop and intercept were calculated in the Origin for each linearly fit line. And the micro-strain and crystal size calculated from the XRD spectrums are shown in Table 5-1. 


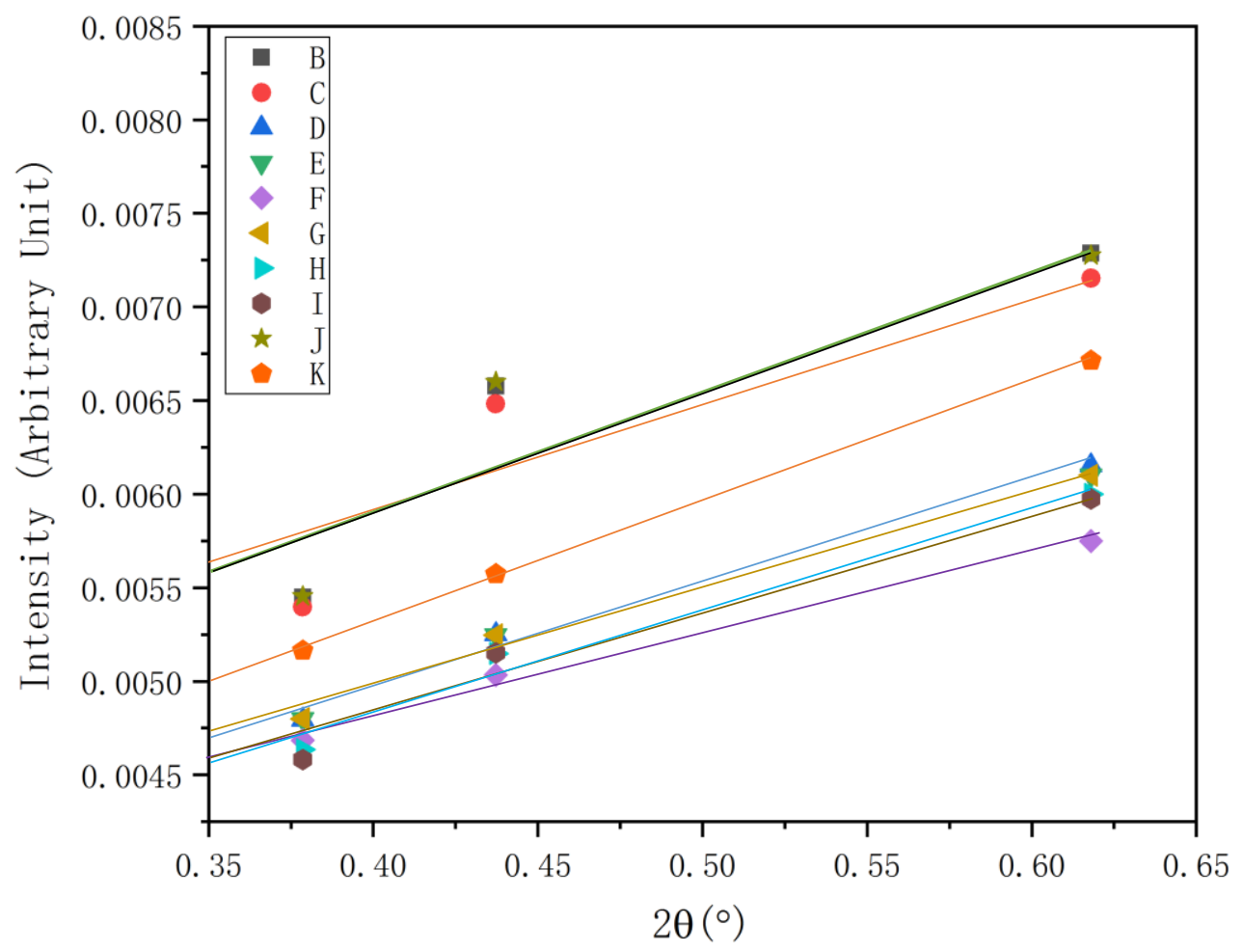

Figure 5-6. Analysis of peak broadening effect of processed powders.

\begin{tabular}{ccccc}
\hline \multicolumn{5}{c}{ Table 5-1. Micro-strain and crystal size of processed powders. } \\
\hline Processed & Rotation Speed & Milling hours & Micro- & Crystal \\
Powders & $($ rpm $)$ & & strain & Size (nm) \\
BM-only & 400 & 41 & $0.77 \%$ & 272 \\
MCB+BM & $4000+400$ & $1+40$ & $1.50 \%$ & 119 \\
M1 & Normal 4000 & 1 & $0.65 \%$ & 280 \\
M2 & Normal 4000 & 18 & $0.55 \%$ & 291 \\
M3 & Normal 4000 & 32 & $0.53 \%$ & 287 \\
M4 & Normal 5000 & 50 & $0.43 \%$ & 308 \\
M5 & Normal 5000 & 22 & $0.53 \%$ & 287 \\
M6 & Normal 5000 & 32 & $0.55 \%$ & 265 \\
M7 & Normal 5000 & 50 & $0.55 \%$ & 297 \\
M8 & Step 5000 & 8 & $0.67 \%$ & 270 \\
M9 & Step 5000 & 11 & $0.65 \%$ & 260 \\
\hline \multicolumn{5}{c}{}
\end{tabular}

Table 5-1 shows that when powders were under the MCB-only normal mode, the crystallographic structure did not change significantly since the micro-strain of powder particles almost remain at the same value. However, the micro-strain of the MCB-only step mode processed powder particles is $0.1 \%$ higher the MCB-only 
step mode processed powder particles. In general, the crystal size of the MCBonly processed powders is almost identical, suggesting the MCB-only process would not significantly change the crystallographic structure and powder size under different running mode and running duration, but it is capable of uniformly distributing nanosize $\mathrm{Y}_{2} \mathrm{O}_{3}$ into the matrix materials resulting in the disappearance of $\mathrm{Y}_{2} \mathrm{O}_{3}$. BM-only also would not change the crystallographic structure and powder size. But, the uniform distribution of $\mathrm{Y}_{2} \mathrm{O}_{3}$ during the $\mathrm{BM}$-only process is still not clear. Although the BM-only and the MCB-only process did not change the crystallographic structure greatly, the combined $\mathrm{MCB}+\mathrm{BM}$ process generated large micro-strain because the $\mathrm{Y}_{2} \mathrm{O}_{3}$ was homogeneously distributed during the MCB process. And since $\mathrm{Y}_{2} \mathrm{O}_{3}$ is nanosize, the large lattice strain was introduced during the BM process since high energy balls could produce a large amount of plastic deformation in powder by ball to ball, ball to wall, and ball to powder collisions. In this condition, the $\mathrm{Y}_{2} \mathrm{O}_{3}$ satisfied the Orowan strengthening mechanism and serve as a hard secondary phase. Therefore, the MCB+BM process has the best performance.

\subsubsection{SEM Analysis}

SEM imaging was conducted on the MCB-only, BM-only and MCB+BM fabricated powder samples showing morphology, topology and dimension. In order to compare the MA effects, BM-only powder sample was used as a reference benchmark. Figure 5-7 shows the SEM micrographs of the BM-only and MCB+BM processed powder at different magnification, suggesting the conventional BM-only process produced randomly shaped particles and the surface of the BM-only processed powders is rough, lamellar structure is clearly shown in the picture (shown as the red circle). But the MCB+BM process generated more spherical powders, and the surface of powders is smoother than the BM-only processed powders. The lamellar structure is not clear in the MCB+BM processed powders, meaning the MA effect was in the final stage.
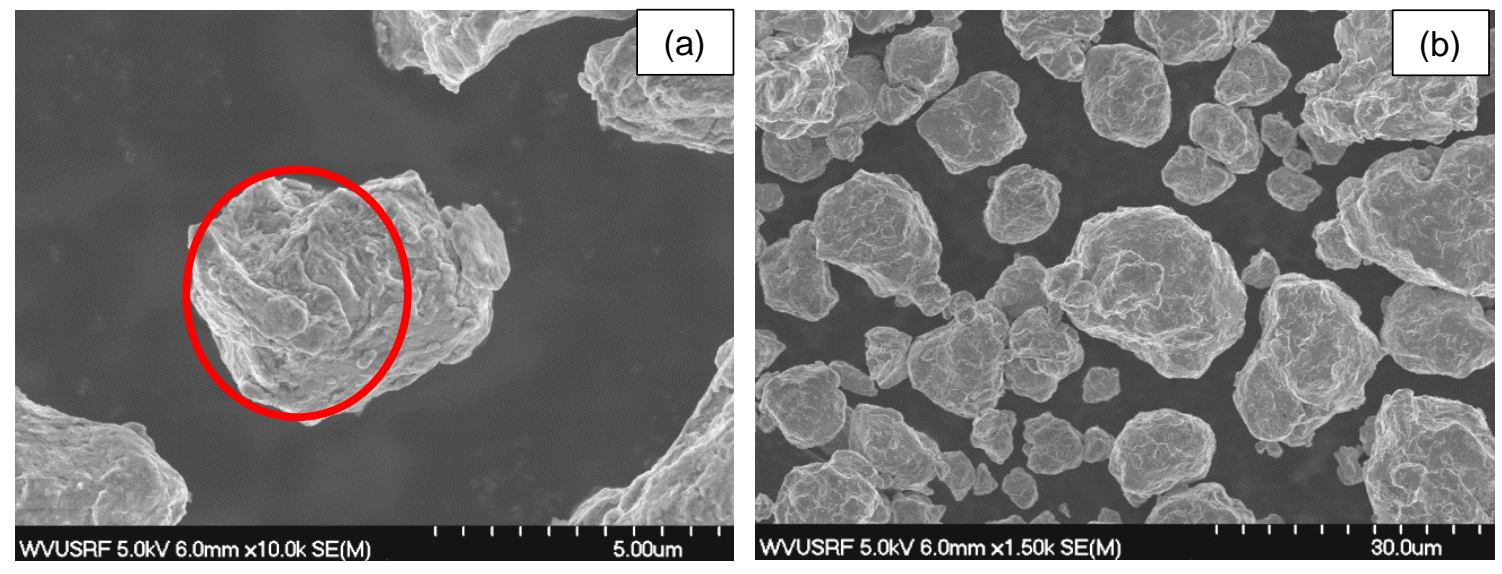

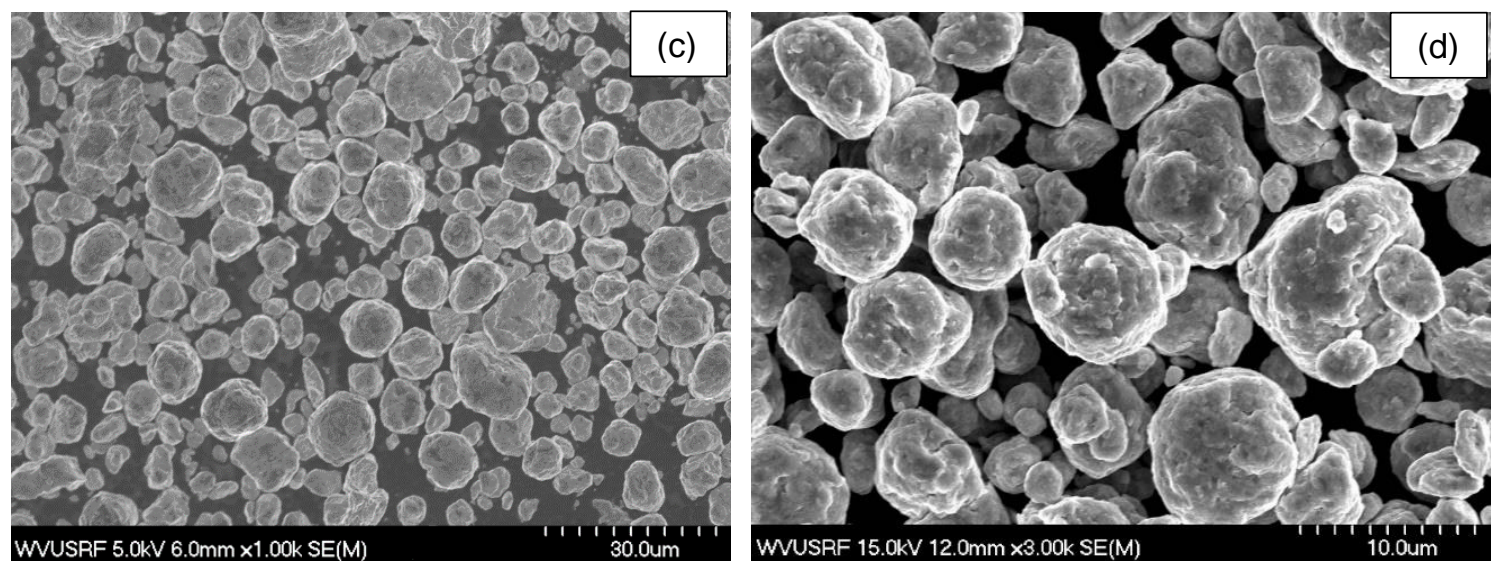

Figure 5-7. SEM micrographs of: (a).BM-only (x 10k); (b). BM-only (x 1.5k) (c). MCB+BM (x 1k); (d). MCB+BM (x 3k).

Figure 5-8 shows the morphology, shape and size distribution of the MCBonly processed powders under different milling time, rotation speed and running mode. In general, the powder particles from 1 hour to 50 hours under different rotation speed remain with some degree of sphericity. The chunky, bulky, and flaky microstructure did not appear in the MCB-only processed powders comparing to the BM processed powders. Figure 5-8 (a) shows the morphology of powders under MCB normal mode 4000rpm after 1hour. Some large size of spherical particles were observed, and some small particles were scattered in the background, suggesting the powder was under mixing and break-down. It is noted that some small particles were bonded onto the surface of the larger spherical particle, meaning the coating of particles started in the early stage.

Figure 5-8 (b) (d) show the morphology of particles under the same rotation speed $4000 \mathrm{rpm}$ for different milling time. The sphericity improved as the increase of the milling time, there were small particles scattering around in the background in (b), but as the milling time increased, the amount of the smaller particles decreased, and the surface of larger spherical particles were coated by the smaller particles. Figure 5-8 (e) (g) show the morphology of particles under the same rotation speed $5000 \mathrm{rpm}$ for different milling time. Similarly, the amount of smaller particles decreased as the milling time increased. However, when the input mechanical energy was increased from 4000rpm to 5000rpm, less small particles were observed in Figure 5-8 (e) (g) than Figure 5-8 (b) (d) respectively. Besides, Figure (f) and ( $g$ ) show almost no smaller particles in the background, and the size and shape of larger spherical tended to be uniform and homogeneous, meaning higher input mechanical energy would improve the MA effect during the process and enhance the morphology of powders. 

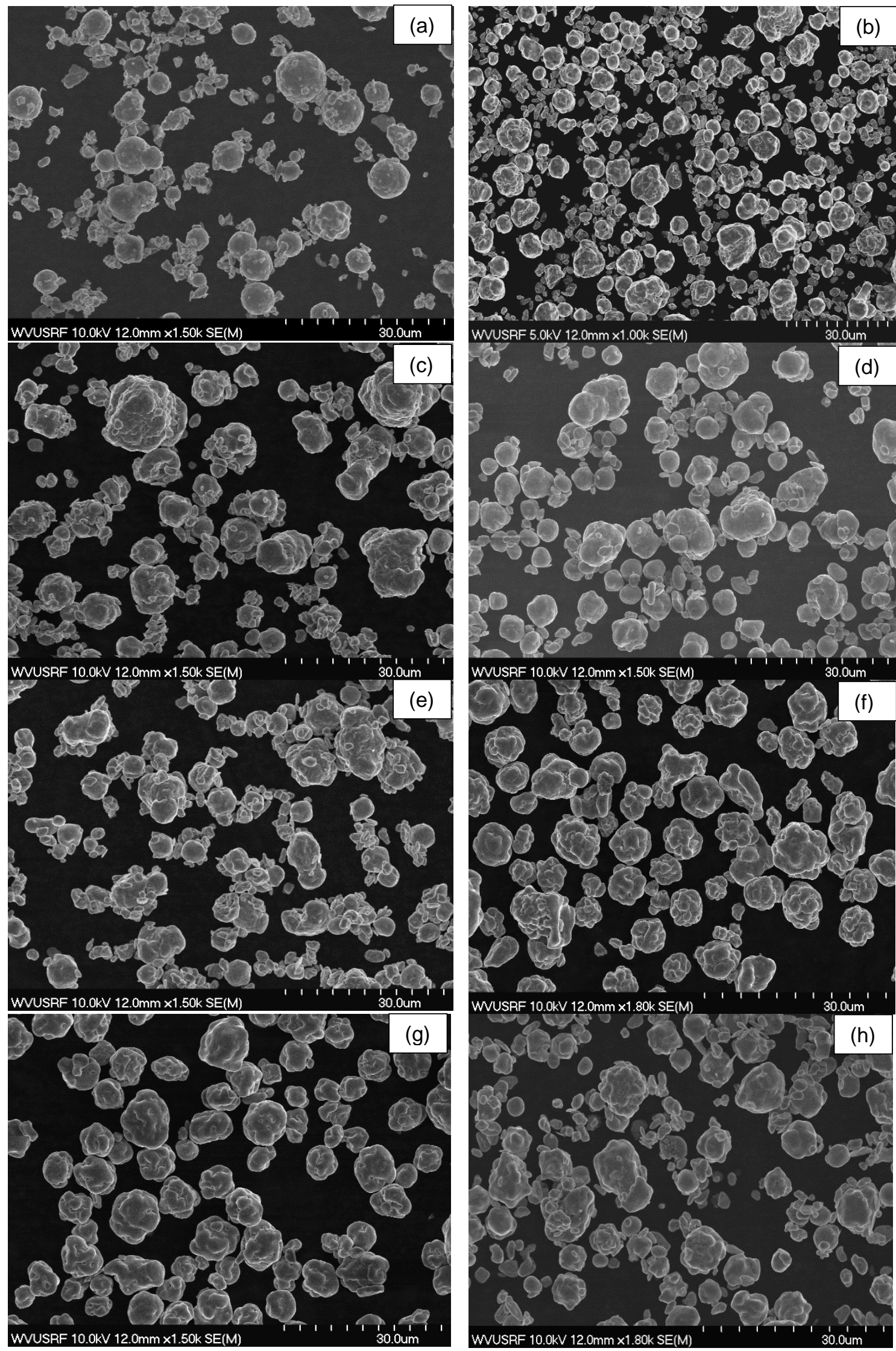

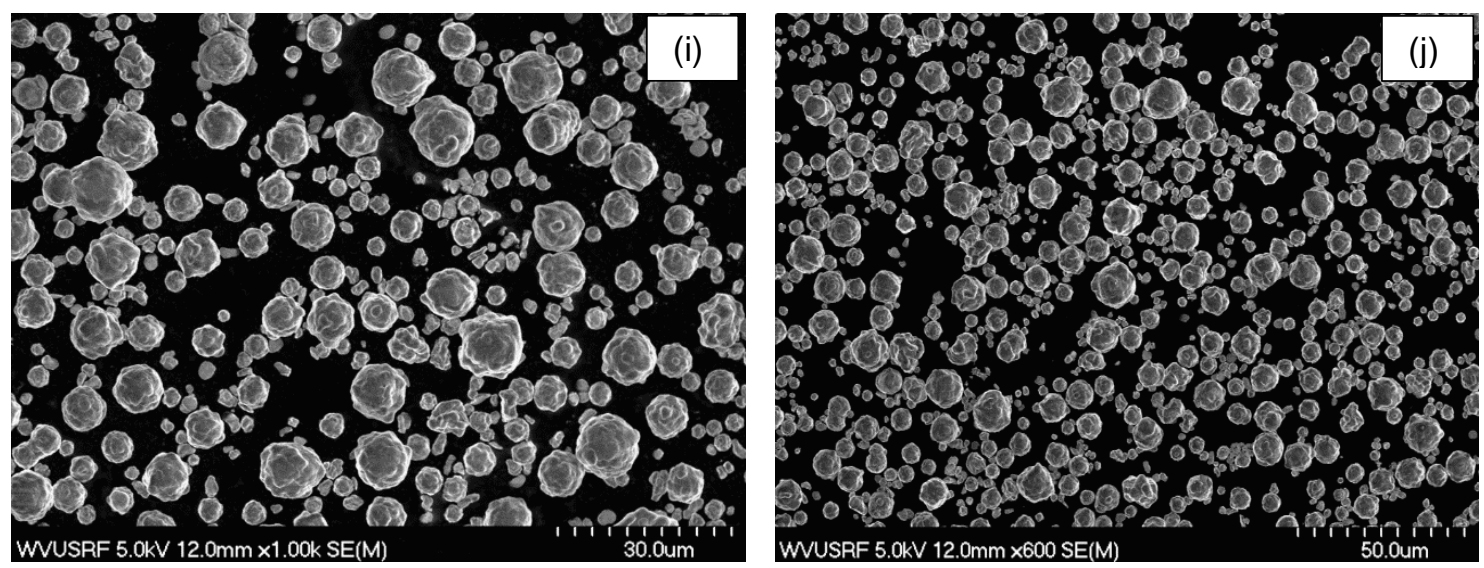

Figure 5-8. SEM images of the processed powders: Normal mode under 4000rpm: (a). 1 hours; (b). 18 hours; (c). 32 hours; (d). 50 hours; Normal mode under 5000rpm: (e). 22 hours; (f). 32 hours; (g). 50 hours; Step mode under 5000rpm: (h). 8 hours; (i). 11 hours (x 1k); (j). 11 hours (x 600).

Figure 5-8 (h) (j) show the morphology of particles under MCB step mode $5000 \mathrm{rpm}$ for different periods. The morphology, shape, and size in Figure 5-8 (h) is similar to Figure 5-8 (e), indicating that the MCB step mode could obtain almost the identical morphology, shape and size of the particle in a shorter amount of time. This confirms the conclusion drawn from the XRD that the MCB step mode has a higher efficiency than the MCB normal mode. Figure 5-8 (j) and (i) display the best morphology and shape of the processed powder. The surface of particles was smoother, and the particles were more spherical with an overall degree of roundness up to 0.93 which is near perfect shape. This makes the MCB-only step processed powder a potential candidate for AM applications.

Figure 5-9 shows SEM micrographs taken at a higher magnification in order to observe the surface of the powder particles. Figure 5-9 (a) shows the powder particles remained unchanged and spherical, and the spiky, chunky and flaky particles were not observed in the image. And it is obvious that some fragments of smaller particles were bonded onto the surface of the larger spherical particle. Figure 5-9 (b) (d) show the surface of particles under the same rotation speed $4000 \mathrm{rpm}$ for different milling time. The surface became smoother as the milling time increased. But the shape and sphericity changed comparing to Figure 5-9 (a), meaning the powder particles were under mechanical deformations. Figure 5-8 (h) (i) show the surface of particles under the same rotation speed $5000 \mathrm{rpm}$ for different milling time. The surface also became smoother as the milling time increased. But the surface roughness and shape of the powder particles under 4000rpm and 5000rpm are similar; they did not change significantly during the process. 

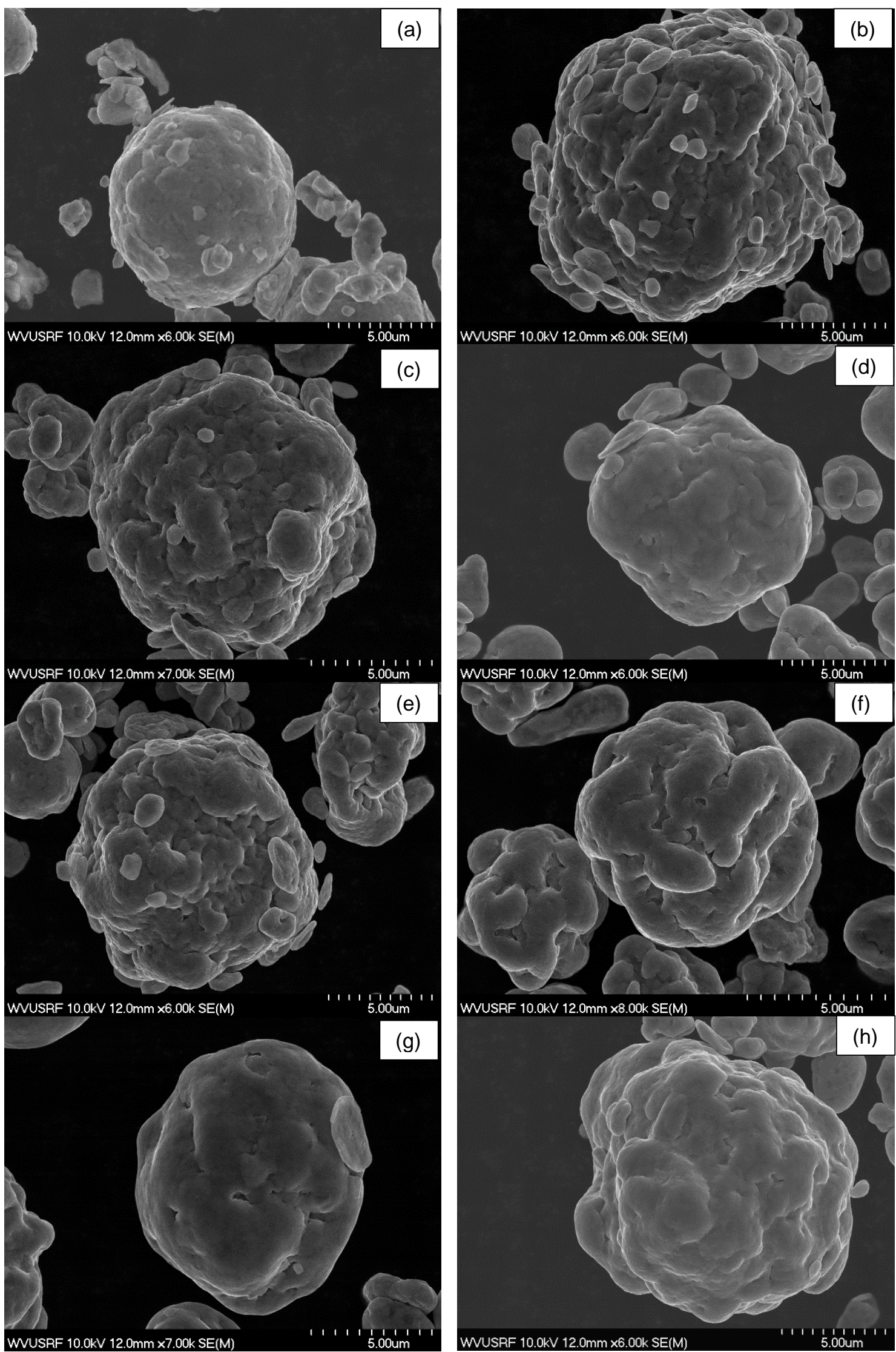


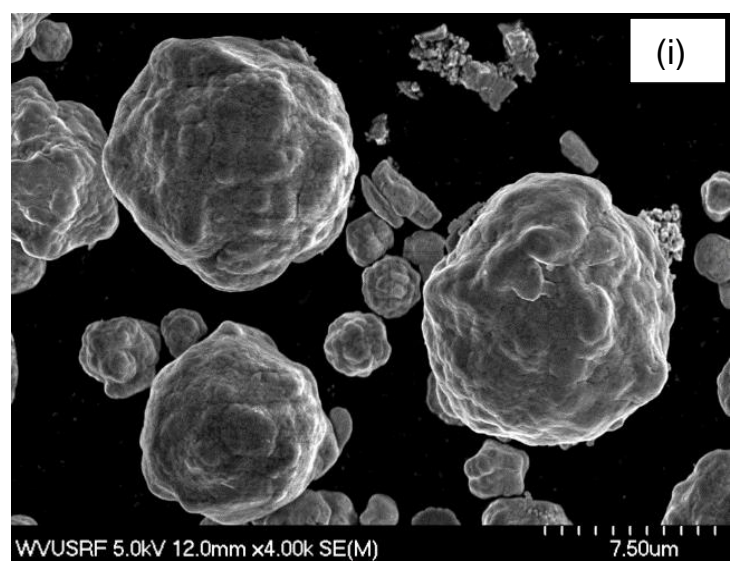

Figure 5-9. SEM images of the surface of the processed powders: Normal mode under 4000rpm: (a).1 hours; (b). 18 hours; (c). 32 hours; (d). 50 hours; Normal mode under 5000rpm: (e). 22 hours; (f). 32 hours; (g). 50 hours; Step mode

under 5000rpm: (h). 8 hours; (i). 11 hours (x 1k); (j). 11 hours (x 600).

Figure 5-8 (h) and (i) show the surface of particles under MCB step mode 5000 rpm for different periods, the MCB step processed particle has a smoother surface than other powder particles. And the coating of hosting particle could be finished in a shorter amount of time under the MCB step process. In summary, the composite and topography were observed in these MCB processed powder particles, indicating small particles were bonded on the surface of major particles or bonded with major particles forming the composite structure as seen in Figure 5-9. All MCB processed powder particles remained spherical, suggesting small micro-strain calculated from the XRD patterns.

\subsubsection{Size Distribution of Processed Powders}

The laser diffraction method is popularly used as a large number of measurement can be obtained within shorter timeframes and repeatable results are ensured through proper sample dispersion, referred to ASTMB822. The processed powders were analyzed by a Laser Particle Analyzer (Model: Malvern Panalytical's Master Sizer 2000). The size distribution results of this Master Sizer 2000 could be formulated as $D(x)=$ sizes, where $D$ is the diameter of particle as measured by laser diffraction, for which $x$ is the mass percent of particles with measured diameter less than D. As shown in Figure 5-9, five variations of powder size distribution were discussed in published results [16].

Additionally, distribution widths can be obtained through standard deviation measurements from the central tendency while the span (D90-D10/D50) is sometimes used to represent the width of a Gaussian size distribution based on size metrics computation. Typically, a higher standard deviation, larger span or size width are common indicators of a wider distributed powder and vice-versa [16]. 
Many commercial feedstocks used in SLM processes follow a Gaussian distribution whilst the addition or removal of powder particles through mixing and sieving operations could substantially affect the behavior of the distribution curve resulting in other model variants as shown in Fig 5-10. In Gaussian (normal) distributions, the mode, mean and median coincides at a single central tendency of the curve while negatively and positively skewed distributions are asymmetrical as a result of higher fractions in coarsened and fine particles respectively.
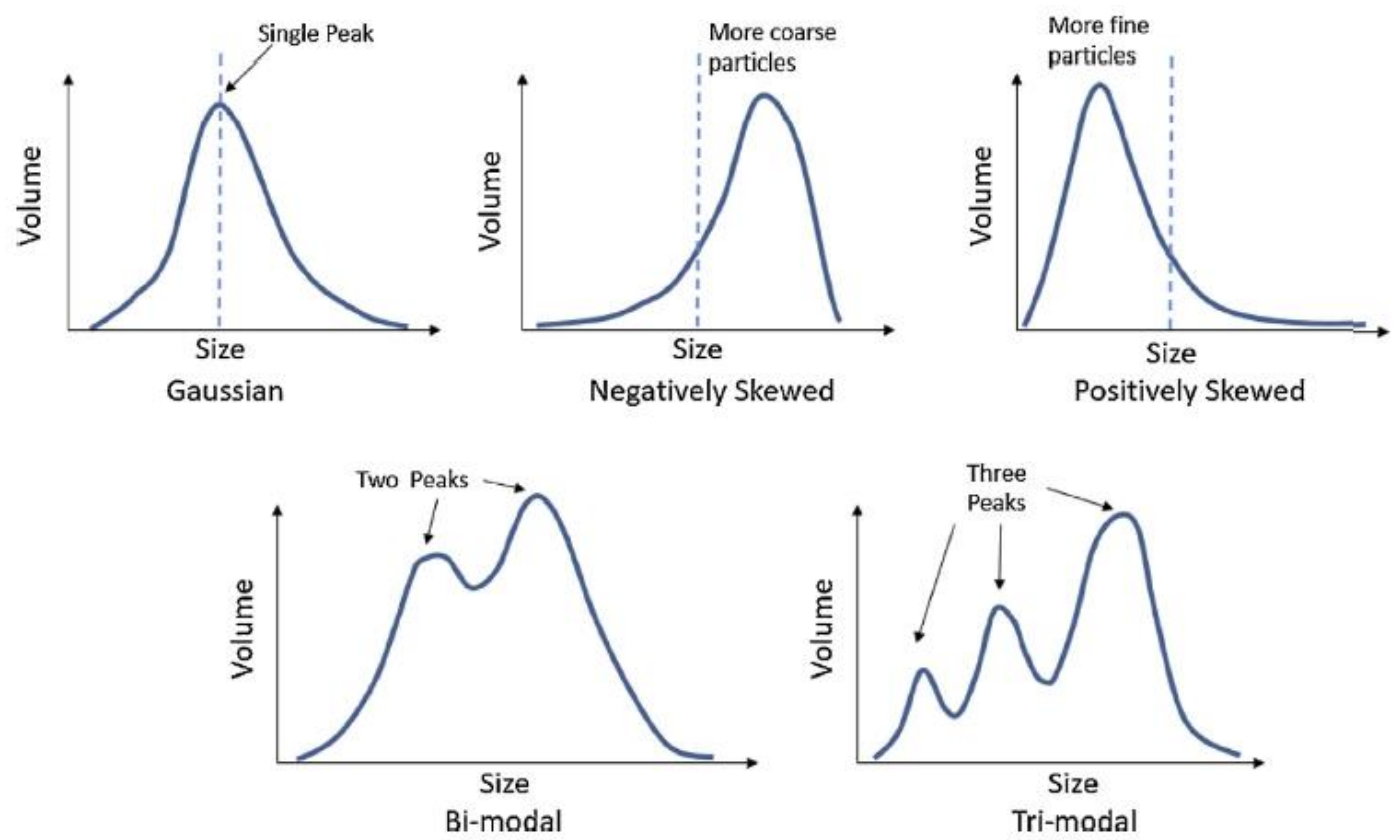

Figure 5-10. Variations of powder size distribution [16]

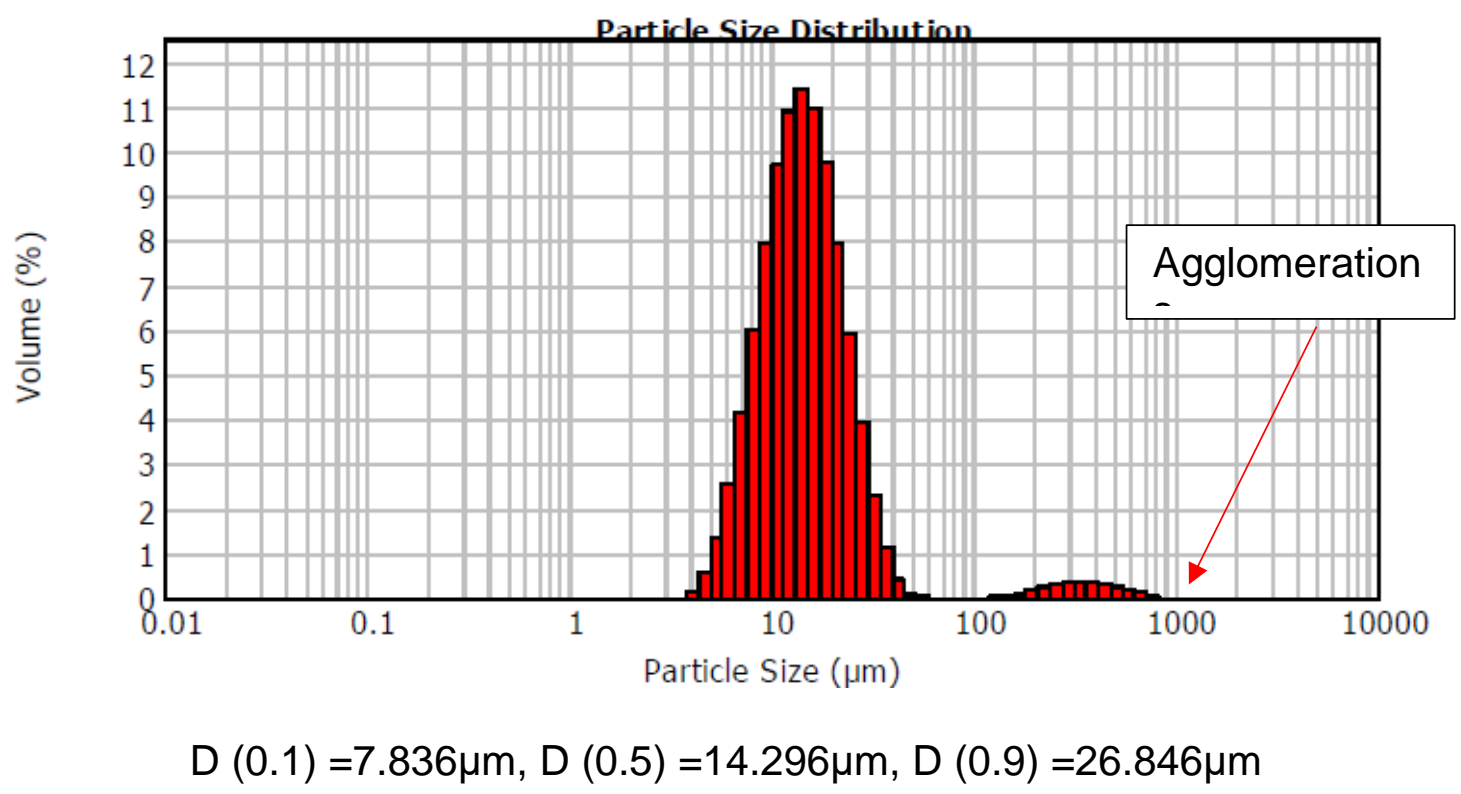

Figure 5-11. Powder size distribution of MCB+BM processed powder 


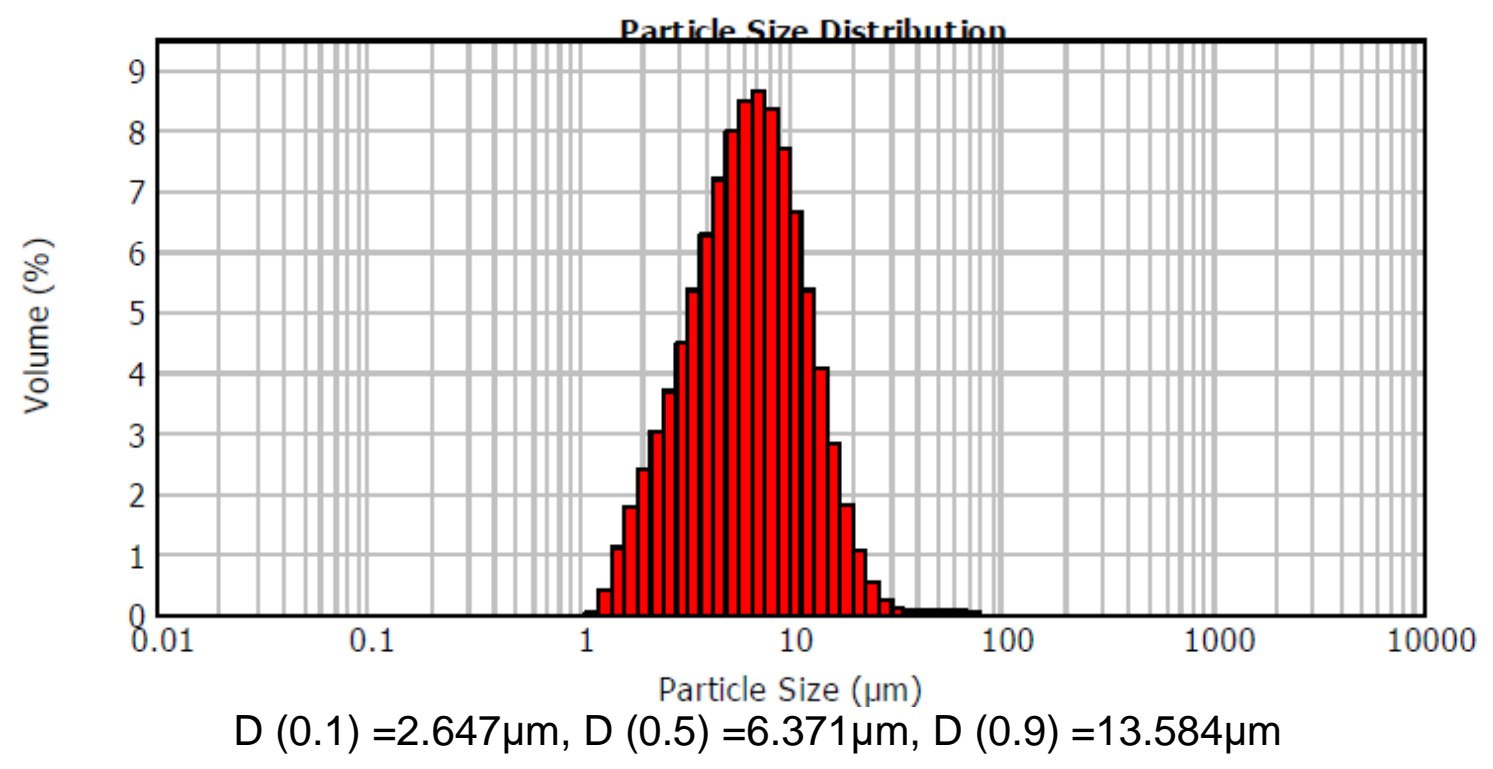

Figure 5-12. Powder size distribution of the BM-only processed powder

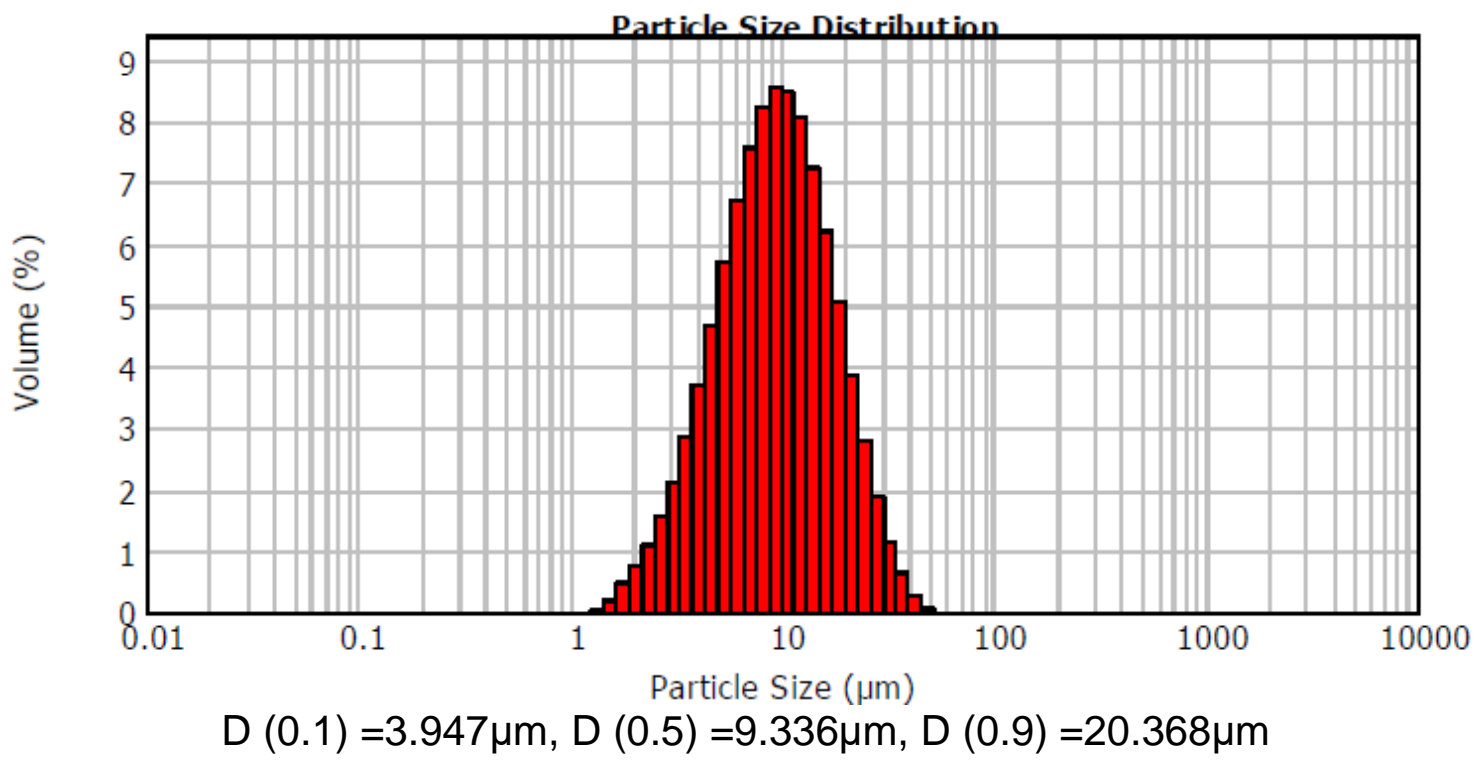

Figure 5-13. Powder size distribution of the MCB-only processed power (MCBnormal-4000 rpm-50 hours). 


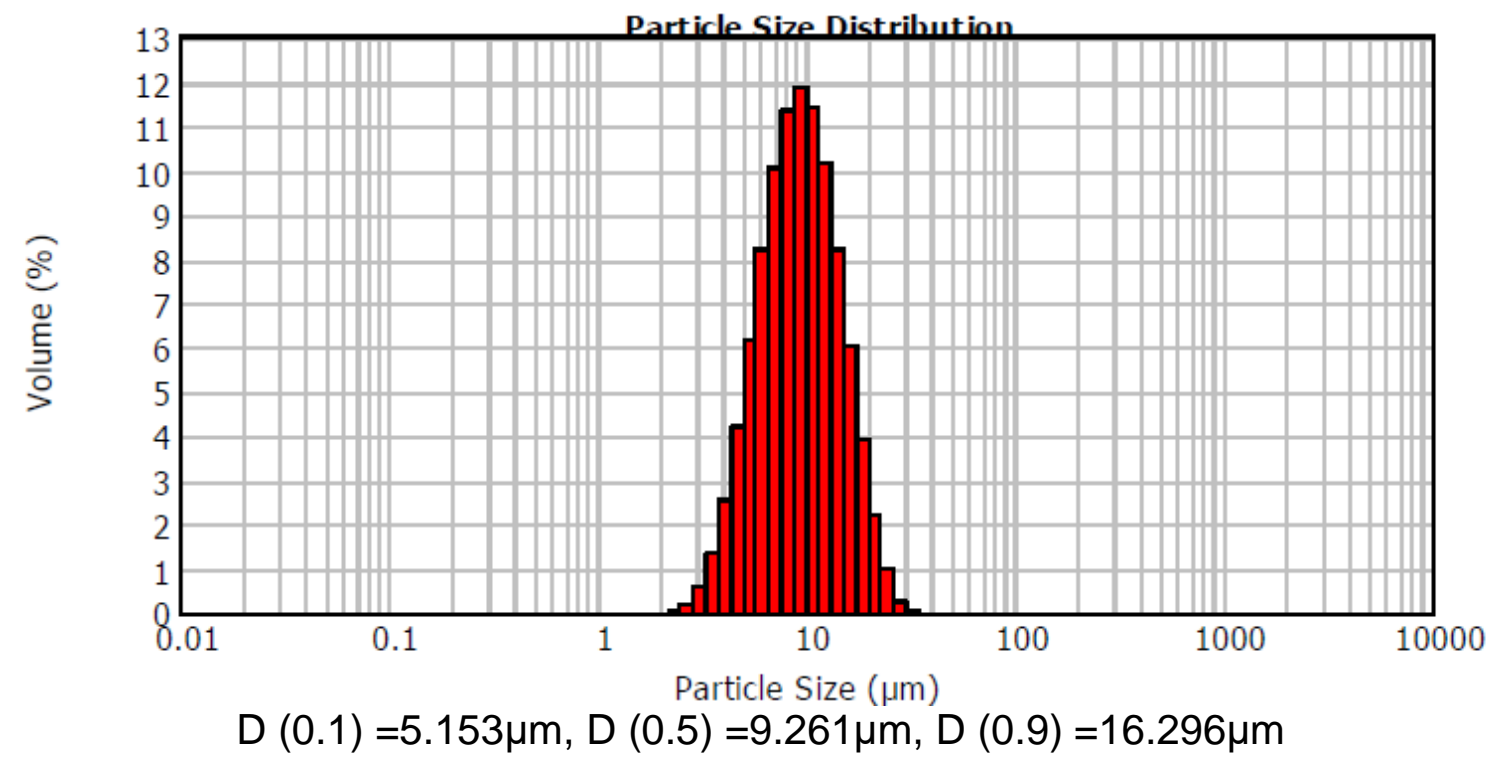

Figure 5-14. Powder size distribution of the MCB-only processed power (MCBnormal-5000 rpm-50 hours).

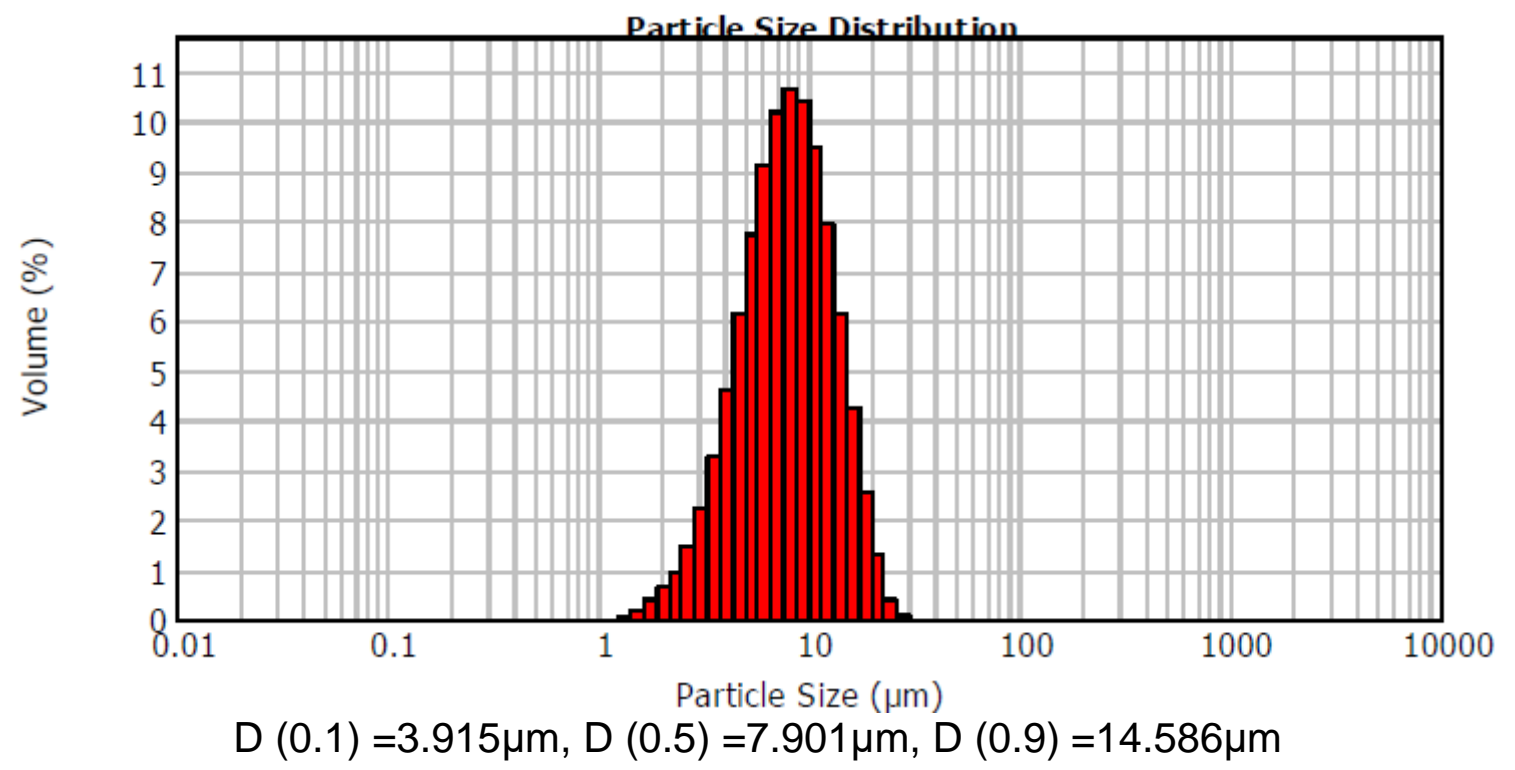

Figure 5-15. Powder size distribution of the MCB-only processed power (MCBstep-5000 rpm-8 hours). 


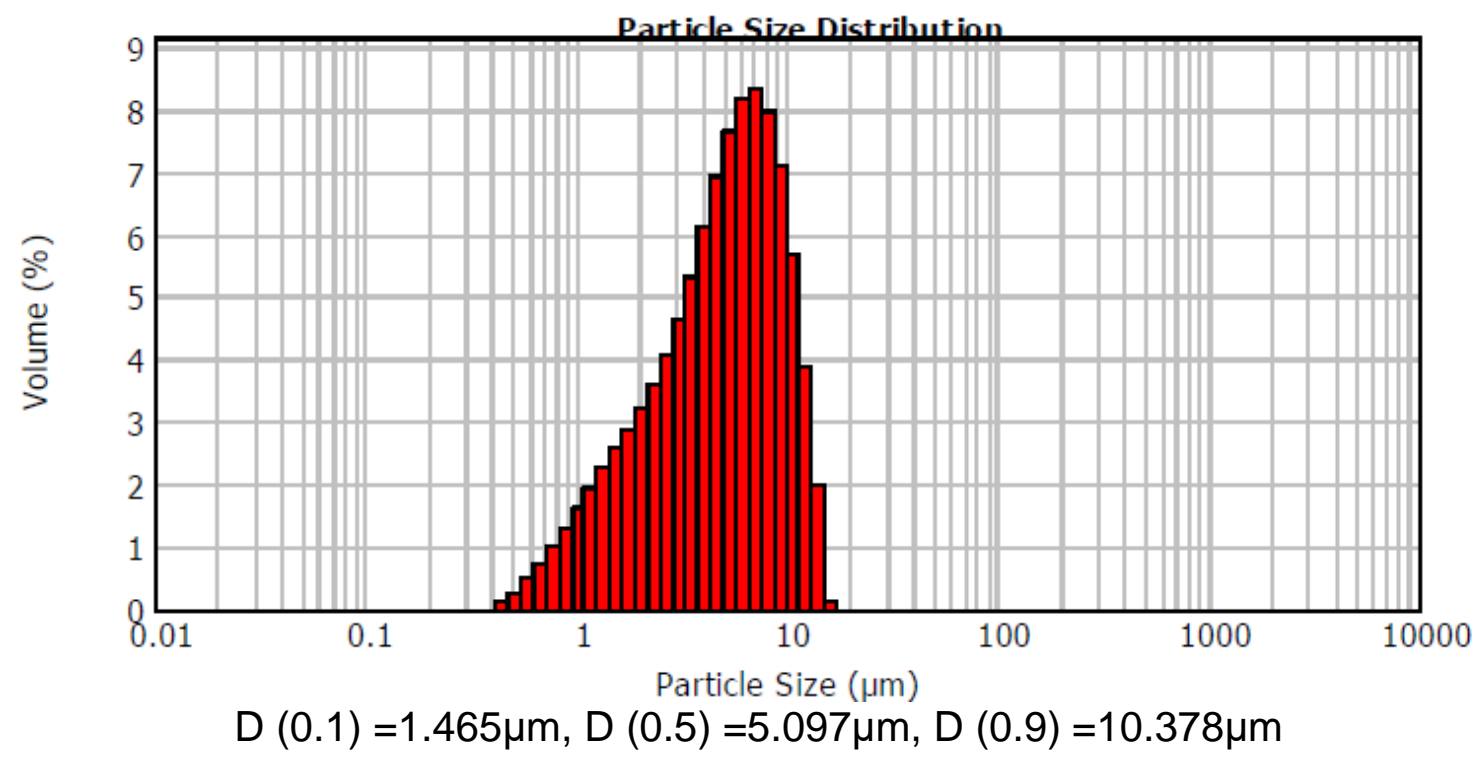

Figure 5-16. Powder size distribution of the MCB-only processed power (MCBstep-5000 rpm-8 hours).

Figure 5-11 to 5-15 show that the powders processed by MCB+BM, the BMonly process, and the MCB-only normal mode processes satisfy the desired Gaussian model. However, the MCB-only step mode processed powder under $5000 \mathrm{rpm} 11$ hours (Figure 5-16) is a while negatively skewed distribution, indicating the amount of smaller particles is larger than other processed powders. The disadvantage of the negatively skewed distribution the smaller particles agglomerate easily due to the Vander Waals force.

Figure 5-17 summarizes the size distribution of the processed powders. It is obvious that the MCB+BM processed powder has the largest average particle size which is desirable for AM applications. The BM-only processed powder has a lower average particle size comparing to the MCB-only normal mode processed powders. As the rotation speed increased during the MCB-only processed, the average particle size did not change significantly. However, the size of $90 \%$ (D 0.9) of the larger particle decreased which narrowed the distribution range which indicates that the higher rotation speed improves the spheroidization and surface modification of powder particles. Figure 5-16 (f) shows that the MCB-only step mode could generate the highest input mechanical energy which results in smaller particle sizes.

To sum up and combine the XRD and SEM analysis, the MCB+BM process has the best performance in powder fabrication. The BM-only process is similar to the MCB-only process based on the XRD and SEM results, but the duration of the $\mathrm{BM}$-only is relatively long. Also, the production of a BM machine is only $64 \mathrm{~g}$ of each batch, while the MCB-only process has a production yield of $300 \sim 350 \mathrm{~g}$ of each batch. Therefore, MCB-only process is a suitable alternative process for producing ODS superalloy powders for AM applications. Since the powders 
processed by $\mathrm{MCB}+\mathrm{BM}$ process, the MCB-only normal mode process and the MCB-only step mode process own a large, medium and small particle size range respectively. Powder fabricated by these three processes were chosen to conduct AM experiments on Laser systems to investigate the feasibility of the produced powders applying to AM technique.

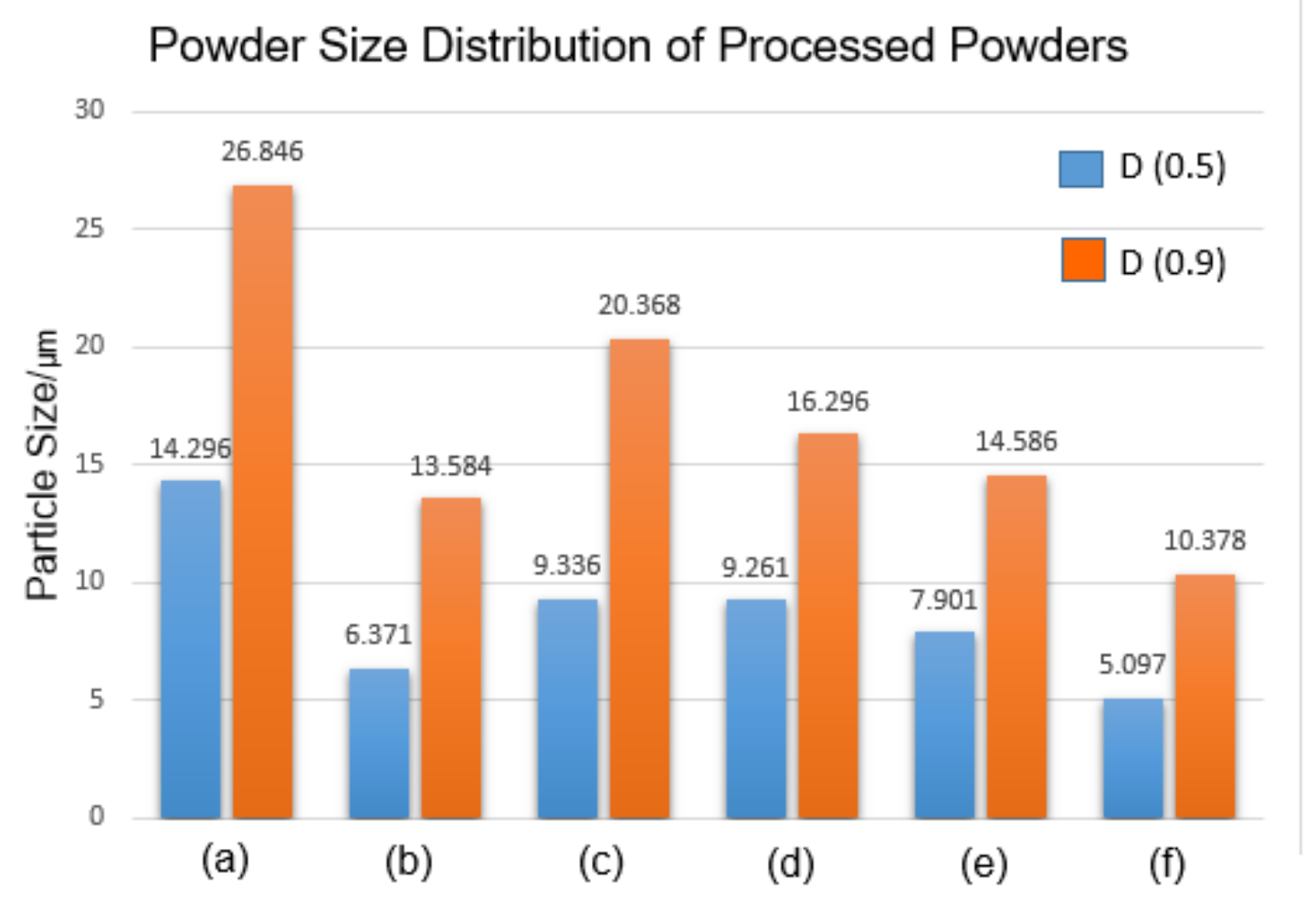

Figure 5-17. Powder size distribution of different processed powders: (a). MCB+BM process; (b). The BM-only process; the normal MCB-only process: (c). 4000 rpm 50 hours; (d). 5000 rpm 50 hours; the step MCB-only process: (e). 5000 rpm 8 hours; (f). 5000 rpm 11 hours.

\subsection{Analysis of As-printed Samples}

\subsubsection{LENS As-printed Samples}

I). The First Batch of Samples

The MCB+BM processed powders were applied on LESN 450 system with a nominal laser spot size of $240 \mu \mathrm{m}$. A MAR-M247A flat plate was selected as the substrate. As shown in Figure 5-18, three as-printed samples were additively manufactured. Samples were fabricated with a laser travel speed of $33 \mathrm{~mm} / \mathrm{s}$. The laser power was selected as $200 \mathrm{~W}, 250 \mathrm{~W}$ and $270 \mathrm{~W}$, producing linear energydefined as laser power $(\mathrm{J})$ /laser travel speed $(\mathrm{mm})$ [54]. Therefore the linear energy is $6.06 \mathrm{~J} / \mathrm{mm}, 7.75 \mathrm{~J} / \mathrm{mm}$ and $8.33 \mathrm{~J} / \mathrm{mm}$ respectively. Hatching lines were made at $0{ }^{\circ}$ horizontally in the first layer and then were rotated $90^{\circ}$ for the next 
layer. The hatch spacing was $0.1524 \mathrm{~mm}$, and the layer thickness was $0.1 \mathrm{~mm}$. The powder feeding rate was $8 \mathrm{rpm}$.

$\begin{array}{lll}200 \mathrm{~W} & 250 \mathrm{~W} & 275 \mathrm{~W} \\ \text { Laser } & \text { Laser } & \text { Laser } \\ \text { Power } & \text { Power } & \text { Power } \\ \text { Coating } & \text { Coating } & \text { Coating }\end{array}$

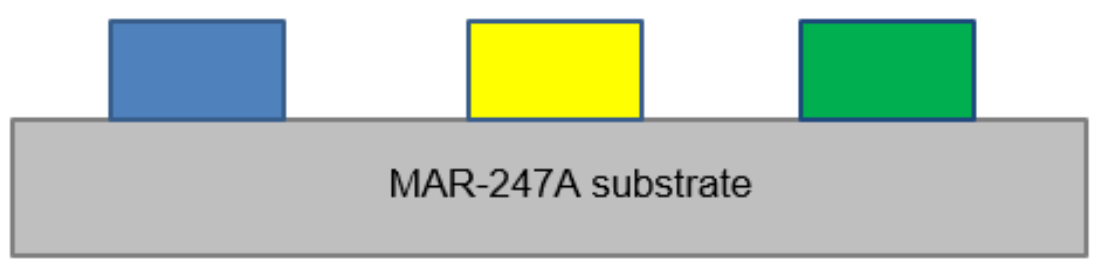

Figure 5-18. A schematic of the first batch of LENS as-printed samples.

Table 5-2. The experimental density, relative density, and input linear energy of as-printed samples.

\begin{tabular}{cccc}
\hline $\begin{array}{c}\text { As-printed } \\
\text { samples }\end{array}$ & $\begin{array}{c}\text { Experimental Density } \\
\left(\mathrm{g} / \mathrm{cm}^{3}\right)\end{array}$ & $\begin{array}{c}\text { Relative } \\
\text { Density } \\
(. \%)\end{array}$ & $\begin{array}{c}\text { Input Linear } \\
\text { Energy } \\
(\mathrm{J} / \mathrm{mm})\end{array}$ \\
$200 \mathrm{~W}$ & 5.67 & $66.63 \%$ & 6.06 \\
$250 \mathrm{~W}$ & 6.33 & $74.38 \%$ & 7.75 \\
$275 \mathrm{~W}$ & 7.13 & $83.78 \%$ & 8.33 \\
\hline
\end{tabular}

Table 5-2 shows the experimental density and relative density of as-printed samples. The as-printed density of samples increased with the increase of the linear energy, meaning the more linear energy, the densifier microstructure and the more chance of forming a melt pool. Figure 5-18 shows the SEM images of the cross-section of $200 \mathrm{~W}-6.06 \mathrm{~J} / \mathrm{mm}, 250 \mathrm{~W}-7.75 \mathrm{~J} / \mathrm{mm}$, and $275 \mathrm{~W}-8.33 \mathrm{~J} / \mathrm{mm}$ asprinted samples. It shows the influence of the laser linear energy on the microstructure of as-printed parts observed at a low magnification (under the same magnification). In order to examine the characteristic microstructure clearly, higher magnifications on the specific locations were investigated and shown in Figure 519.

Figure 5-19 (a) shows clear pores existing in the as-printed ODS part which explains the low density of this as-printed sample. Columnar structures were found clearly in Figure 5-19 (b) and (c), but not in (a), suggesting a higher input linear energy would cause columnar structure since it could provide a more thermal driving force for the grain growth of the microstructure. No clearly pores were found in a low magnification in Figure 5-19 (b) and (c). The growth directions of columnar structure and the building direction of the as-printed ODS parts are displayed by arrows in the SEM image. The growth direction of the columnar structure was found that it was approximately $45^{\circ}$ from the building direction. 

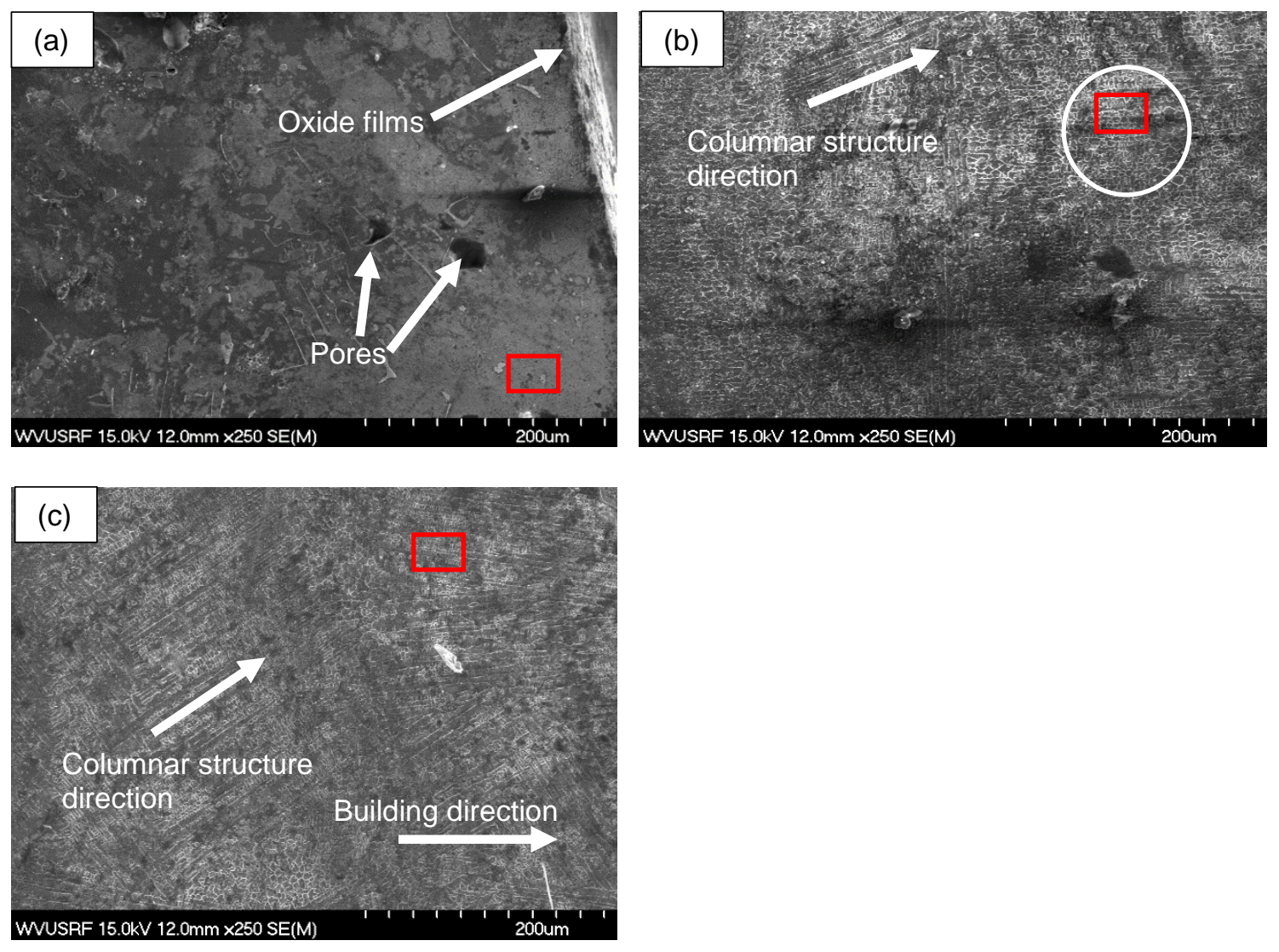

Figure 5-19. SEM showing images of the characteristic microstructures of asprinted ODS parts at different laser powder and input linear energy: (a). 200W$6.06 \mathrm{~J} / \mathrm{mm}$; (b). $250 \mathrm{~W}-7.75 \mathrm{~J} / \mathrm{mm}$; (c). $275 \mathrm{~W}-8.33 \mathrm{~J} / \mathrm{mm}$

As the laser power increased, the columnar structure arrays became finer, exhibiting a typical epitaxial growth along the growth direction. However, in Figure 5-19 (b), as the building direction forwarded, the columnar structure became dispersed and unclear (shown by the circle). But the columnar structure in Figure 5-19 (c) was still clearly found as the building direction forwarded, meaning the input energy of $250 \mathrm{~W}-7.55 \mathrm{~J} / \mathrm{mm}$ sample was not sufficient and decreased with advancement of the building direction comparing the $275 \mathrm{~W}-8.33 \mathrm{~J} / \mathrm{mm}$ sample.

Figure 5-20 shows the characteristic microstructures of as-printed ODS parts in the specific locations (as indicated in the red block in Figure 5-19) at a higher magnification. No columnar structures were found in Figure 5-20 (a), but some tiny upright $\gamma^{\prime}$ phase was observed. It was hard to identify every columnar dendrite in Figure 5-20 (b) since severe clustering occurred during the solidification process within the melt pool. Also, short cracks were found in the inter-dendritic region in Figure 5-20 (b). The continuous columnar dendrites are still clearly observed in Figure 5-20 (c). But small and short cracks were still found in the interdendritic region. 

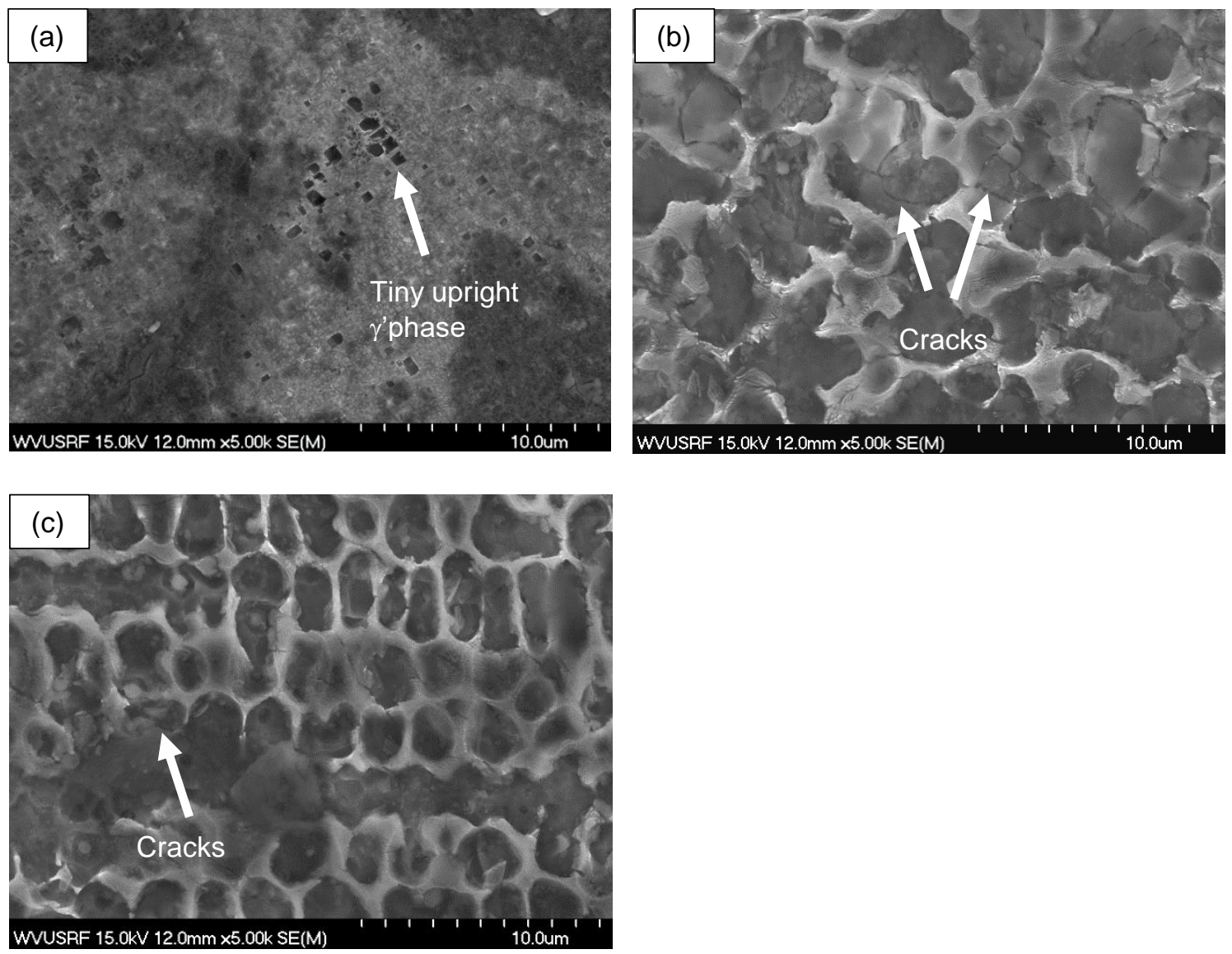

Figure 5-20. High-magnification of SEM micrographs showing the characteristic microstructures of as-printed ODS parts in: (a). Figure 5-19 (a); (b). Figure 5-19 (b); (c). Figure 5-19 (c).

Unlike the ambiguous epitaxial characteristics shown in Figure 5-20 (b), the columnar dendrites generally displayed the epitaxial growth with a higher degree of clustering on increasing the laser power. Generally, the major input energy and heat induced by laser radiation were transmitted through the substrate of previous as-printed layers, which in turn facilitated the formation of typical columnar dendrite structures along the building direction [54-56]. Furthermore, residual thermal stress as a result of the repeated rapid melting and solidification at a higher laser power was remained in the workpiece [57], which results in the generation of thermal cracks in both dendrite and inter-dendritic regions that were observed in the SEM micrographs.

As regards the increasing of the laser power, the instantaneous and overall temperature within the melt pool increased remarkably due to more heat and energy induced by the laser beam generated during the process. As a consequence, the heat accumulated during the process which caused the internal energy and thermodynamic potentials improved. The improvement enhanced the epitaxial growth of the columnar dendrites and the dispersion performance [56]. 
In order to examine the chemical composition of the columnar dendrites and the inter-dendrite zones that were observed in different process conditions. EDS point scan was conducted to identify the chemical composition as shown in Figure 5-21. For EDS spot 1, it shows $\mathrm{C}, \mathrm{O}, \mathrm{Cr}, \mathrm{Al}, \mathrm{Ni}$, and $\mathrm{Y}$. And the major component is $\mathrm{Cr}, \mathrm{Al}$, and $\mathrm{O}$, meaning it formed complex oxides and carbide during the process. And the $\mathrm{Y}_{2} \mathrm{O}_{3}$ tended to grow on the grain boundary. EDS spots show $\mathrm{C}, \mathrm{O}, \mathrm{Ni}, \mathrm{Cr}$, $\mathrm{Al}$, and $\mathrm{W}$. The yttrium was not found in this spot. The major composition is $\mathrm{C}, \mathrm{Ni}$, and $\mathrm{Cr}$, meaning a complex carbide formed at this location.

EDS point analysis indicated that carbon was introduced during the process. It is because the powders were processed by $\mathrm{MCB}+\mathrm{BM}$ process. A processing control agent with the composition of $\mathrm{CH}_{3}\left(\mathrm{CH}_{2}\right)_{16} \mathrm{CO}_{2} \mathrm{H}$ to boost the MA effect during the BM process. Some of the carbon remained after the BM process and reacted with major elements $\mathrm{Ni}, \mathrm{Cr}$, and $\mathrm{Al}$ to form carbides during the printing process.
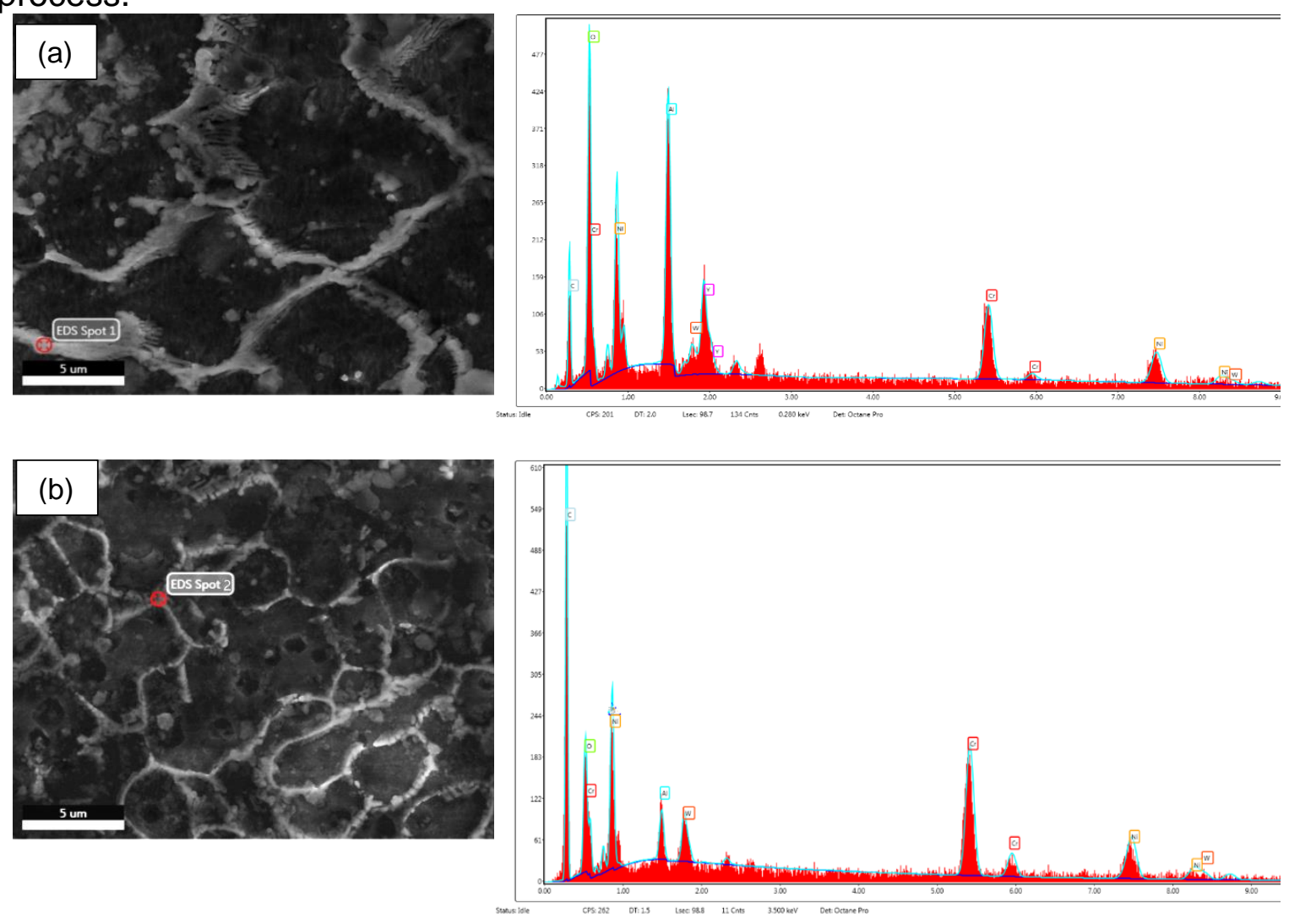

Figure 5-21. EDS point analysis of as-printed ODS parts at different laser powder and input linear energy: (a). 250W-7.75 $/ \mathrm{mm}$ in mid-layer; (b). $275 \mathrm{~W}-8.33 \mathrm{~J} / \mathrm{mm}$ in mid-layer. 


\section{II). The Second Batch of Sample}

The first batch of samples has reviewed the influence of different laser powder on as-printed microstructure. In order to investigate the influence of different laser scanning speed on as-printed microstructure. A second batch of sample was conducted on LENS 450 system. Also, for the purpose of exploring the feasibility of the MCB-only processed powders being applied in AM process. The as-printed sample was deposited by the MCB-only-step-5000 rpm 11 hours processed powders. Since the MCB-only process only generates pre-alloys, the laser scanning speed was decreased to improve the input linear energy. Thus, more thermal and grain growth driving force would be provided for grain growth to form densified macrostructures.

Figure 5-22 shows a schematic and images of the second batch printed sample. A stainless steel flat plate was selected as substrate. The laser power was selected as $250 \mathrm{~W}$. The hatching line remained the same as previous experiments. But the laser travel speed was decreased to $10 \mathrm{~mm} / \mathrm{s}$, therefore, providing a 25 $\mathrm{J} / \mathrm{mm}$ linear energy which is a significant enhancement from previous experiments. The layer thickness was still $0.1 \mathrm{~mm}$. 20 layers were printed. The size of the asprinted sample is $10 \mathrm{~mm} \times 10 \mathrm{~mm} \times 2 \sim 3 \mathrm{~mm}$, as indicated as 1 in Figure 5-22 (b). The as-printed experimental density of $250 \mathrm{~W}-25 \mathrm{~J} / \mathrm{mm}$ sample is $8.13 \mathrm{~g} / \mathrm{cm}^{3}$. And the relative density is $95.53 \%$ which is relatively high comparing to previous results.
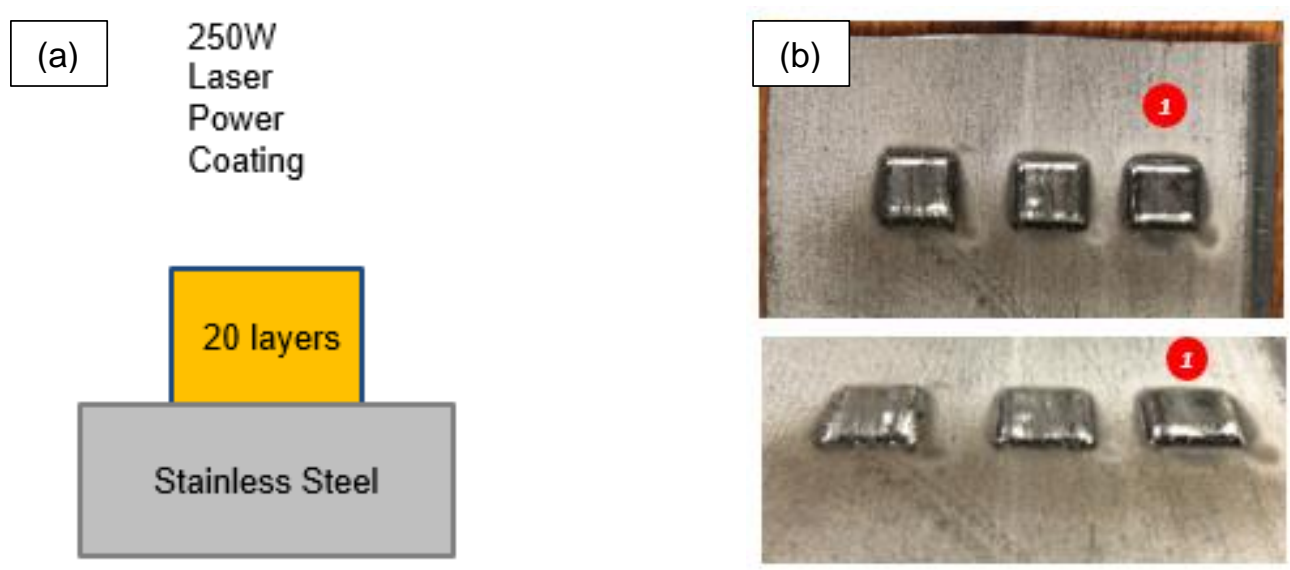

Figure 5-22. A schematic (a) and images (b) of as-printed ODS part: 250W$25 \mathrm{~J} / \mathrm{mm}$ 

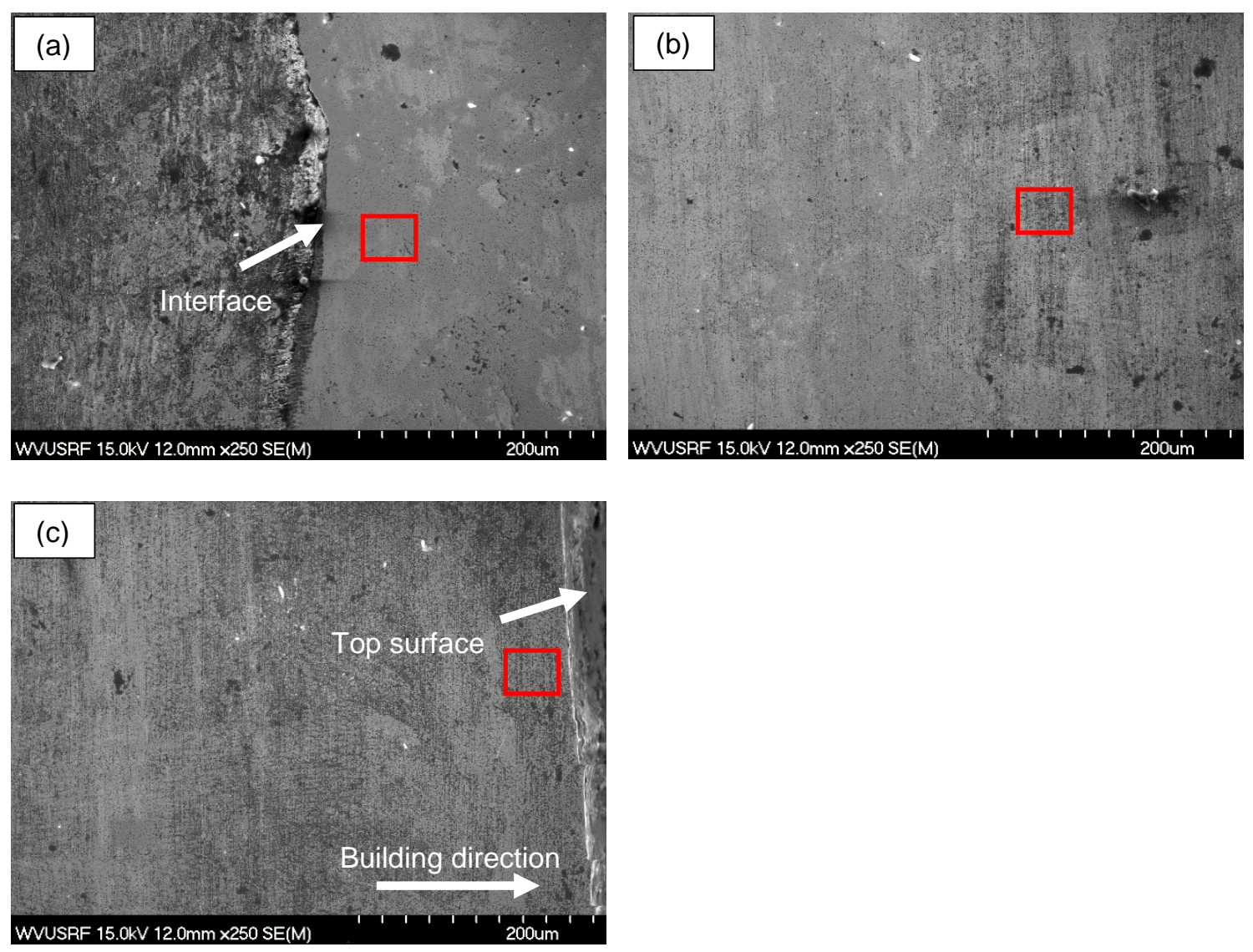

Figure 5-23. SEM micrographs showing the characteristic microstructures of the cross-section of as-printed ODS part $(250 \mathrm{~W}-25 \mathrm{~J} / \mathrm{mm})$ : (a). The interface of the substrate and deposited part; (b). Mid-layer of the deposited part; (c). Top-layer of the deposited part.

Figure 5-23 shows the characteristic microstructures of the cross-section of the as-printed ODS part. No obvious cracks and pores were found in the microstructure as a low magnification. In order to examine the characteristic microstructure clearly, higher magnifications on the specific locations (as indicated in the red blocks in Figure 5-23) were investigated and shown in Figure 5-24.

SEM images at a high magnification clearly show that the $\gamma^{\prime}$ phase precipitated during the printing process but it did not grow due to the rapid cooling in the early stage of printing. In the near-interface area shown in Figure 5-24 (a), spherical and tiny $\gamma^{\prime}$ phase started precipitated from the matrix. More $\gamma^{\prime}$ phase was found in the mid-layer and top-layer, as shown in Figure 5-24 (b) and (c), most of the $\gamma^{\prime}$ phase in the mid-layer became cuboid from spherical. However, the $\gamma^{\prime}$ phase displayed as stretched cuboid in the top-layer, meaning the $\gamma^{\prime}$ phase tended to mismatch as the building direction forwarded. Furthermore, more amount of precipitated $\gamma$ ' phase was observed as the building direction forwarded, suggesting a reheating and remelting occurred by the heat transmitted from previously deposited layers and the substrate. 

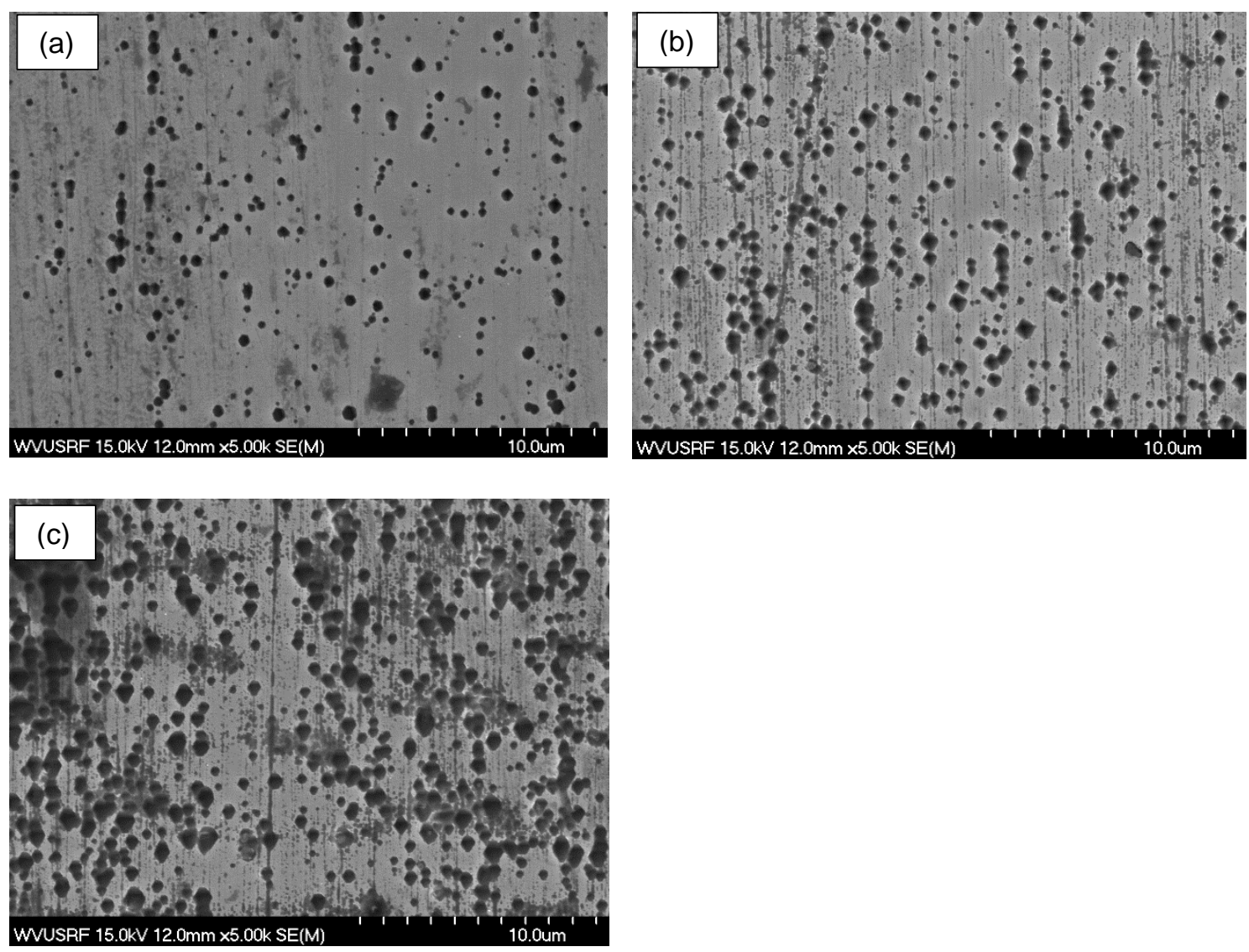

Figure 5-24. High-magnification of SEM micrographs showing the characteristic microstructures of the as-printed ODS part in: (a). Figure 5-23 (a); (b). Figure 523 (b); (c). Figure 5-23 (c).

In order to confirm the precipitated phase is the $\gamma^{\prime}$ phase instead of pores, EDS point analysis, and XRD were conducted to examine the chemical composition and the crystal structure. Figure 5-26 shows the EDS point analysis of the specific locations in the microstructure. EDS spot 1 pinpointed the cuboid $\gamma^{\prime}$ phase in the mid-layer, and it shows $\mathrm{Ni}$ and $\mathrm{Al}$ are the major compositions at this location. $\mathrm{C}$ and $\mathrm{Cr}$ were also found in the EDS spectrum. EDS spot 2 pinpointed a stretched cuboid $\gamma$ ' phase in the top layer. It shows $\mathrm{C}, \mathrm{Ni}$ and $\mathrm{Cr}$ are the major compositions at this locations. Published results have shown that $\mathrm{C}$ could form carbides with $\mathrm{Cr}$. It indicates that carbides might form at the location.

Figure 5-26 shows the XRD pattern of the cross-section of the as-printed ODS part and the signals from the substrate has been removed. The XRD shows the peaks of $\gamma$ matrix and the $\gamma$ ' phase. But two types of crystal structure existed in the $\gamma^{\prime}$ phase which is FCC and BCT. The major crystal structure of this $\gamma^{\prime}$ phase in this as-printed sample is FCC. However, the intensity of the BCT $\gamma$ ' phase is higher than the $\gamma$ matrix, meaning the $\gamma^{\prime}$ phase precipitated during the printing process, but it was under stretched or compression. The thermal driving force for the $\gamma^{\prime}$ precipitation was not sufficient. The cuboid and upright $\gamma^{\prime}$ phase observed in Figure 
5-23 (b) confirms the existence of the FCC $\gamma^{\prime}$ phase. And the stretched/mismatched $\gamma^{\prime}$ phase found in Figure 5-23 (c) confirms the BCT $\gamma^{\prime}$ phase due to the rapid cooling in top-layers.
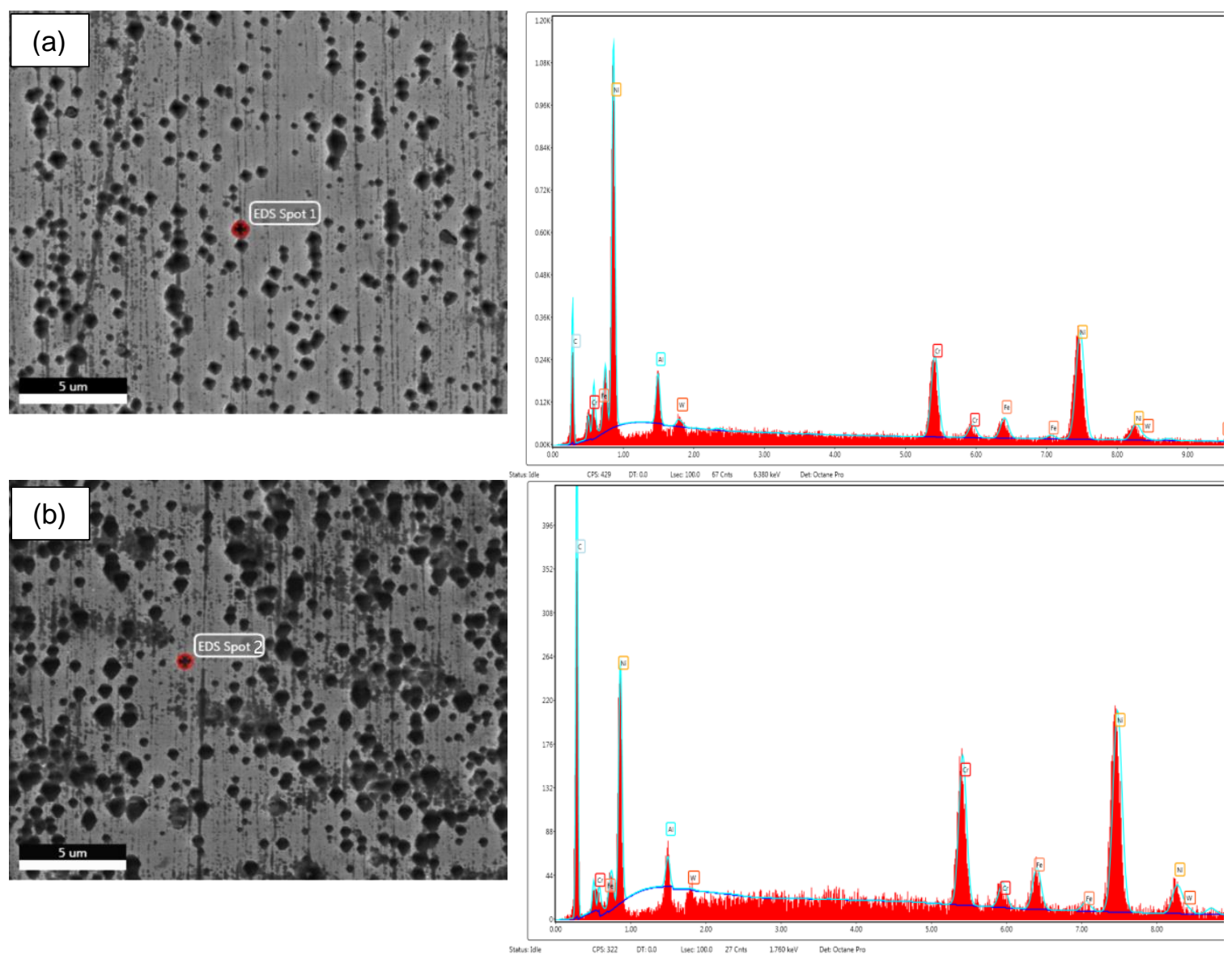

Figure 5-25. EDS point analysis of as-printed ODS part (250W-25J/mm): (a). mid-layer; (b). top-layer.

In summary, as the laser scanning speed decreased considerably, the speed of the heat and energy loss and transmission within the melt pool was decreased because of a longer residence of the laser beam at the melt pool. Thus, the cooling rate of the deposited parts was decreased. Therefore, the cooling time was increased comparatively, and it provided more strengthened kinetics for the nucleation and grain growth [56]. So more $\gamma^{\prime}$ phase was found in this second batch as-printed sample than the first batch of as-printed samples. 


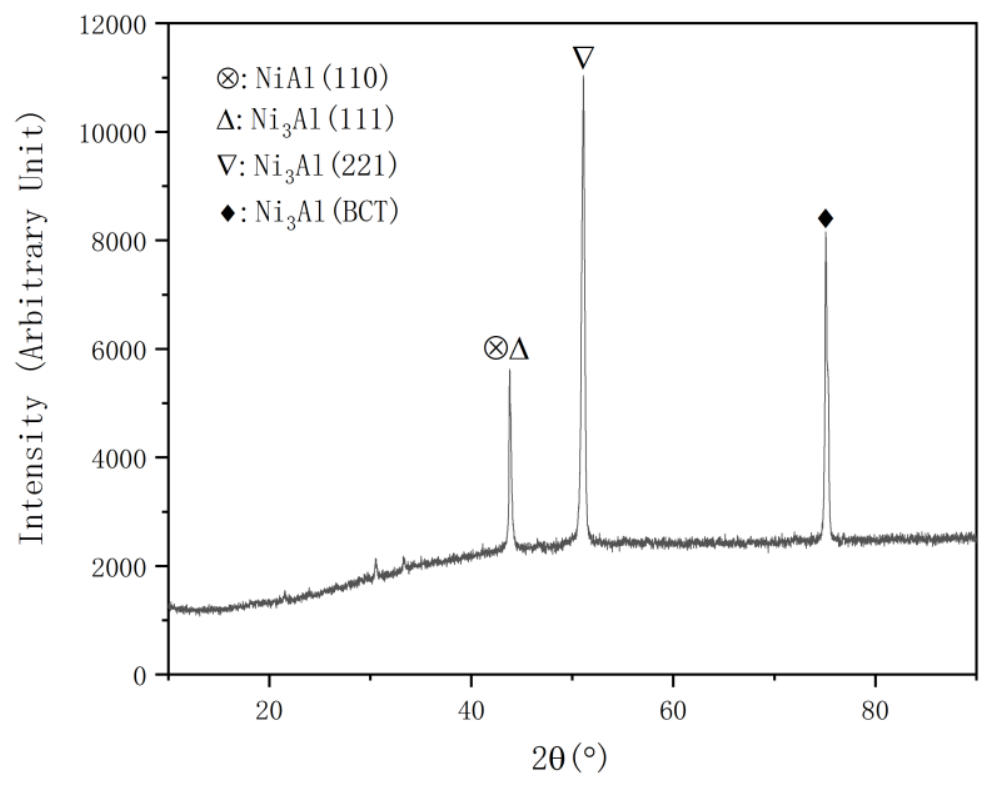

Figure 5-26. XRD pattern of the cross-section of the as-printed ODS part: $250 \mathrm{~W}$ $25 \mathrm{~J} / \mathrm{mm}$

\subsubsection{The Laser Cladding As-printed Sample}

A laser cladding experiment was conducted in Siemens Company, Pittsburgh. The LENS experiments have shown that increasing the input linear energy is helpful for the precipitation of the $\gamma$ ' phase, but the crystal structure of the $\gamma^{\prime}$ phase is a mixture of FCC and BCT, meaning the driving force for the grain growth of the $\gamma^{\prime}$ phase was not adequate. In order to achieve the typical $\gamma^{\prime}$ phase in the as-printed microstructures, a 5kW laser power was selected in this laser cladding experiment to provide sufficient input energy. And the influence of the input energy on the as-printed microstructures was investigated.

Figure 5-27 shows the as-printed ODS part on a MAR-M247A flat plate as the substrate. The thickness of the deposited part is $7 \mathrm{~mm}$ which is much thicker than the LENS as-printed sample. Warps were found around the edge and on the top of the deposited layers. In order to avoid the warps, the sample was cut crosssectionally and analyzed in the middle of the cross-section. The measured density laser cladding as-printed sample is $8.07 \mathrm{~g} / \mathrm{cm}^{3}$ and the relative density is $94.83 \%$. 

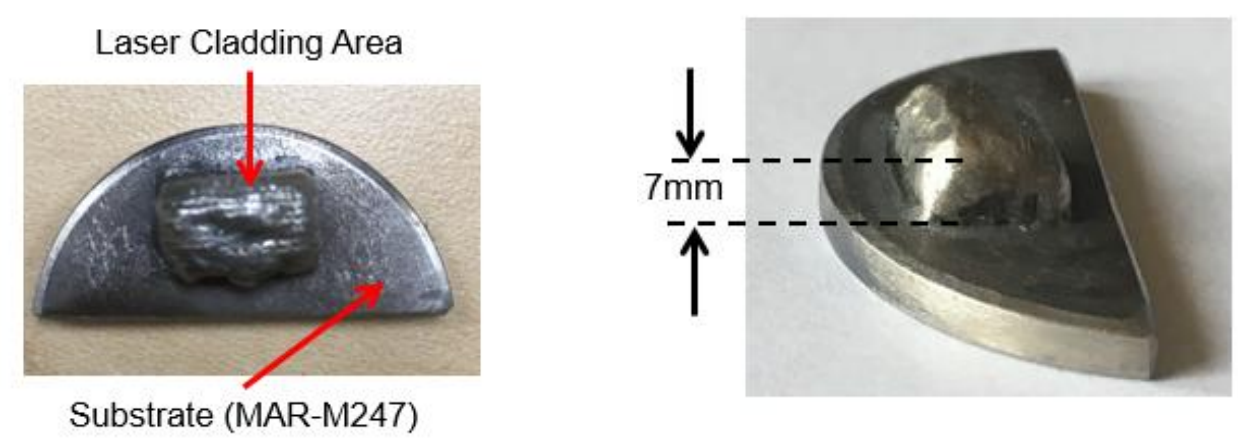

Figure 5-27. Images of laser cladding as-printed samples.
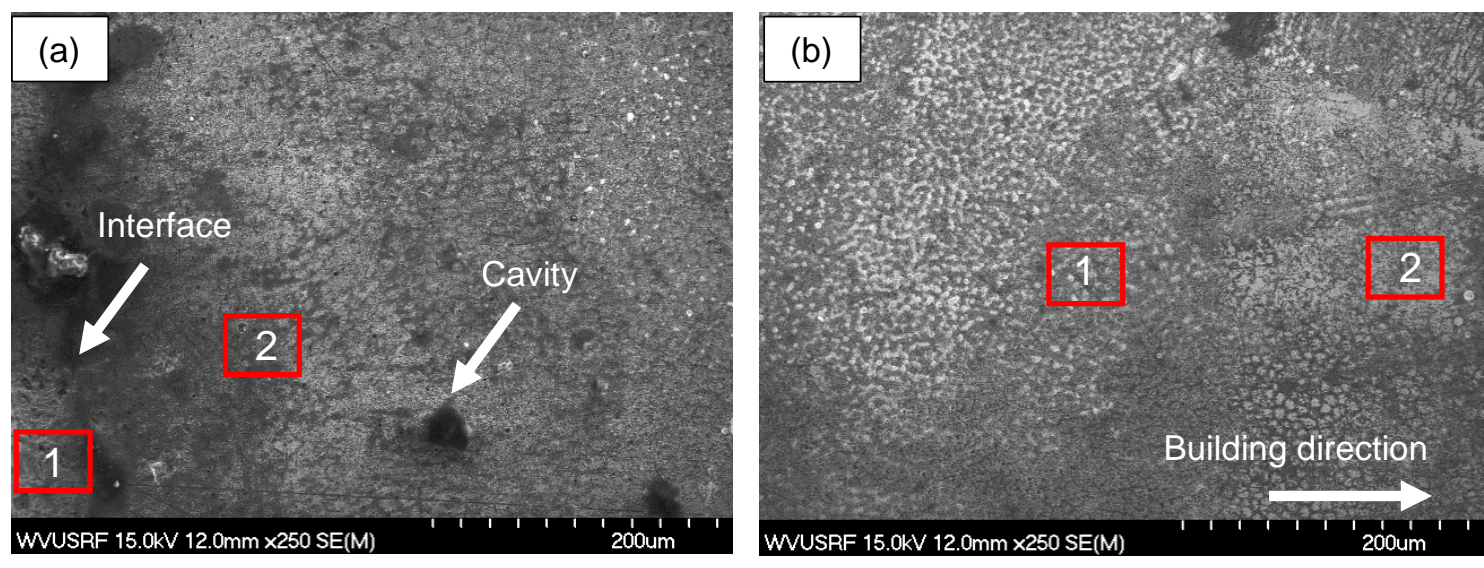

Figure 5-28. SEM micrographs showing the characteristic microstructures of the cross-section of as-printed ODS part (5kW): (a). The interface of the substrate and deposited part; (b). Mid-layer of the deposited part.

Figure 5-28 shows the characteristic microstructures of the cross section of the laser cladding as-printed ODS part. No obvious cracks and pores were found in the microstructure as a low magnification, except for the area near the interface. In order to examine the characteristic microstructure clearly, higher magnifications on the specific locations (as indicated in the red blocks in Figure 5-28) were investigated and shown in Figure 5-29.

SEM images at a high magnification clearly show that the $\gamma^{\prime}$ phase precipitated during the printing process. In the near-interface area shown in Figure 5-29 (a), upright $\gamma^{\prime}$ phase is obviously round in the substrate and the near-interface area. The phase of the $\gamma^{\prime}$ phase in the near-interface area is similar to the $\gamma^{\prime}$ phase in the substrate, indicating the laser power for the precipitation and the epitaxial grain growth of the $\gamma^{\prime}$ phase. But is the size of the $\gamma^{\prime}$ phase in the near-interface area is slightly smaller than $\gamma^{\prime}$ phase in the substrate. Figure 5-29 (c) and (d) show the morphology and size of the $\gamma^{\prime}$ phase in the mid-layer of the deposited part. The $\gamma^{\prime}$ phase became stretched and less as the building direction forwarded which is contrary to the LENS as-printed samples. 

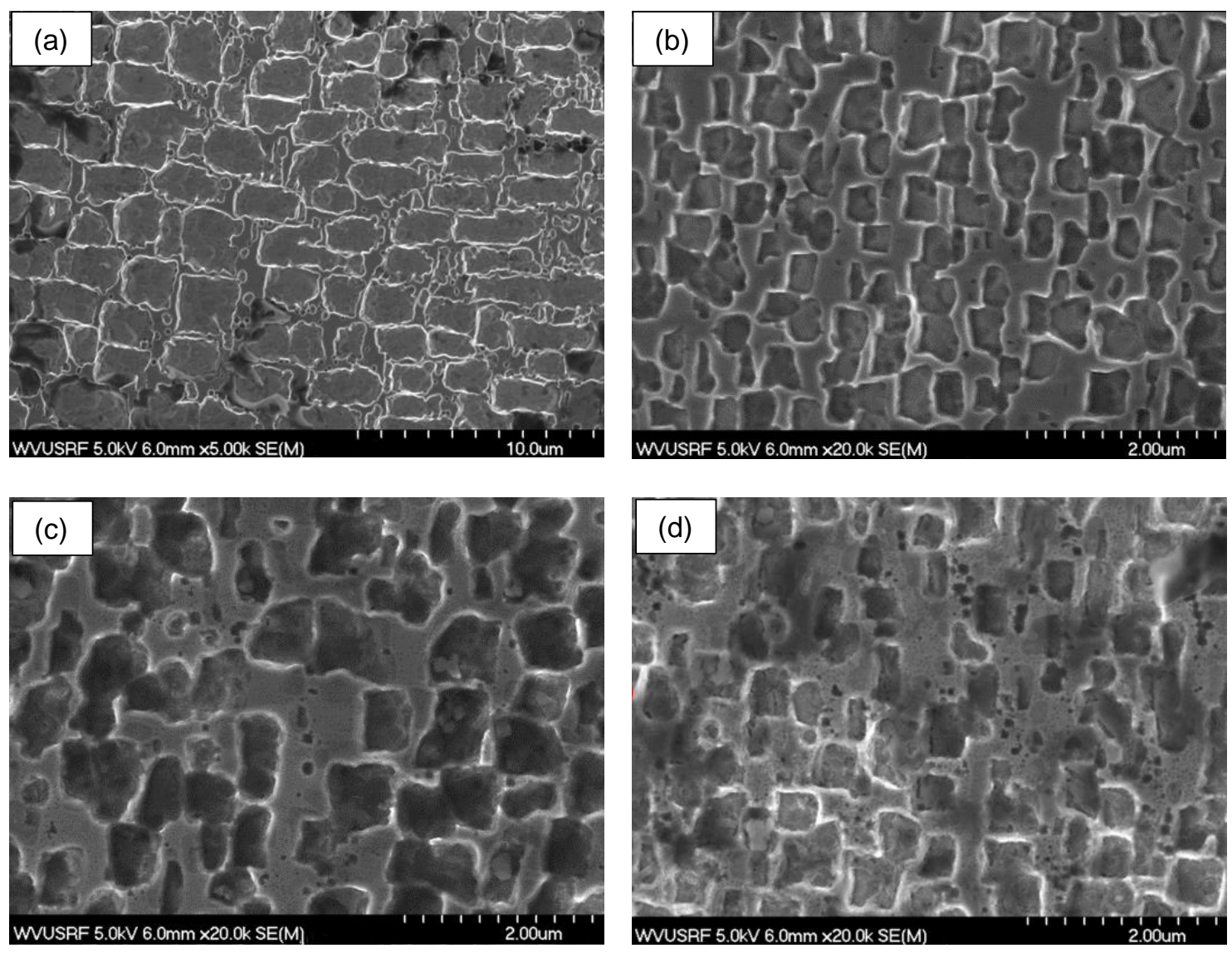

Figure 5-29. High-magnification of SEM micrographs showing the characteristic microstructures of the laser cladding as-printed ODS part in: (a). Figure 5-29 (a) block 1; (b). Figure 5-28 (a) block 2; (c). Figure 5-28 (b) block 1; (d). Figure 5-28

(b) block 2 .

This contrary of the $\gamma^{\prime}$ phase in the LENS as-printed sample and the laser cladding as-printed sample suggests that the laser cladding provided greatly enough power such that the $\gamma^{\prime}$ phase precipitated and grew in the first stage. The $\gamma^{\prime}$ phase precipitated faster than the LENS as-printed in such high input energy. And once the $\gamma^{\prime}$ phase was saturated under the high input energy, less and less $\gamma^{\prime}$ phase would precipitate along the building direction. However, for the LENS asprinted sample, the input energy was only enough for the precipitation of the $\gamma^{\prime}$ phase. The growth of the $\gamma^{\prime}$ phase required more energy and thermal driving force. As the building direction forwarded, the reheating and remelting from the previous layers and the substrate would boost the $\gamma$ ' phase to precipitate along the building direction.

In order to confirm the precipitated phase is the $\gamma^{\prime}$ phase instead of pores, XRD was conducted to examine the crystal structure. Figure 5-30 shows the XRD 
pattern of the cross section of the laser cladding as-printed ODS part and the signals from the substrate has been removed. The XRD shows the peaks of $\gamma$ matrix and the $\gamma^{\prime}$ phase. Unlike the LENS as-printed samples, only very few BCT $\gamma^{\prime}$ phase is shown in the XRD pattern. Most of the $\gamma^{\prime}$ phase is in FCC structure, $\mathrm{Ni}_{3} \mathrm{Al}$ (111). This is a confirmation that the laser cladding provided sufficient energy for the $\gamma^{\prime}$ phase to precipitate from the matrix and grow during the process. And the $\gamma^{\prime}$ phase was almost saturated in the matrix. In summary, much higher input energy would cause a densified microstructure, the precipitate of the $\gamma^{\prime}$ phase and the grain growth of the $\gamma^{\prime}$ phase.

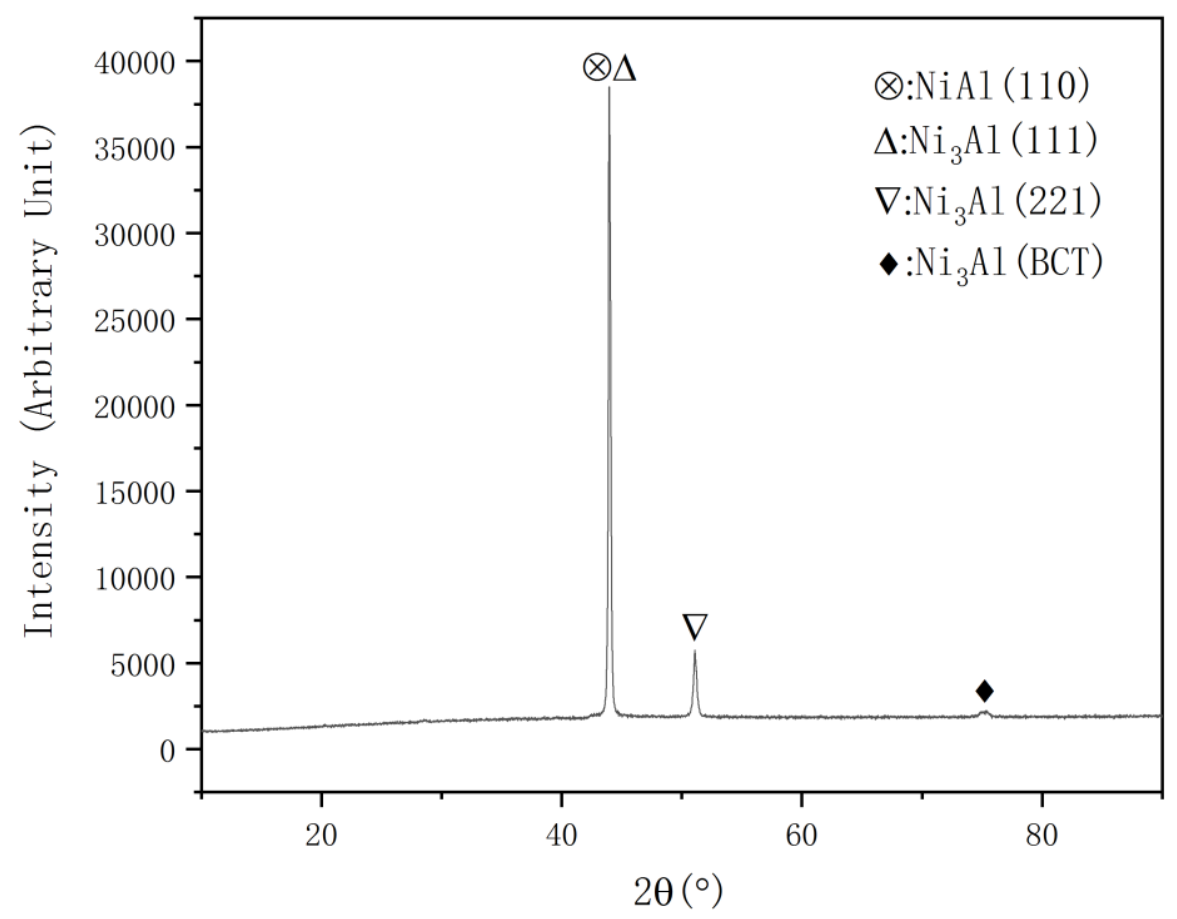

Figure 5-30. XRD pattern of the cross section of the laser cladding as-printed ODS part 


\section{CHAPTER 6: CONCLUSIONS}

\section{I). Powder Fabrication}

In this study, an MCB technique and its combined technique were employed to fabricate homogeneous ODS Ni-based superalloy powers with $\mathrm{Y}_{2} \mathrm{O}_{3}$ uniformly distributed in the powders. Initially, the powders were processed by the MCB process and the BM process and then characterized by using XRD and SEM/EDS. The results imply that:

- During the MCB process, the Y2O3 particles were bonded and coated onto the surface of hosting particles such as $\mathrm{Ni}$ and $\mathrm{Cr}$ to form a nanosize amorphous thin film. This caused the disappearance of $\mathrm{Y}_{2} \mathrm{O}_{3}$ peak in the XRD spectrum.

- The soft Al particles were subjected to mixing, break-down, and coating under shearing force and were randomly bonded to the hosting particles or existed as elemental particles in the powder mixture.

- The MCB process was capable of generating pre-alloyed powders with $\gamma^{\prime}$ matrix existing in the powders. And the milling time of the MCB process was successfully decreased to 11 hours which is much more effective than the conventional BM process.

- The MCB processed powders were further processed by utilizing a BM machine to improve the MA effect of the powder. And the $\gamma^{\prime}$ phase formed after the BM process. It could also introduce the lattice strain and defects.

- The particle size of the powders increased significantly after the MCB+BM process.

- As a benchmark and reference experiment, BM-only processed powder was subjected generated much similar crystal structures in powders to the MCB-only process, but no $\gamma$ 'phase has been formed during the process.

- Powders processed by MCB+BM generated larger micro-strain and smaller crystal size than BM-only and MCB-only.

- $\mathrm{MCB}$ is a potential alternative to produce ODS superalloy powders for AM applications.

II). Additive Manufacturing

The MCB+BM processed powders were applied on LENS 450 system into densified bulks. The MCB-only processed powders were applied on LENS 450 system and deposited by laser cladding. The as-printed samples were characterized by XRD, SEM/EDS. And the results suggest that:

- The density is affected by the input linear energy. The higher the input linear energy, the densifier microstructure.

- The microstructure is also influenced by the input linear energy. The first batch of the LENS as-printed samples showed very little $\gamma^{\prime}$ phase. While as the input linear energy increased in the second batch LENS experiment, the $\gamma$ 'phase precipitated in the microstructure. 
- The laser power of the laser cladding was the highest, and the $\gamma$ 'phase near completely precipitated in the microstructure.

- Higher laser power will generate higher melt pool temperature, and thus provide sufficient driving force to form $\gamma$ 'phase. 


\section{CHAPTER 7: RECOMMENDATIONS FOR FUTURE WORKS}

This work showed explanatory research was done on $\mathrm{MCB}+\mathrm{BM}$ processed and the MCB-only processed ODS superalloy on their processing. One of the next work that can be performed on this ODS superalloy system is investigating their performance in a thermo-chemical environment for understanding their combined corrosive and oxidation behaviors.

Moreover, in this work, it was investigated the possibility of applying ODS superalloy in the field of AM. The recommended future work is that the as-printed ODS superalloy needs to be tested regarding the mechanical properties, corrosion resistance, and oxidation resistance. The following outline could be a recommended method for achieving this goal:

- The composition of designed ODS super alloy should be adjusted to investigate the effect of the content of oxide dispersoid on powder properties and as-printed microstructures.

- The fabrication method by utilizing MCB-only process should be modified for ODS superalloy powder production.

- The MCB-only processed powders should be applied on EOS M290 which is the standard, and commercialized powder bed AM technique to investigate the powder performance and as-printed microstructures.

- The processing parameters and melt pool geometry should be adjusted, conducted and refined to investigate the effect of parameters and melt pool on microstructures.

- Mechanics performance testing should be carried out to test the mechanical properties of as-printed samples, i.e., Tensile strength, Young's modulus, and fracture strength, etc. 


\section{REFERENCE}

1. Zhou, Y., et al., Microstructure characterizations and strengthening mechanism of multi-principal component AlCoCrFeNiTi0. 5 solid solution alloy with excellent mechanical properties. 2008. 62(17-18): p. 2673-2676.

2. Donachie, M.J. and S.J. Donachie, Superalloys: a technical guide. 2002: ASM international.

3. Schaffer, G., et al., The stability of the oxide dispersion in INCONEL alloy MA6000. 1989. 37(9): p. 2551-2558.

4. Kim, C.S., I.-H.J.J.o.n. Kim, and nanotechnology, Effect of Al and Y2O3 on Mechanical Properties in Mechanically Alloyed Nanograin Ni-Based Alloys. 2015. 15(8): p. 6160-6163.

5. Glasgow, T.K., An oxide dispersion strengthened Ni-W-Al alloy with superior high temperature strength. 1976.

6. Durand-Charre, M., The microstructure of superalloys. 2017: Routledge.

7. MINO, K., K.J.T.o.t.I. ASAKAWA, and S.I.o. Japan, An oxide dispersion strengthened nickel-base superalloy with excellent high temperature strength. 1987. 27(10): p. 823-842.

8. $\quad$ Ardell, A.J.M.T.A., Precipitation hardening. 1985. 16(12): p. 2131-2165.

9. Irmann, R.J.T.R., SAP2A new material of the powder metallurgy of alu2 minum. 1949. 36: p. 19226.

10. Kang, S. and R.J.M.T.A. Benn, Microstructural development in high volume fraction gamma prime Ni-base oxide-dispersion-strengthened superalloys. 1985. 16(7): p. 1285-1294.

11. Benjamin, J. and T.J.M.T. Volin, The mechanism of mechanical alloying. 1974. 5(8): p. 1929-1934.

12. Rieken, J.R., et al., Reactive gas atomization processing for Fe-based ODS alloys. 2012. 428(1-3): p. 65-75.

13. Busby, J.T.J.J.o.N.M., Economic benefits of advanced materials in nuclear power systems. 2009. 392(2): p. 301-306.

14. Ma, L., et al., Characterization of oxide-dispersion-strengthened (ODS) alloy powders processed by mechano-chemical-bonding (MCB) and balling milling (BM). 2014. 31: p. 146-155.

15. Kang, B., et al. ODS coating development by cold spray method using powder mix prepared by combined MCB and ball milling processes. in 24th Annual Conference on Fossil Energy Materials, Pittsburgh, PA, USA. 2010.

16. Tan, J.H., W.L.E. Wong, and K.W.J.A.M. Dalgarno, An overview of powder granulometry on feedstock and part performance in the selective laser melting process. 2017.

17. Pollock, T.M., S.J.J.o.p. Tin, and power, Nickel-based superalloys for advanced turbine engines: chemistry, microstructure and properties. 2006. 22(2): p. 361-374.

18. Srinivasan, D., et al., Strengthening mechanisms (via hardness analysis) in nanocrystalline NiCr with nanoscaled Y2O3 and Al2O3 dispersoids. 2006. 416(1-2): p. 211-218. 
19. Hu Benfu, et al., Research and development of new high performance powder superalloys. 2007. 2007(2): p. 49-53.

20. Howson, T., J. Stulga, and J.J.M.T.A. Tien, Creep and stress rupture of oxide dispersion strengthened mechanically alloyed Inconel alloy MA 754. 1980. 11(9): p. 1599-1607.

21. Huang Ganqi and Li Hankang, Superalloys. 2000, Metallurgical Industry Press.

22. Mathon, M., et al., Study of PM2000 microstructure evolution following FSW process. 2009. 386: p. 475-478.

23. Sakasegawa, H., et al., Stability of non-stoichiometric clusters in the MA957 ODS ferrtic alloy. 2011. 417(1-3): p. 229-232.

24. McClintock, D.A., et al., Mechanical properties of irradiated ODSEUROFER and nanocluster strengthened 14YWT. 2009. 392(2): p. 353359.

25. Lucon, E., R. Chaouadi, and M.J.J.o.N.M. Decréton, Mechanical properties of the European reference RAFM steel (EUROFER97) before and after irradiation at 300 C. 2004. 329: p. 1078-1082.

26. Ukai, S., et al., High-temperature strength characterization of advanced 9Cr-ODS ferritic steels. 2009. 510: p. 115-120.

27. Brocq, M., et al., Nanoscale characterization and formation mechanism of nanoclusters in an ODS steel elaborated by reactive-inspired ball-milling and annealing. 2011. 409(2): p. 80-85.

28. Froyen, L., et al., Synthesizing aluminum alloys by double mechanical alloying. 1995. 47(3): p. 16-19.

29. Ying, D., D.J.M.S. Zhang, and E. A, Processing of Cu-Al2O3 metal matrix nanocomposite materials by using high energy ball milling. 2000. 286(1): $\mathrm{p}$. 152-156.

30. Song, K., et al., Internal oxidation of dilute $\mathrm{Cu}-\mathrm{Al}$ alloy powers with oxidant of Cu2O. 2004. 380(1-2): p. 117-122.

31. Zhang, L., et al., Microstructural characterization of Co-based ODS alloys. 2012. 21(11): p. 2487-2494.

32. Suryanarayana, C.J.P.i.m.s., Mechanical alloying and milling. 2001. 46(12): p. 1-184.

33. Kang, B.S., et al., Method of producing an oxide dispersion strengthened coating and micro-channels. 2013, Google Patents.

34. Yokoyama, T., H.J.K.P. CC, and P. Journal, Nanoparticle technology for the production of functional materials. 2005. 23: p. 7-17.

35. Amare, B.N., Mechanical and Microstructure Study of Nickel-Based ODS Alloys Processed by Mechano-Chemical Bonding and Ball Milling. 2015: West Virginia University.

36. Li, R., et al., Densification behavior of gas and water atomized $316 \mathrm{~L}$ stainless steel powder during selective laser melting. 2010. 256(13): p. 4350-4356.

37. Ahsan, M.N., et al., A comparative study of laser direct metal deposition characteristics using gas and plasma-atomized Ti-6Al-4V powders. 2011. 528(25-26): p. 7648-7657. 
38. Choi, J.-P., et al., Densification and microstructural investigation of Inconel 718 parts fabricated by selective laser melting. 2017. 310: p. 60-66.

39. Kantzos, C., et al., An Investigation of Process Parameter Modifications on Additively Manufactured Inconel 718 Parts. 2018: p. 1-7.

40. Antony, L.V. and R.G.J.J. Reddy, Processes for production of high-purity metal powders. 2003. 55(3): p. 14-18.

41. Frazier, W.E.J.J.o.M.E. and Performance, Metal additive manufacturing: a review. 2014. 23(6): p. 1917-1928.

42. Kelly, A., Strengthening methods in crystals. 1971: Elsevier Pub. Co.

43. Moon, J., et al., Orowan strengthening effect on the nanoindentation hardness of the ferrite matrix in microalloyed steels. 2008. 487(1-2): p. 552557.

44. Pan, X. and X.J.J.o.S.S.C. Ma, Phase transformations in nanocrystalline TiO2 milled in different milling atmospheres. 2004. 177(11): p. 4098-4103.

45. Orowan, E.J.M., London, Discussion in The Symposium on Internal Stresses in Metals and Alloys, Inst. 1948. 451.

46. Ansell, G. and F.J.A.M. Lenel, Criteria for yielding of dispersionstrengthened alloys. 1960. 8(9): p. 612-616.

47. Denisenko, É., et al., Mechanical properties of dispersion-strengthened $\mathrm{Cu}$ Al $2 O 3$ materials. 1980. 19(4): p. 265-268.

48. Weertman, J.J.M.S. and E. A, Hall-Petch strengthening in nanocrystalline metals. 1993. 166(1-2): p. 161-167.

49. $\quad$ Du Pasquier, A., C. Huang, and T.J.J.o.P.S. Spitler, Nano Li4Ti5012LiMn2O4 batteries with high power capability and improved cycle-life. 2009. 186(2): p. 508-514.

50. Murata, K., et al., Composite powders processed by an advanced mechanical method for the fabrication of cermet anodes of solid oxide fuel cells. 2004. 37(4): p. 568-571.

51. Nam, J. and J.J.N.M. Lee, Mechano-chemical synthesis of nanosized stainless steel powder. 1999. 12(1-4): p. 475-478.

52. Welham, N.J., P.E. Willis, and T.J.J.o.t.A.C.S. Kerr, Mechanochemical formation of metal-ceramic composites. 2000. 83(1): p. 33-40.

53. Lu, L., Y.J.J.o.A. Zhang, and Compounds, Influence of process control agent on interdiffusion between $\mathrm{Al}$ and $\mathrm{Mg}$ during mechanical alloying. 1999. 290(1-2): p. 279-283.

54. Stevens, E.L., et al., Variation of hardness, microstructure, and Laves phase distribution in direct laser deposited alloy 718 cuboids. 2017. 119: p. 188-198.

55. Dinda, G., et al., Laser aided direct metal deposition of Inconel 625 superalloy: Microstructural evolution and thermal stability. 2009. 509(1-2): p. 98-104.

56. Jia, Q., D.J.J.o.A. Gu, and Compounds, Selective laser melting additive manufacturing of Inconel 718 superalloy parts: Densification, microstructure and properties. 2014. 585: p. 713-721.

57. Liu, F., et al., Microstructure and residual stress of laser rapid formed Inconel 718 nickel-base superalloy. 2011. 43(1): p. 208-213. 